\title{
Technologies to Enhance Operation of the Existing Natural Gas Compression Infrastructure
}

\author{
Quarterly Technical Progress Report \\ Reporting Period Start Date: 07/01/03 \\ Reporting Period End Date: 09/30/03
}

\author{
Principal Authors: \\ Anthony J. Smalley \\ Ralph E. Harris \\ Gary D. Bourn
}

October 2003

DOE Award No. DE-FC26-02NT41646

SwRI Project No. 18.06223

Submitting Organization:

Southwest Research Institute ${ }^{\circledR}$

6220 Culebra Road

San Antonio, TX 78238-5166 


\section{DISCLAIMER}

"This report was prepared as an account of work sponsored by an agency of the United States Government. Neither the United States Government nor any agency thereof, nor any of their employees, makes an warranty, express or implied, or assumes any legal liability or responsibility for the accuracy, completeness, or usefulness of any information, apparatus, product, or process disclosed, or represents that its use would not infringe privately owned rights. Reference herein to any specific commercial product, process, or service by trade name, trademark, manufacturer, or otherwise does not necessarily constitute or imply its endorsement, recommendation, or favoring by the United States Government or any agency thereof. The views and opinions of authors expressed herein do not necessarily state or reflect those of the United States Government or any agency thereof." 


\section{ABSTRACT}

This report documents work performed in the fourth quarter of the project entitled: Technologies to Enhance Operation of the Existing Natural Gas Compression

Infrastructure. The project objective is to develop and substantiate methods for operating integral engine/compressors in gas pipeline service, which reduce fuel consumption, increase capacity, and enhance mechanical integrity. The report describes the following work: second field test; test data analysis for the first field test; operational optimization plans. 


\section{TABLE OF CONTENTS}

Page

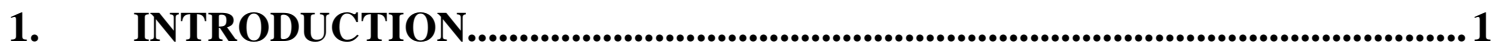

2. EXECUTIVE SUMMARY ................................................................................... 4

3. EXPERIMENTAL ........................................................................................................6

4. RESULTS AND DISCUSSION ...................................................................... 8

INDUSTRY ADVISORY COMMITTEE (IAC) TASK …………………………….... 8

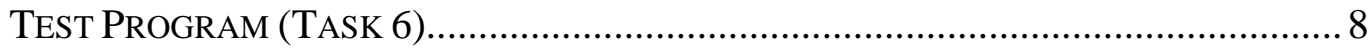

5. DATA ANALYSIS ............................................................................................. 40

ENGINE SIMULATION MODEL ……………………………............................ 40

Relating Combustion Balancing to Engine PeRformance with AiR

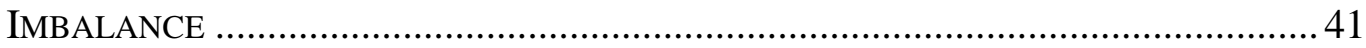

EQUIVALENCE RATIO BALANCING.................................................................. 45

RELATING SYSTEM MECHANICAL EFFICIENCY TO OIL TEMPERATURE AND TIME 47

ENGINE-COMPRESSOR SYSTEM THERMAL EFFICIENCY …………………….......50

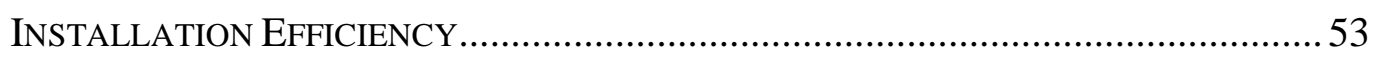

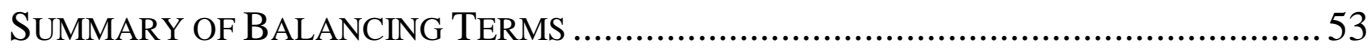

6. OPERATIONAL OPTIMIZATION .......................................................................55

7. CONCLUSIONS .........................................................................................................5

8. REFERENCES.........................................................................................................61

9. LIST OF ACRONYMS AND ABBREVIATIONS ..........................................62 


\section{LIST OF FIGURES}

Figure 1. Williams SOUR LAKE Station, Unit 6 ............................................. 9

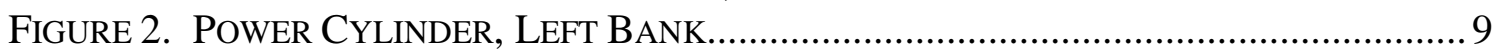

Figure 3. ENGINE LOCAL PANEL AND HPFI ${ }^{\mathrm{TM}}$ DiSPLAY PANEL .................................. 10

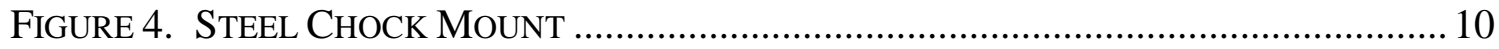

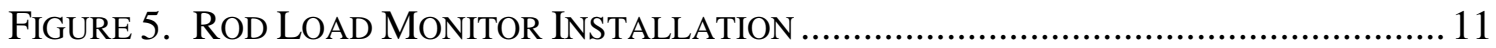

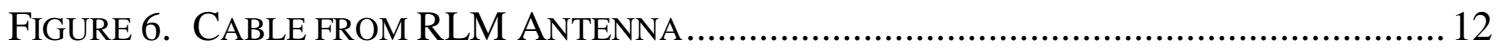

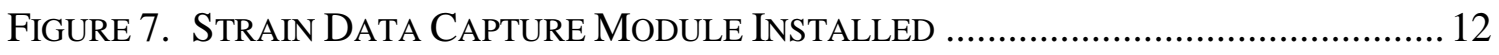

Figure 8. COMPRESSOR CyLindER AND PRESSURE TRANSDUCERS ON EACH END ......... 13

FIGURE 9. POWER CYLINDER WITH PRESSURE TRANSDUCER ...................................... 14

Figure 10. Details of PoWER Cylinder PRESSURE TransduCER INSTALlation ...... 14

Figure 11. PRESSURE TRANSDUCER IN AIR INTAKE MANIFOLD ................................... 15

Figure 12. PRESSURE TRANSDUCER IN EXHAUST MANIFOLD ..................................... 16

FIGURE 13. ENCODER, OUTBOARD OF FLYWHEEL ON MOUNTING TRIPOD .................... 17

Figure 14. Detailed View Of ENCODER AND CONNECTION TO FlyWHEEL .................. 18

FIGURE 15. ACCELEROMETER MOUNTED ON FRAME .................................................. 18

Figure 16. Flow Transmitter CONNECTIONS TO ORIFICE IN FuEl Gas Line ............. 19

FIGURE 17. $\mathrm{O}_{2}$ /NOX SENSOR AND CONNECTION TO LINE FROM STACK........................... 19

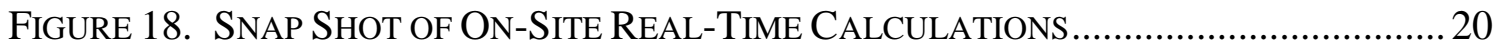

FIGURE 19. TyPiCAL POWER CYLINDER PRESSURE DATA .......................................... 23

Figure 20. TyPiCAL COMPRESSOR CYLINDER PRESSURE DATA ................................... 24

Figure 21. Typical Inlet MANifold Pressure Trace AND ORdER SPECTRUM ......... 24

Figure 22. EXHAUst MANifold PRESSURE Trace AND ORder SPECTRUM .................. 25

Figure 23. VARIATION In INLET AND EXHAUst PRESSURES AT POINT OF

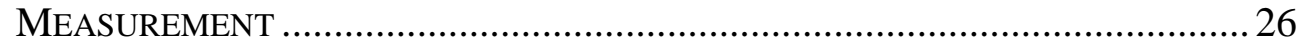

Figure 24. TyPiCAL Rod LOAd VARIATION OVER ONE REVOLUTION ........................... 27

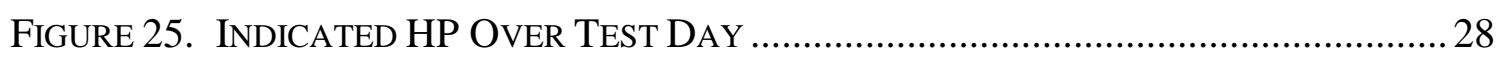

FIGURE 26. RATIO OF INDICATED HP DURING TEST DAY ..........................................29

FIGURE 27. POWER CYLINDER COMPRESSION PRESSURE.............................................. 30

FIGURE 28. COMPRESSOR EFFICIENCY ................................................................. 31

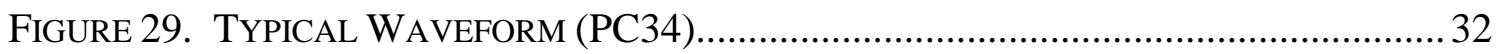

Figure 30. PEAK-TO-PEAK VARiation in CRANKShaft Web BENDing Stream

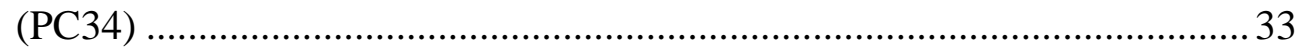

Figure 31. TyPiCAL 20 SucCESSIVE CyCleS - POWER CYLINDER 1 ........................... 34

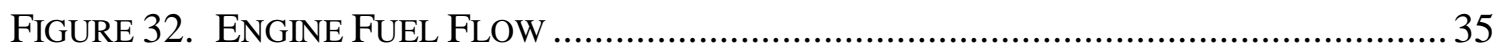

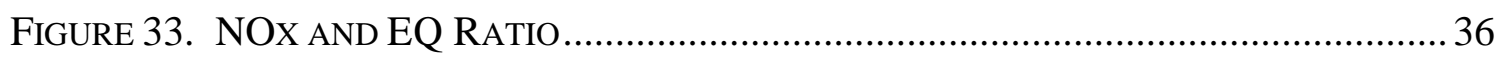

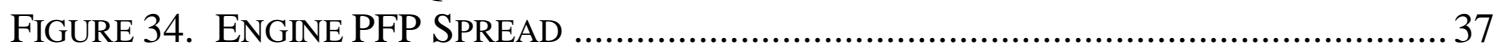

FIGURE 35. CPR BALANCING FEASIBILITY DEMONSTRATION ........................................ 38

Figure 36. RATIO OF PFP TO COMPRESSION PRESSURE - AVERAGE AND COV ............. 38 


\section{LIST OF FIGURES - CONTINUED}

Page

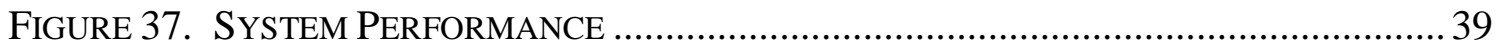

Figure 38. UnbalanCED ENGINE SimULATION - SPREAD IN COMPRESSION

PRESSURE INDUCED BY EVEN INCREMENT SPREAD IN AMP - 15\%

RANDOM SPREAD IN A/F RATIO................................................................. 41

Figure 39. Predicted Cylinder Pressures - Simulation With Evenly DiSTRIBUTED VARIATION OF AIR MANIFOLD PRESSURE.................................42

Figure 40. VARIATION OF A/F RATIO ACROSS CYLINDERS to ACHIEVE BALANCED PEAK-FIRING PRESSURE WITH SPREAD IN COMPRESSION PRESSURE

Figure 41. 6-Cylinder ENGINE SiMULATION COMPARISON - BALANCED AND UnBALANCED PEAK CYLINDER PRESSURE.

Figure 42. ENGine Simulation - Pressures For Constant EQuivalence RATIO WITH SPREAD IN COMPRESSION PRESSURE..........................................46

Figure 43. RATIO OF PFP TO COMPRESSION PRESSURE FROM HBA-6T SIMULATIONS (BASIS FOR INVENTION DISCLOSURE) ....................................... 46

Figure 44. ENGINE HP, COMPRESSOR HP, AND INFERRED MECHANICAL EFFICIENCY 47

FIGURE 45. BTU/HP-HR. DATA FROM STATION RECORDS ............................................ 48

FIGURE 46. HBA8 SUMP TEMPERATURE DATA (1984) ................................................. 49

Figure 47. OIL OUTLET TEMPERATURE VERSUS TIME FROM STATION RECORDS (NOTE INCREASE OVER 5 HOURS MATCHES MECHANICAL EFFICIENCY TREND)

Figure 48. COMPRESSOR PERFORMANCE DATA FROM DIPS (HBA-6T) 51 


\section{INTRODUCTION}

This report documents work performed in the fourth quarter (July 1, 2003 through September 30, 2003) of the project entitled: Technologies to Enhance Operation of the Existing Natural Gas Compression Infrastructure.

The project objective is to develop and substantiate methods for operating integral engine/compressors in gas pipeline service, which reduce fuel consumption, increase capacity, and enhance mechanical integrity.

The project has been structured in three phases - the first to last eighteen (18) months, with nine (9) tasks. These tasks, with their objectives, are as follows:

1. Research Management Plan: To define a work breakdown structure and supporting narrative that addresses the overall project objectives.

2. Technology Status Assessment: To describe current and competing technologies for pipeline compression, with strengths and weaknesses.

3. Industry Advisory Committee (IAC): To interact with industry advisors and their suppliers and, thereby, focus the work and help transfer knowledge into practice.

4. Test Plan: To develop a test plan which addresses project objectives, and which will serve as a basis for tests to be performed at various industry sites.

5. Data Acquisition System (DAS): To develop a data system which will support project objectives and acquire all needed data with appropriate format, data rates, and display. 
6. Test Program: To perform tests on a representative series of engine/compressors; gather data to develop required relationships for efficiency, capacity, and mechanical integrity.

7. Data Analysis: To relate power cylinder standard deviation, balancing process, and compressor cylinder operation to fuel flow, compression efficiency, and crankshaft strain through models.

8. Methods for Optimized Operation: To apply the models and develop optimized methods for balancing and operating engine/compressors.

9. Program Management: To perform planning, administrative, and technical direction functions to achieve project objectives; to communicate with and report to the DOE and other co-funding organizations.

So far, progress has been made under Tasks 1 through 9, and is discussed in the subsequent sections of this quarterly report.

In the first quarter, Task 1 was completed, and progress was made on Tasks 2, 3, 4, 5, and 9.

In the second quarter, Tasks 2, 4, and 5 were completed; further progress was made on Tasks 3 and 9, and initial progress was made on Task 6 (calibration and site visit for first test site).

In the third quarter, the initial test at the first site was completed (Task 6) and data analysis was started (Task 7). 
In the fourth quarter, the initial test at the second site was completed (Task 6), and data analysis was started on this data (Task 7). Analysis of data from the first site was completed (Task 7). Operational optimization plans (Task 8) were prepared for the return to site 1 . 


\section{EXECUTIVE SUMMARY}

Tasks 1, 2, 4, and 5 were completed prior to this quarter.

An Industry Advisory Committee (IAC) was formed in the first quarter. A first IAC meeting was held January 14, 2003, and provided valuable project direction. A second IAC meeting was held June 24, 2003, and provided further focus to the direction of the project. This activity falls under project Task 3.

Following an initial site visit, the first field test was held at El Paso Corporation's Station 823 in Kinder, Louisiana on a Clark HBA-6, April 15-17, 2003. This was the first major activity under Task 6, and the data was reported in the previous quarterly report. A separate data report was delivered.

Since the initial field test, significant analysis of data obtained during the test has been performed, as part of Task 7, and analysis performed since the previous quarterly report is presented in this report.

Potential operational optimization methods based on analysis of the first test site data have been formulated for evaluation on a return visit as part of Task 8 . These include:

- Use of Knock Detection to Safely Advance Timing

- Air Fuel Ratio Control

- Starting with Hot Oil

- Operating with Oil at Increased Temperature

- Combustion Balancing as Opposed to Peak-Firing Pressure Balancing

- Use of Rod Load Monitor to Load to 100 Percent 
Following an initial site visit, the second field test was held at Williams (Transco) Station 40 at Sour Lake, near Beaumont, Texas (August 26-28, 2003). This is the second major activity under Task 6.

The following report discusses progress since the last quarterly report in more detail. 


\section{EXPERIMENTAL}

According to the Test Plan, the following data channels were to be acquired simultaneously and processed as part of the testing:

- Compressor Cylinder Dynamic Pressure - used for compressor horsepower and flow determination (Sensotec piezo-restrictive transducer).

- Engine Dynamic Cylinder Pressure - used for engine horsepower determination, engine balance, and engine statistics (Kistler quartz piezoelectric transducer).

- Engine Intake and Exhaust Dynamic Pressure Measurements - used to correlate acoustic dynamic effects to engine statistics (Kistler piezo-resistive transducer (watercooled)).

- Torsional Vibrations (IRV) - used as a surrogate for mechanical integrity (BEI 512 pulse encoder).

- Bearing Centerline Vibration Measurements - used as a surrogate for mechanical integrity (PCB velocimeters).

- Crankshaft Dynamic Strain - acquired using SwRI's Strain Data Capture Module (SDCM). Used as a direct measurement of shaft loading, and used to provide link between engine statistical quantities (PFP), and crankshaft fatigue damage [1].

- Engine Fuel Flow - used to document overall engine efficiency (AGA3 method using Emerson Flobas 103).

- Suction Header and Discharge Header Pressures and Temperatures - used for installation efficiency determination (Sensotec piezo-restrictive transducer).

- Engine Exhaust $\mathrm{NO}_{X}$ and $\mathrm{O}_{2}$ Levels - used for input into an engine performance model (NGK fast-response transducer).

- Compressor Rod Load - used for both mechanical integrity and loading optimization (strain gage-based; bridged to cancel bending). 
For the first test at TGP's Kinder, Louisiana station (April 15-17, 2003), the majority of these channels were successfully acquired as a coherent data set for every test condition. All channels were calibrated prior to the tests. In addition to the channels listed above, a portable emissions analyzer (an ECOM $\mathrm{A}+$ ) was used to measure concentration of $\mathrm{NO}$, $\mathrm{NO}_{2}, \mathrm{NO}_{\mathrm{X}}, \mathrm{O}_{2}$, and $\mathrm{CO}$ in the exhaust.

A few of the channels listed above gave problems at the first site. The engine fuel flow meter was calibrated prior to the test, but it was discovered during the test that it was set for a much higher flow rate than was needed and did not give useful data. The rod load monitor RF transmitter drifted too much. This is a development device and the underlying problem has now been corrected. The power cylinder \#1 pressure transducer gave suspect data.

At the second test site (Transco Station 40, Sour Lake, Texas, August 26-28, 2003), the fuel flow was successfully measured throughout the test series. The rod load monitor worked successfully. Exhaust manifold dynamic pressure was acquired, as well as air manifold pressure. Station records were used for suction and discharge pressure and temperature for the compressor. All cylinder pressure transducers functioned satisfactorily. 


\section{RESULTS AND DISCUSSION}

\section{IndUStRy AdVISORY COMmITTEE (IAC) TASK}

An Industry Advisory Committee (IAC) meeting was planned for the Gas Machinery Conference (GMC) in October 2003. Since this is in the fifth quarter of the project and the previous IAC meeting was held June 24, 2003, there was no IAC meeting in the fourth quarter. Periodic communication with the committee was performed.

\section{Test Program (Task 6)}

The first test at the second site (Williams Transco's Station 40 at Sour Lake, Texas) was completed in August 2003. Data was acquired as described in the experimental section of this report. Tests were performed to investigate how compressor operation and engine balancing affect integrity and performance of the engine.

The test unit is a GMW10 with three compressor cylinders - one of six similar units at the station. It has a nominal power of $2500 \mathrm{HP}(1865 \mathrm{MW})$ and a nominal speed of 250 RPM. Figure 1 shows the test unit and its three compressor cylinders. Figure 2 shows five power cylinders, the left bank.

This engine has recently been retrofitted with $\mathrm{HPFI}^{\mathrm{TM}}$, Enginuity's High Pressure Fuel Injection System, and a turbocharger which replaces the previous scavenging system. Figure 3 shows the engines local control panel; to the right can be seen the $\mathrm{HPFI}^{\mathrm{TM}}$ panel displaying power cylinder and balance information. The unit is chock-mounted, as shown in Figure 4; this helps increase cooling under the sump and reduces thermal distortion of the block. 


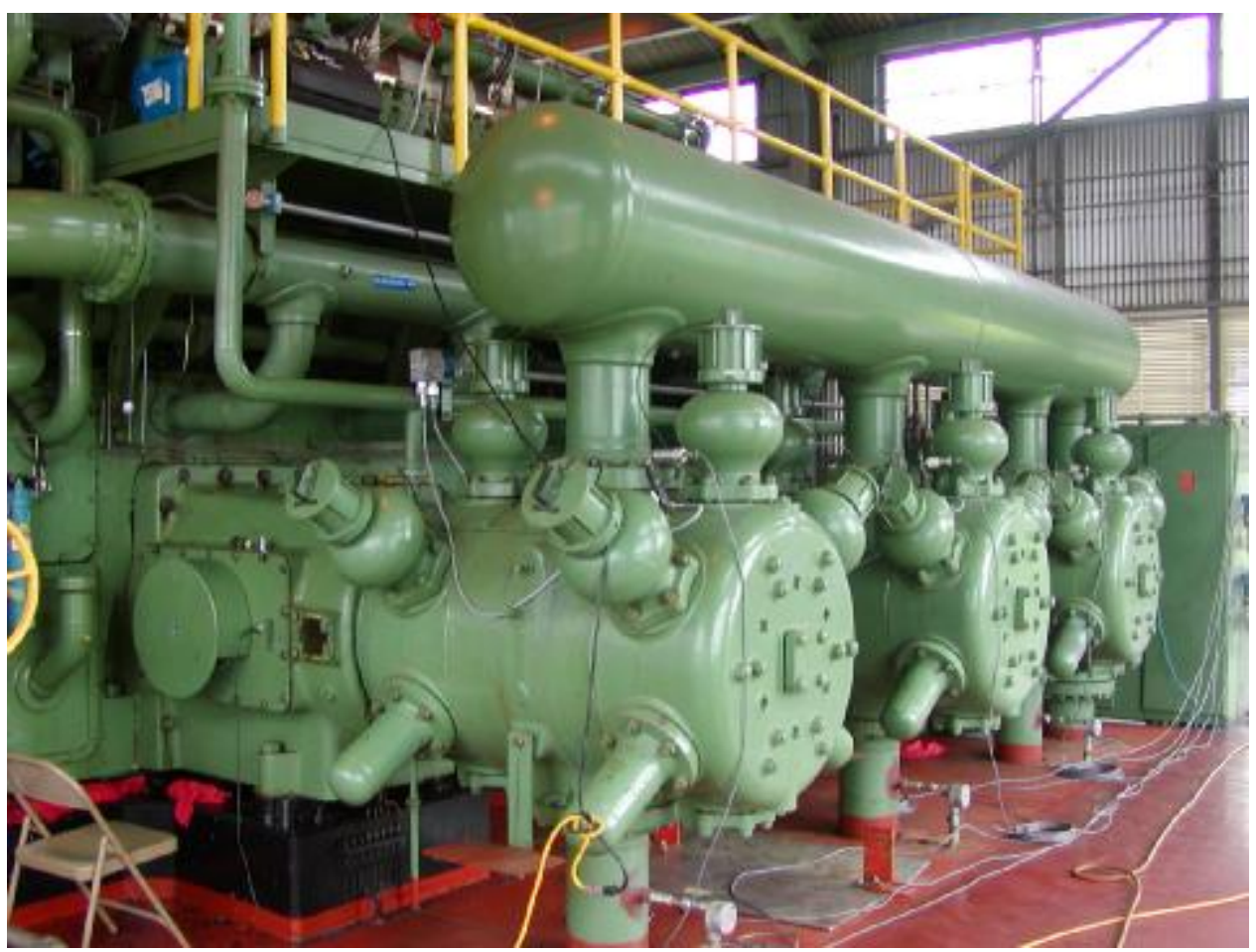

Figure 1. Williams Sour Lake Station, Unit 6

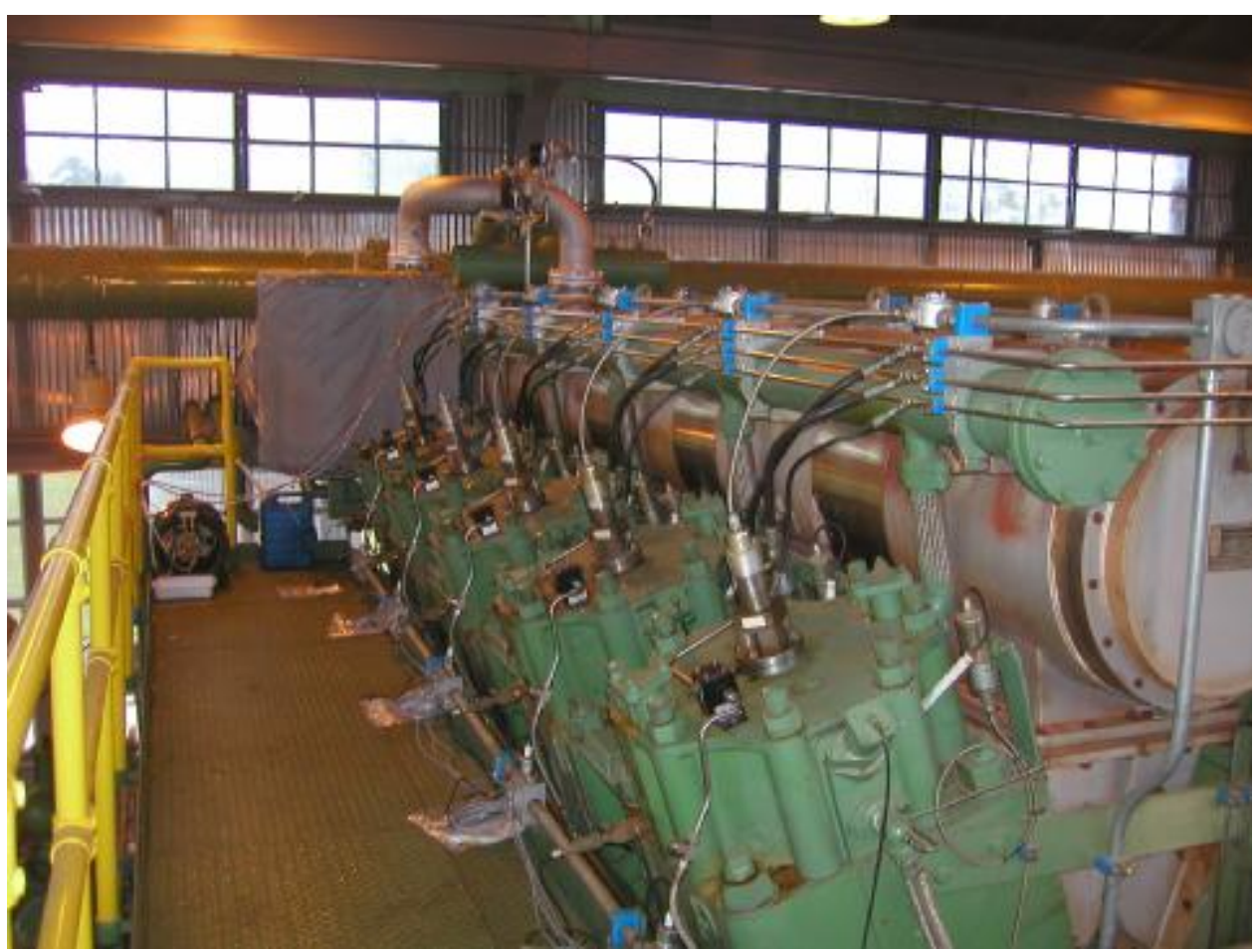

Figure 2. Power Cylinder, Left Bank 


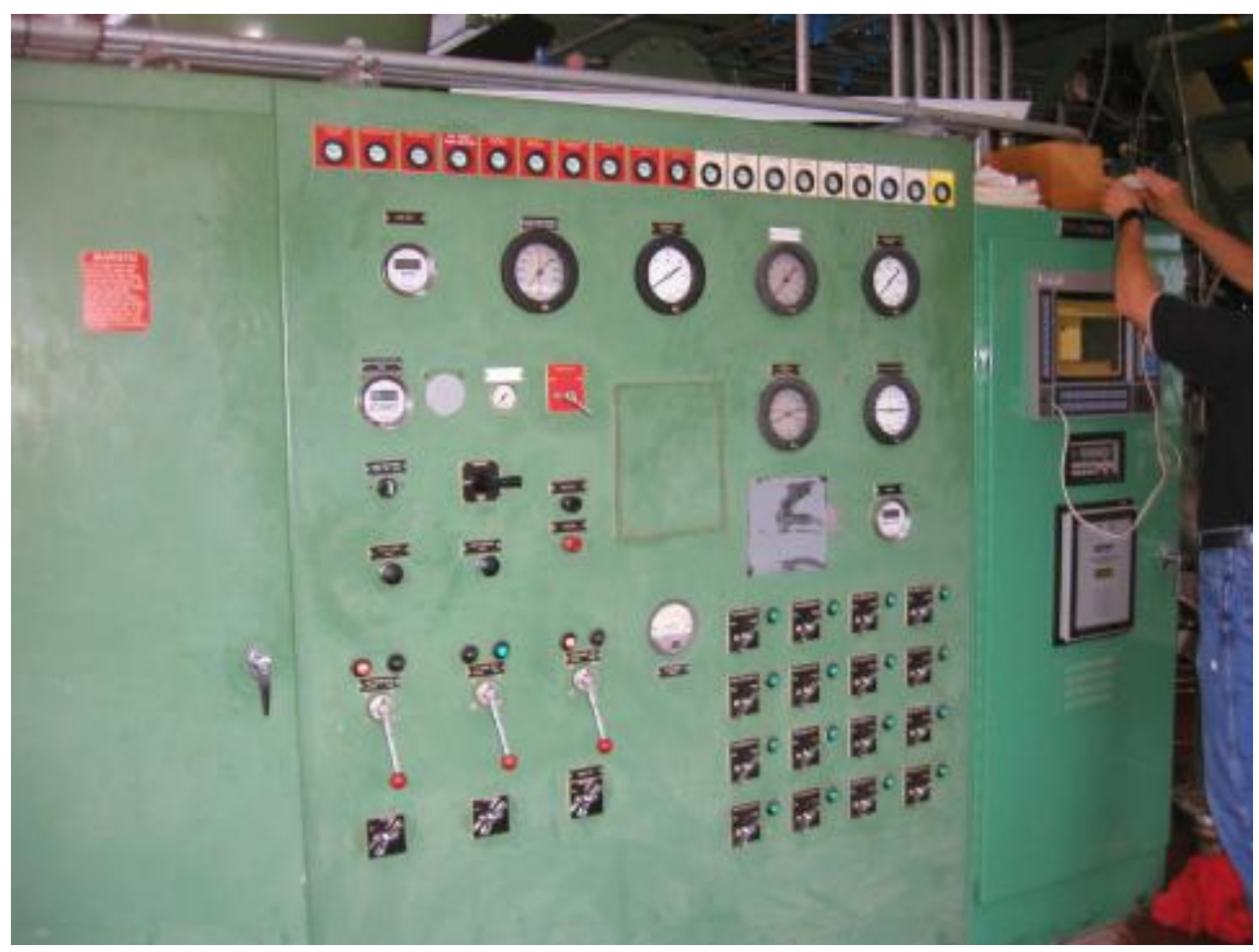

Figure 3. Engine Local Panel and $\mathrm{HPFI}^{\mathrm{TM}}$ Display Panel

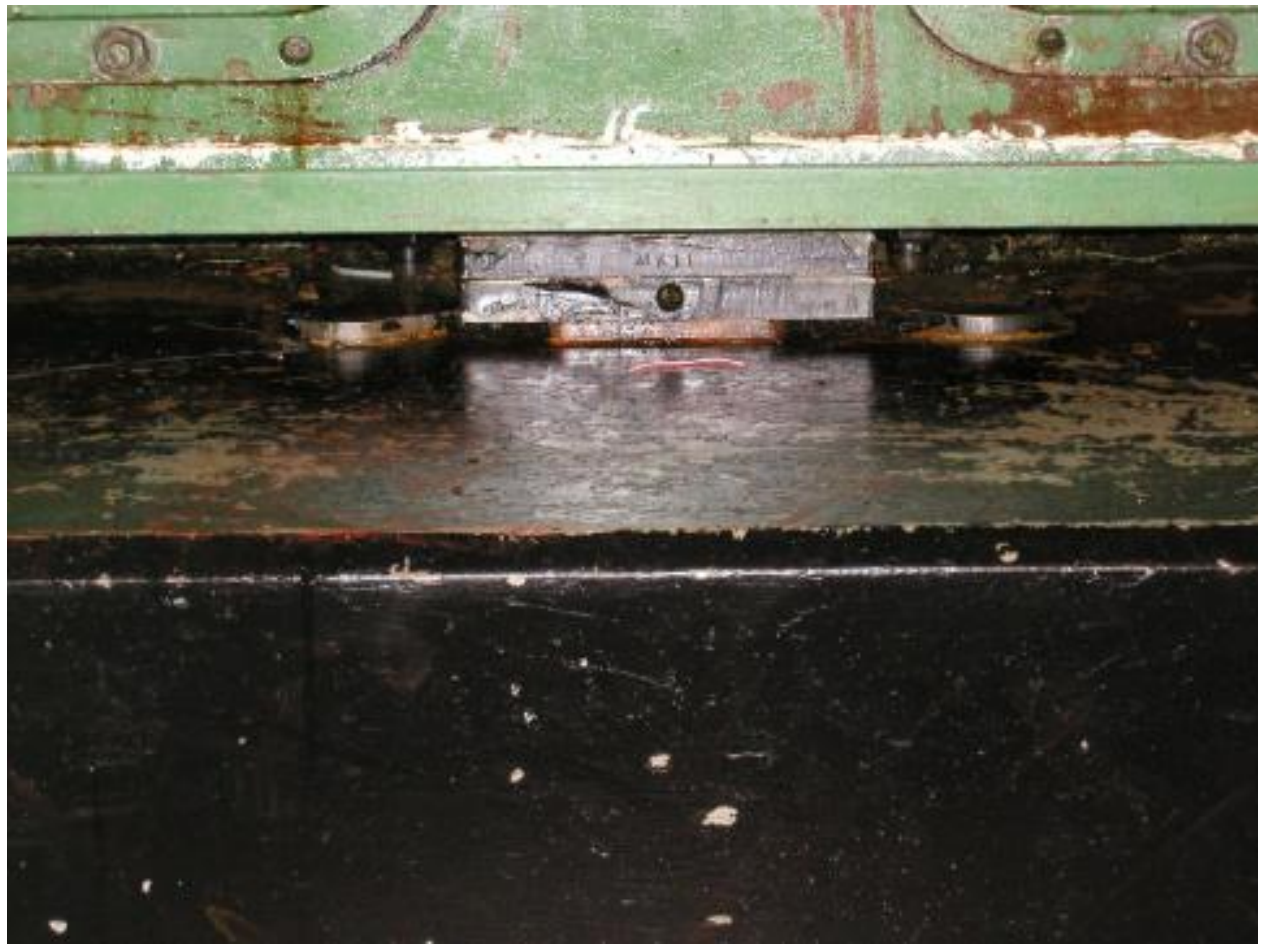

Figure 4. Steel Chock Mount 
The next thirteen (13) figures show some of the instrumentation installed for the test. Figure 5 shows the Rod Load Monitor (RLM) system. There are strain gages installed on the rod and a transmitter attached to the crosshead. The gages are bridged to reveal tensile and compressive loads, and to cancel bending. The stationary antenna is apparent in the foreground. This system continuously monitors rod load, and 512 samples are acquired digitally each revolution, triggered by the encoder pulse train. Figure 6 shows the cable from the antenna attached to the doghouse cover.

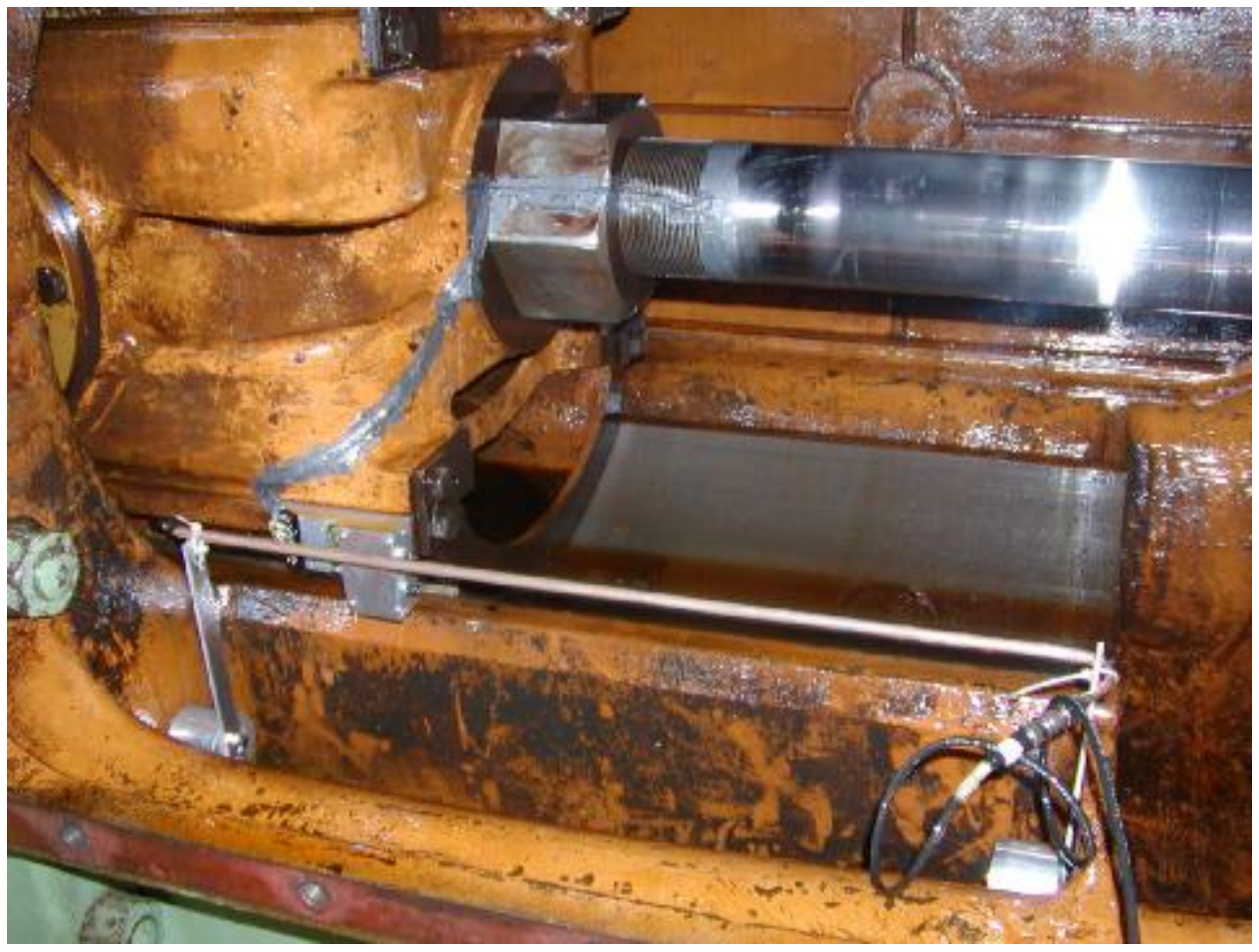

Figure 5. Rod Load Monitor Installation

Figure 7 shows one of the strain data capture modules installed on the crankshaft. The lead from the strain gage is apparent to the on-board data acquisition system. The gage is installed to measure bending of the crank web. The data is downloaded at the end of each day's testing. 


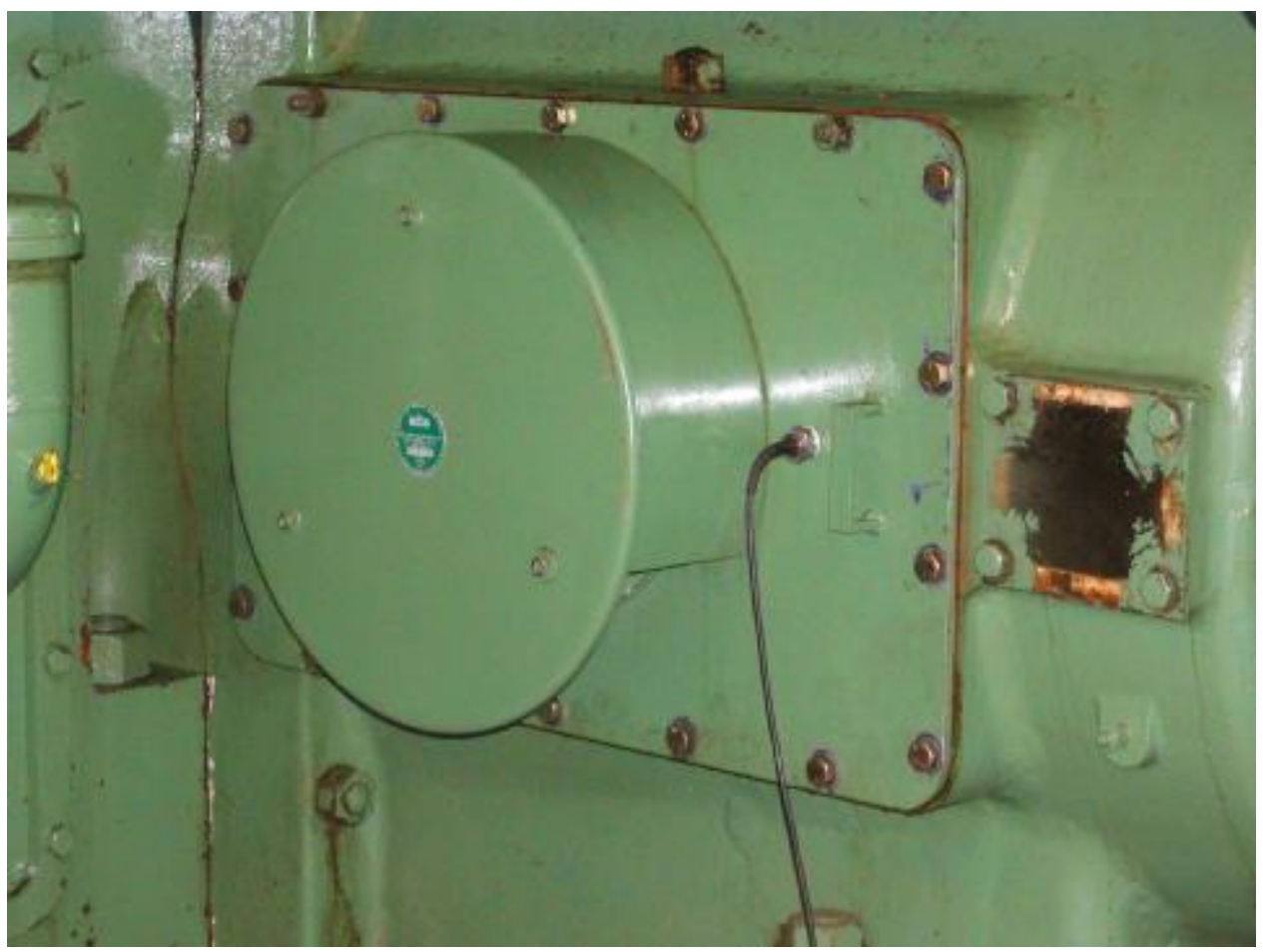

Figure 6. Cable from RLM Antenna

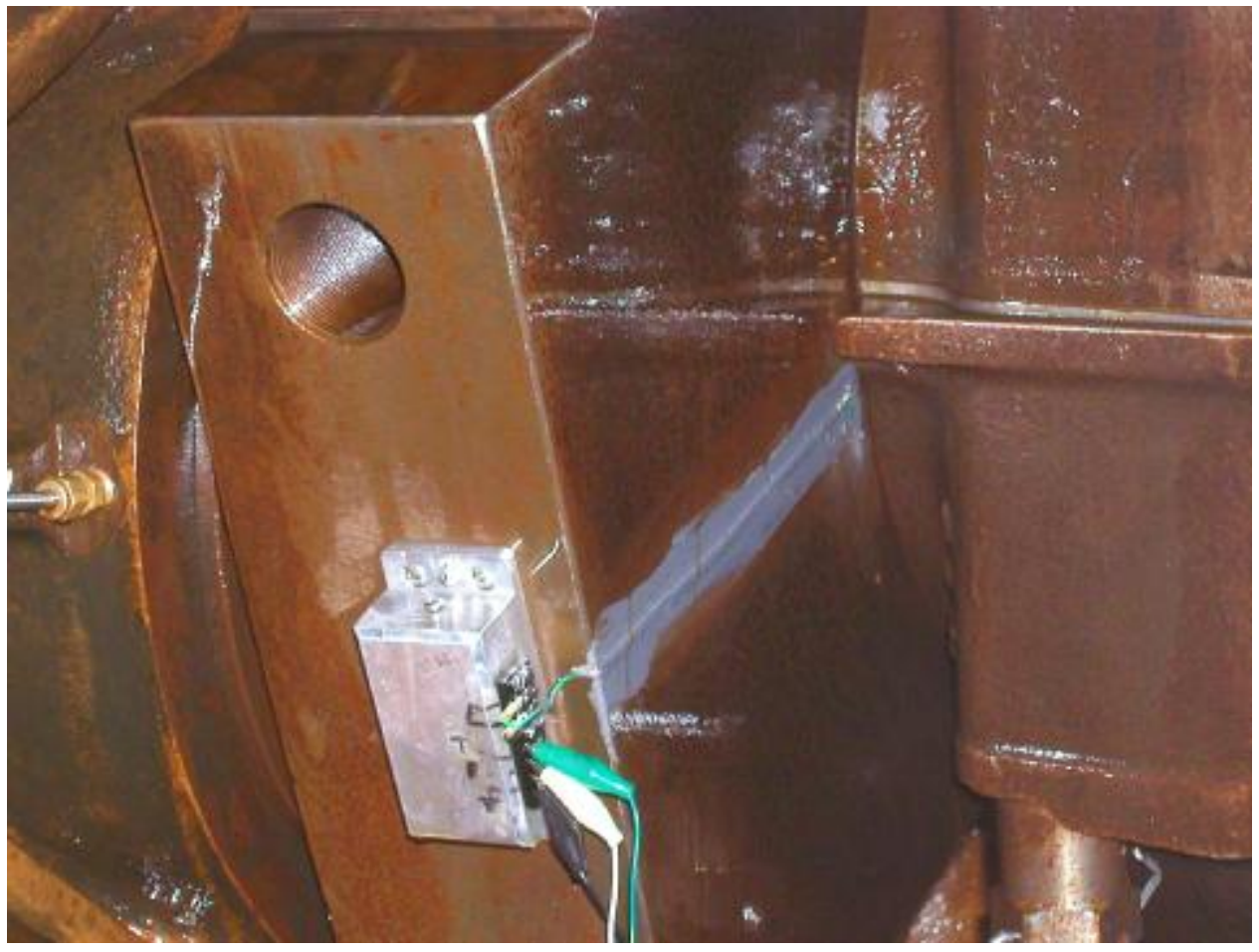

Figure 7. Strain Data Capture Module Installed 
Figure 8 shows the two pressure transducers installed on a typical compressor cylinder one on the head end and one on the crank end. Both compressor and power cylinder transducers, installed by SwRI, are "piggy-backed" on the same measurement port as the permanently installed $\mathrm{HPFI}^{\mathrm{TM}}$ instruments.

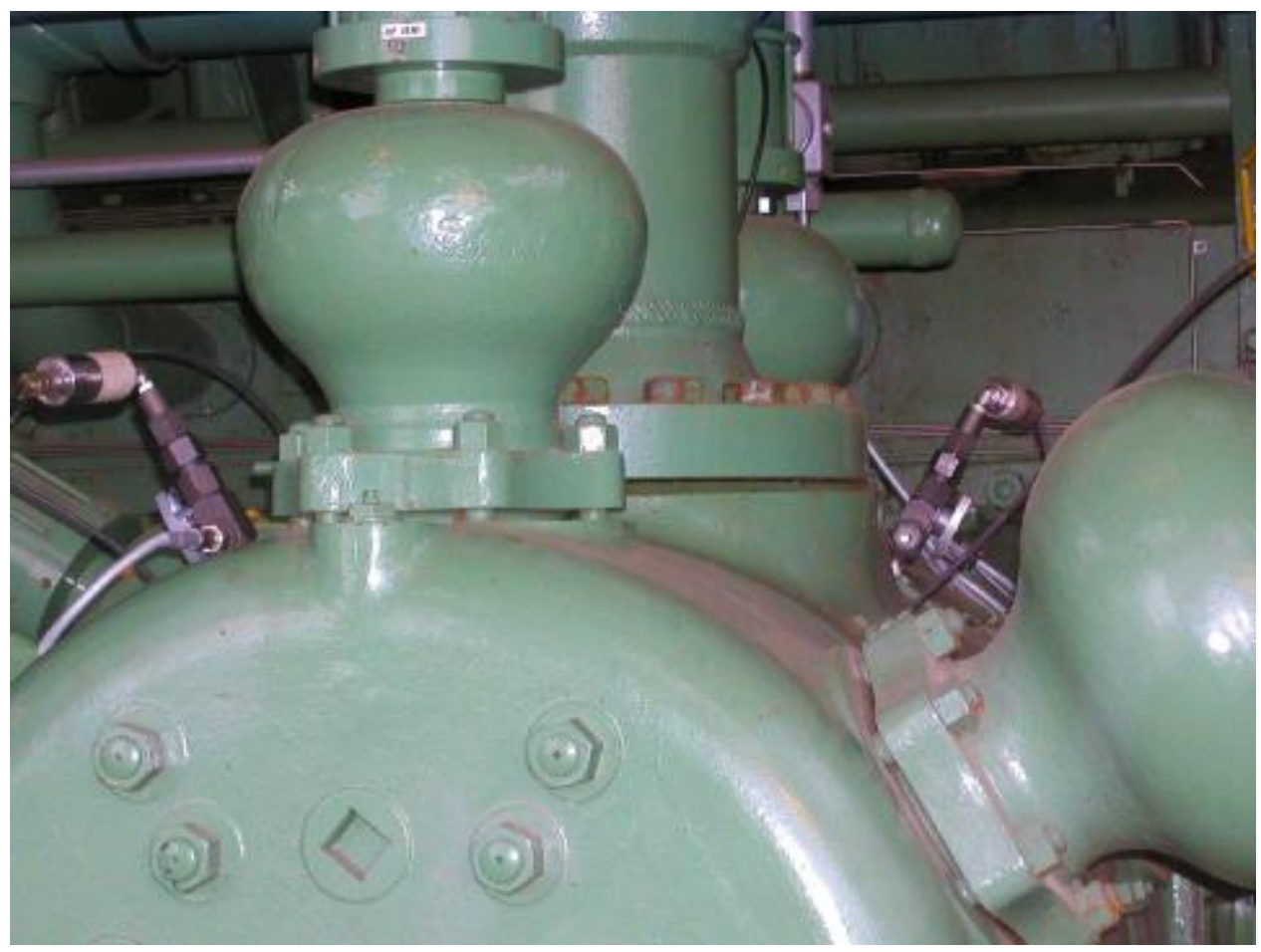

Figure 8. Compressor Cylinder and Pressure Transducers on each End

Figure 9 shows a power cylinder with SwRI's pressure transducer installed in the foreground. The HPFI ${ }^{\mathrm{TM}}$ system has its own pressure transducer, inboard of the SwRI transducer.

Figure 10 shows the power cylinder pressure transducer installation in more detail. 


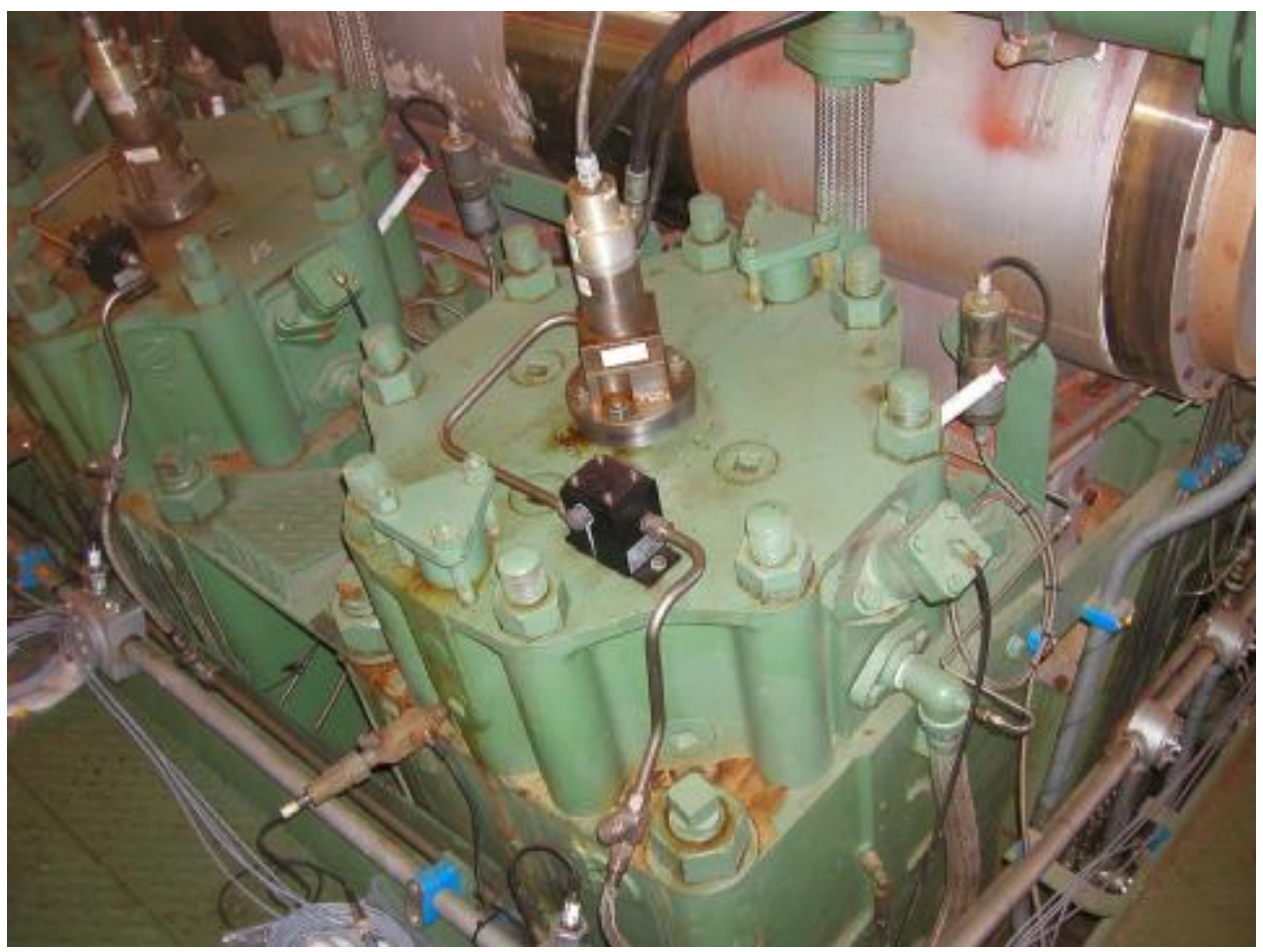

Figure 9. Power Cylinder with Pressure Transducer

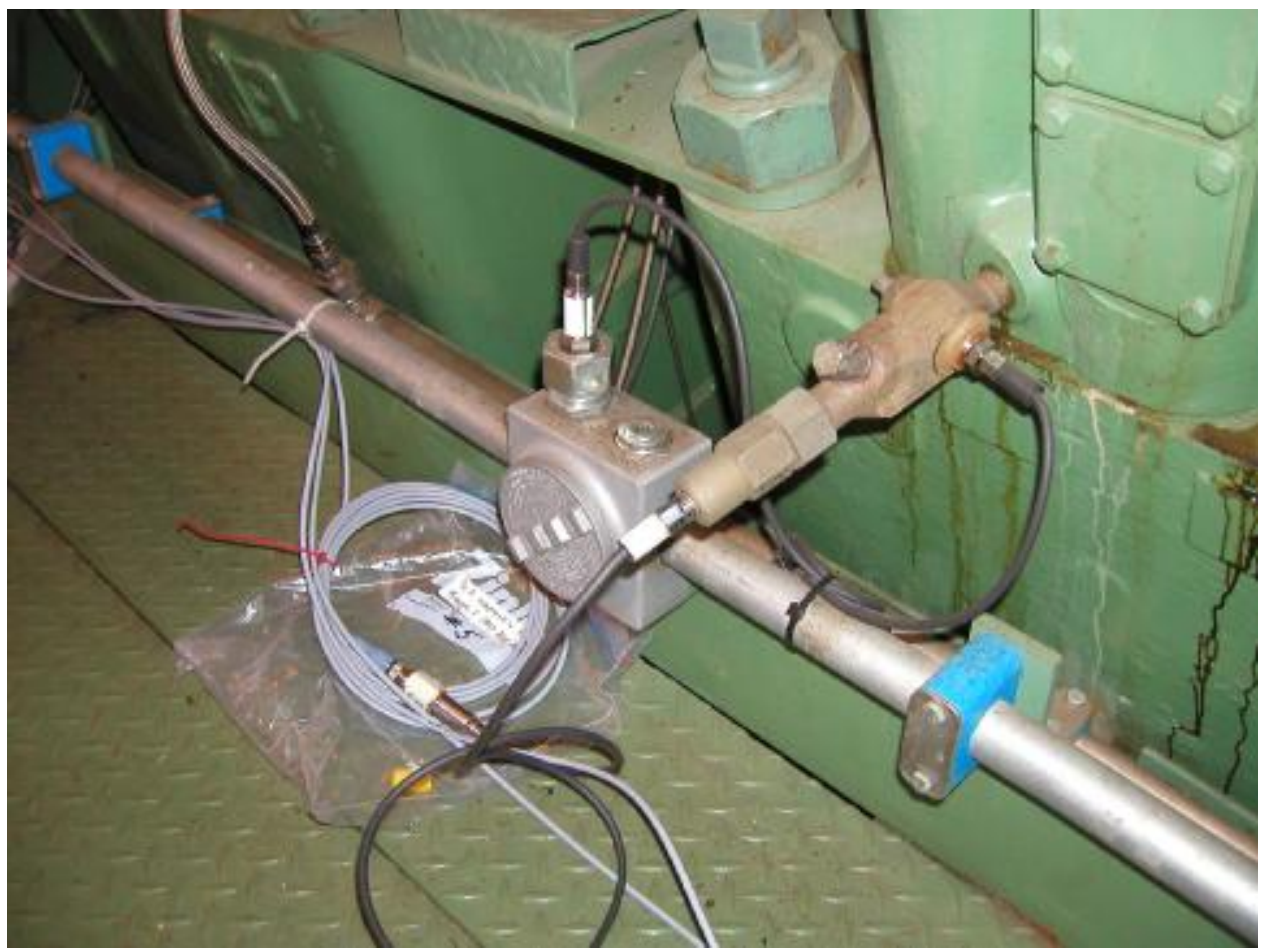

Figure 10. Details of Power Cylinder Pressure Transducer Installation 
Figure 11 shows the air intake manifold pressure transducer. The recently installed turbocharger is apparent in the background. Figure 12 shows the exhaust manifold pressure transducer. These fast-acting transducers record both the pressure level and its dynamic variation in intake and exhaust manifolds at the location where they are installed.

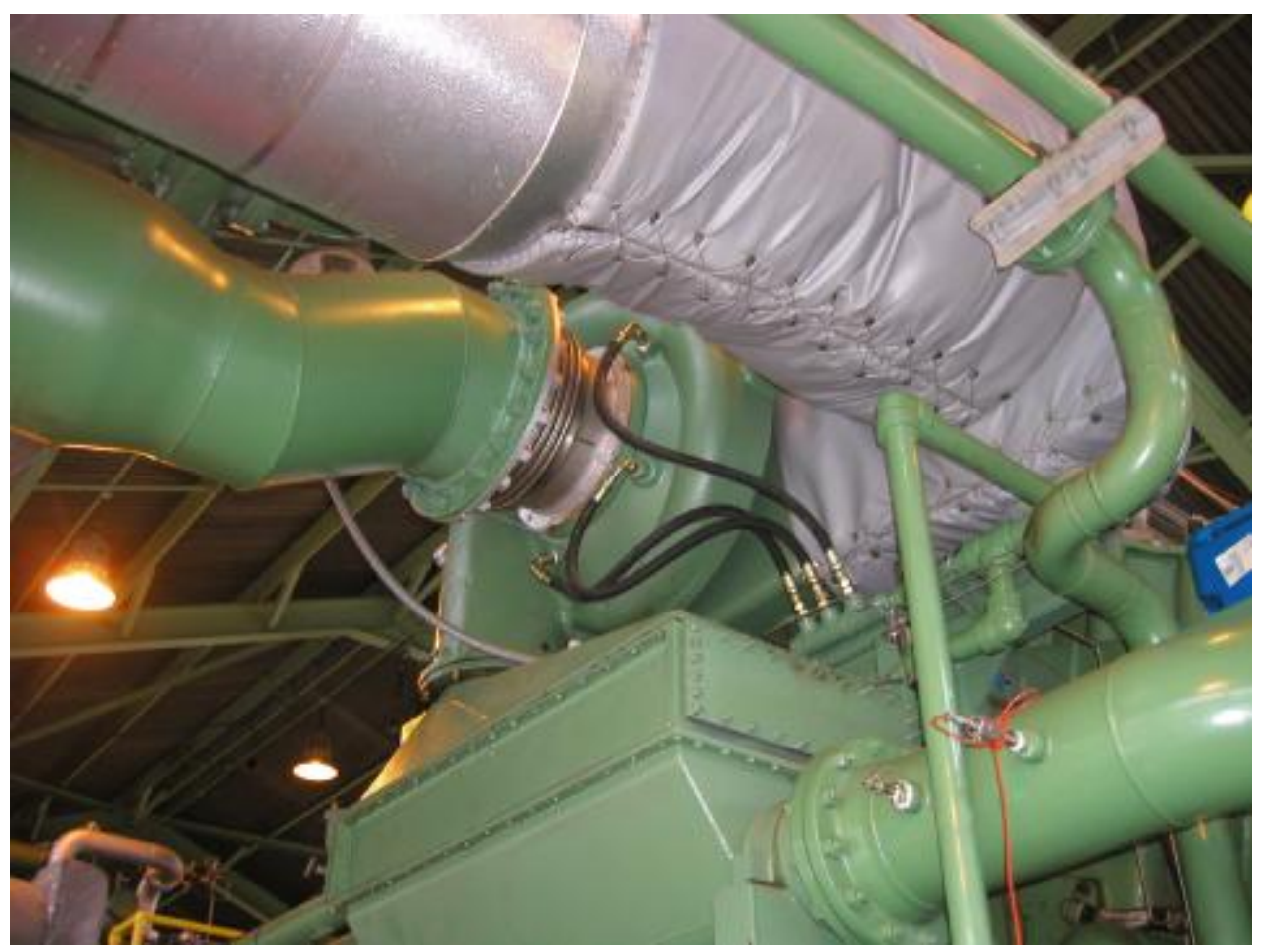

Figure 11. Pressure Transducer in Air Intake Manifold

Figure 13 shows the tripod which supports the encoder in a position aligned with the crankshaft's center of rotation. A flexible shaft connects the encoder to the flywheel. The encoder provides a 512 per rev trigger for acquisition of dynamic signals. The pulse train is also fed to an analog frequency to voltage converter, which measures instantaneous rotational velocity. Figure 14 shows the encoder and coupling shaft in more detail. 


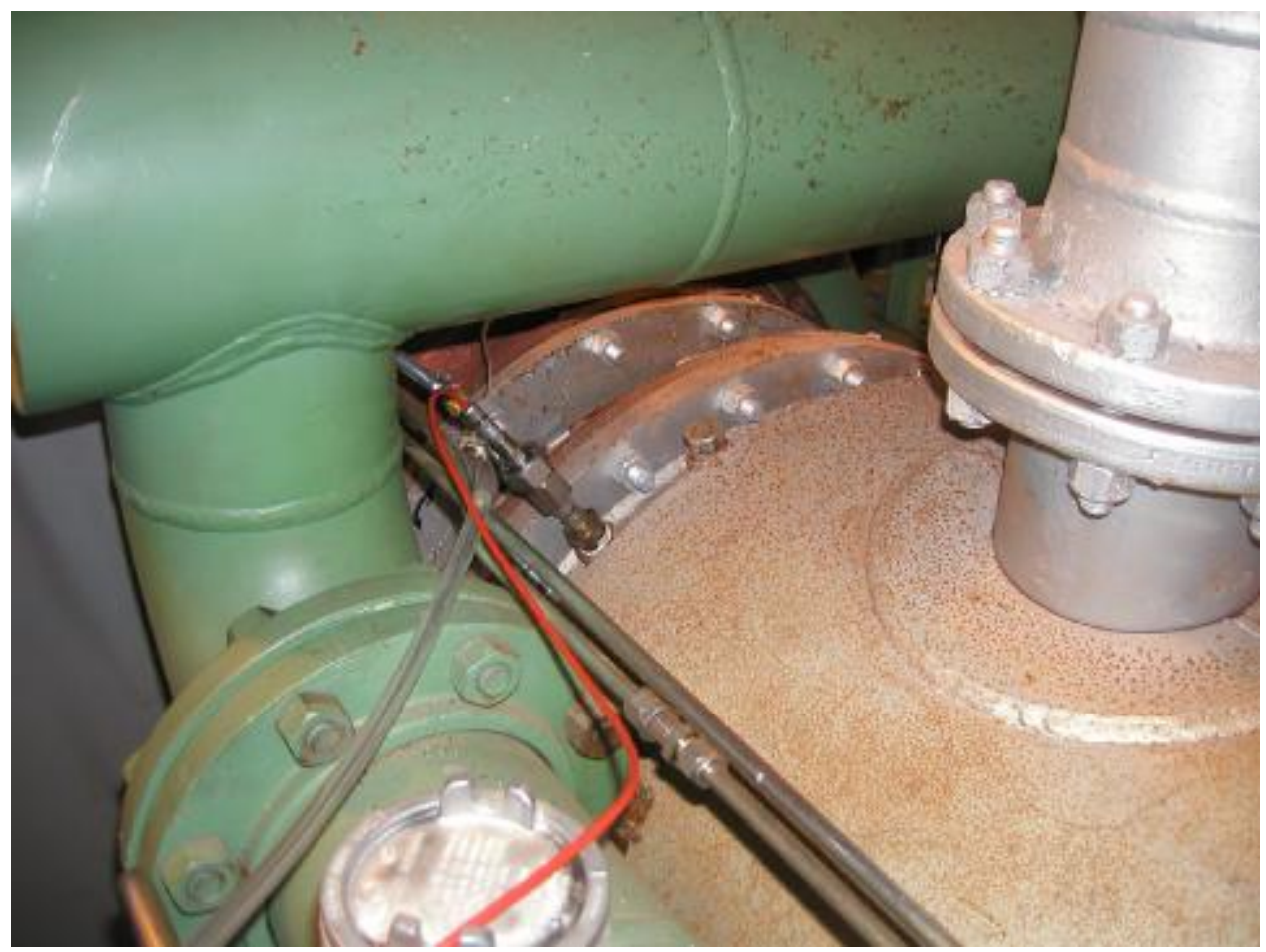

Figure 12. Pressure Transducer in Exhaust Manifold

Figure 15 shows one of the accelerometers mounted on the engine/compressor frame, which measures vibration as a possible indicator of loading severity. Figure 16 shows where the fuel flow measurement transmitter connects to the flange taps of the existing fuel flow measurement orifice. Figure 17 shows the $\mathrm{NGK}$ combined $\mathrm{O}_{2} / \mathrm{NOx}$ sensor connected to a pipe already installed, which connects to the exhaust stack. 


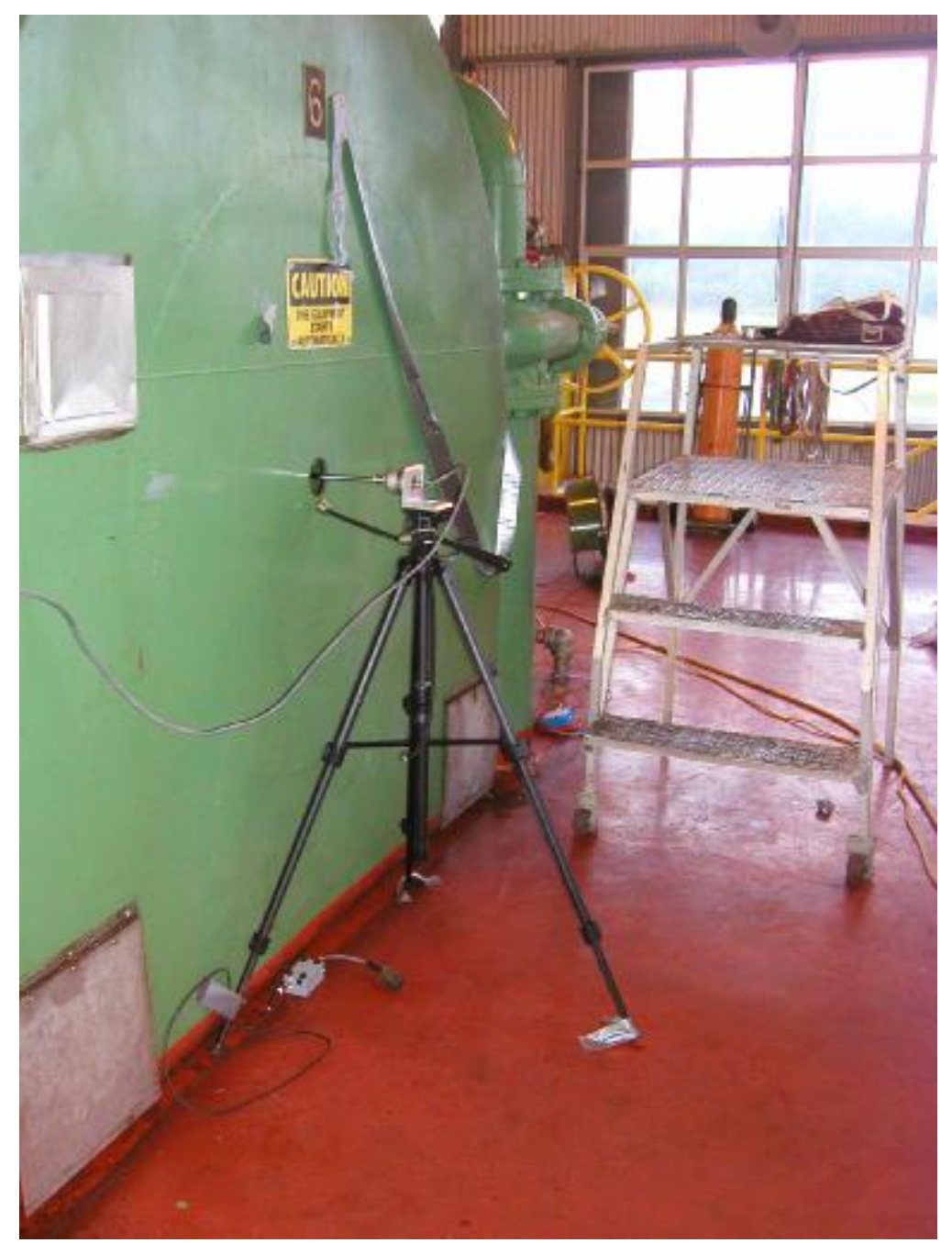

Figure 13. Encoder, Outboard of Flywheel on Mounting Tripod 


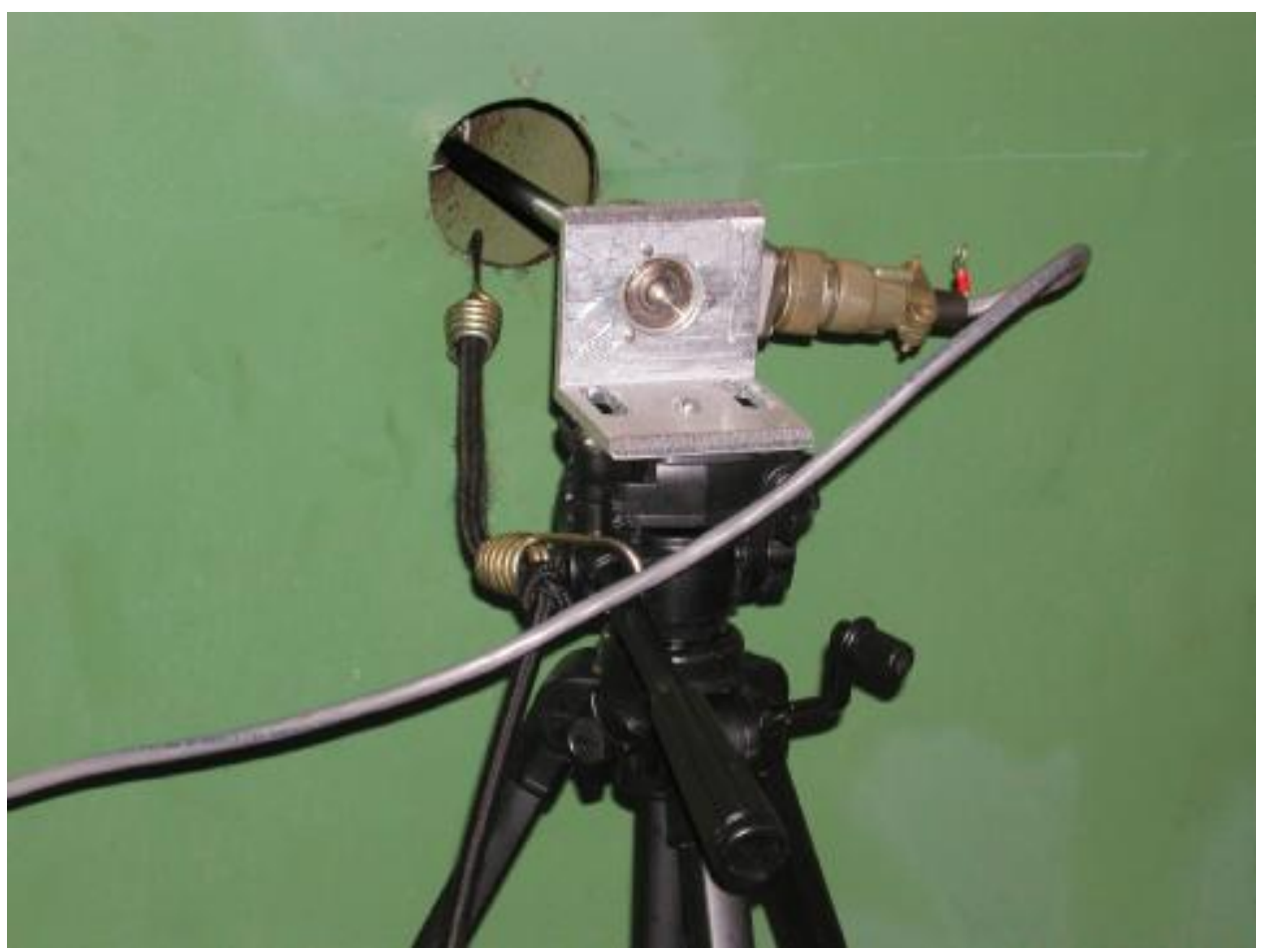

Figure 14. Detailed View of Encoder and Connection to Flywheel

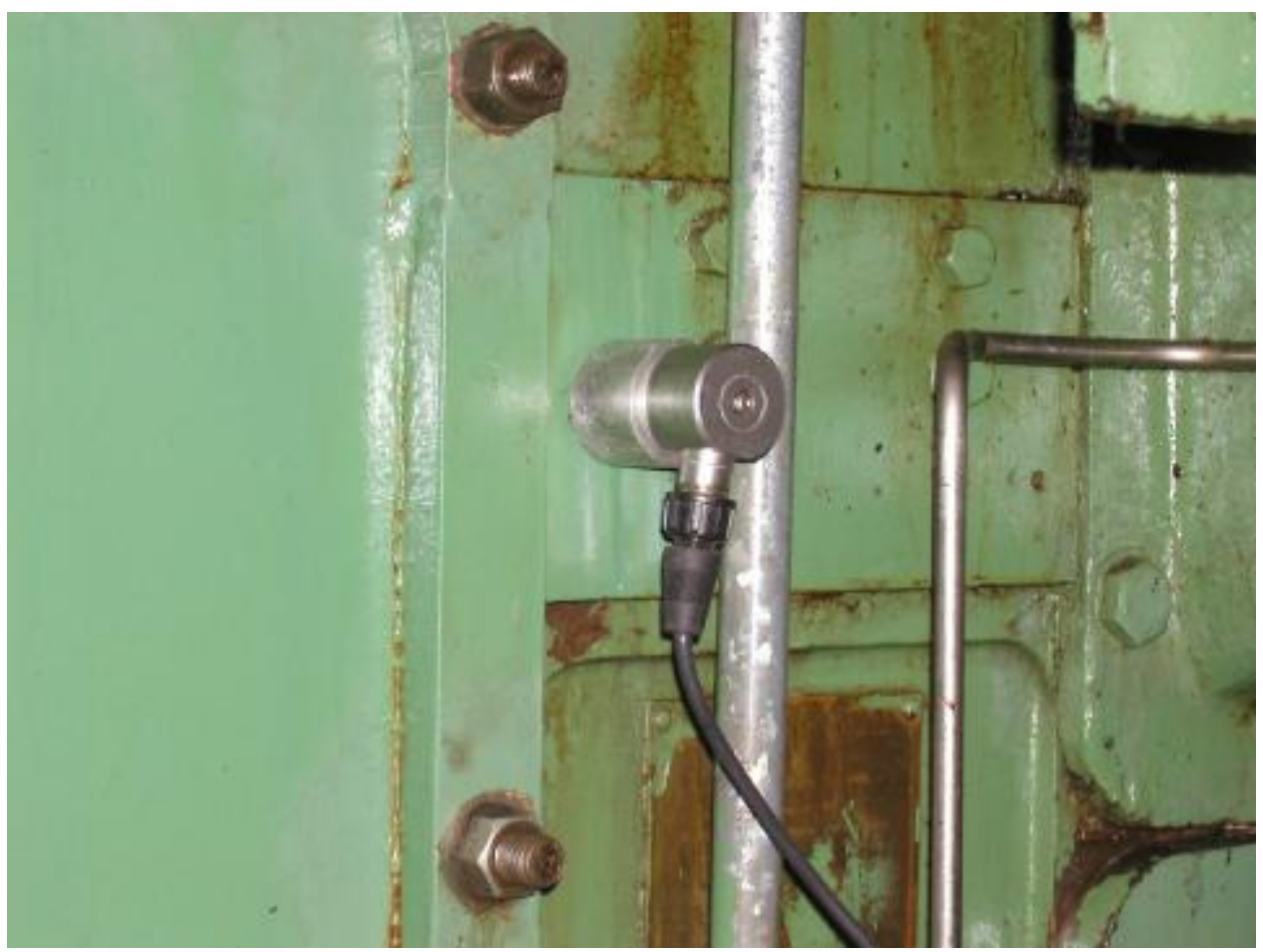

Figure 15. Accelerometer Mounted on Frame 


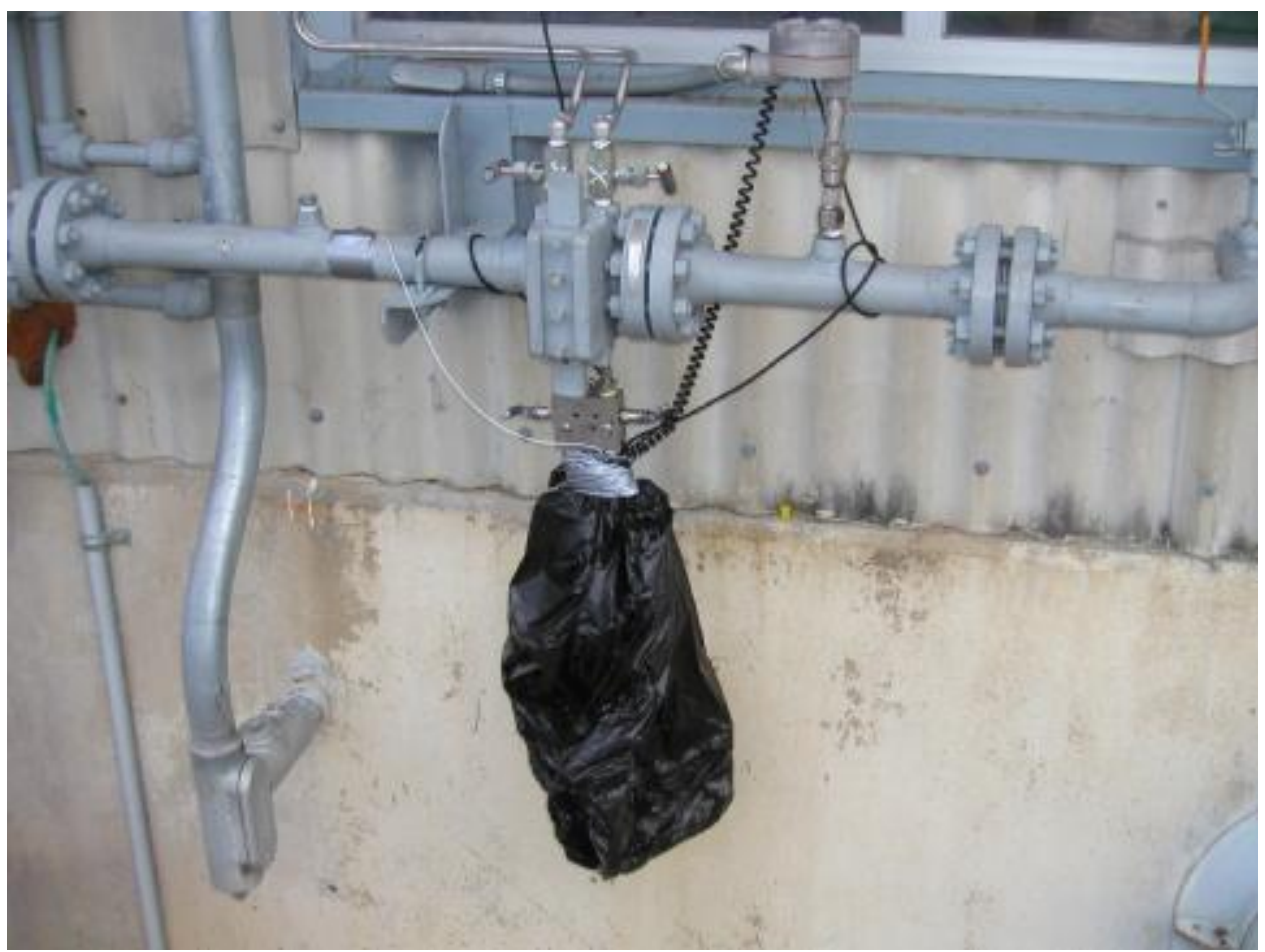

Figure 16. Flow Transmitter Connections to Orifice in Fuel Gas Line

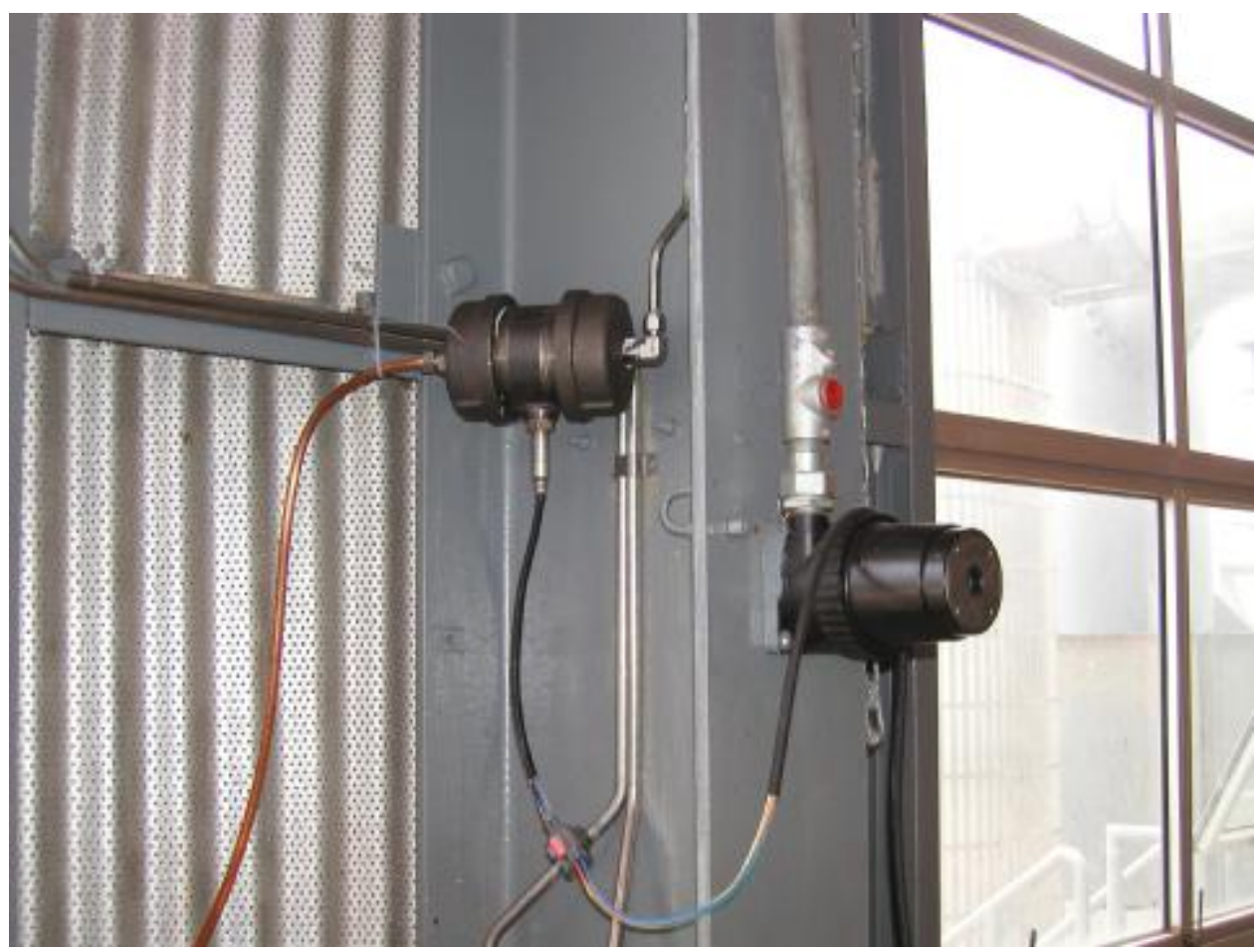

Figure 17. $\mathrm{O}_{2} / \mathrm{NOx}$ Sensor and Connection to Line from Stack 
Figure 18 presents the tabular screen used to display snapshot information relating to both the compressor and engine cylinders. For the ten power cylinders, the top half of the screen shows in columns the instantaneous peak-firing pressure, the instantaneous angular location (after TDC), the pressure at 20 degrees before TDC ("compression pressure"), the average peak-firing pressure, the standard deviation in peak-firing pressure, the indicated horsepower, the instantaneous indicated mean effective pressure (IMEP), the average HP, the standard deviation in horsepower, and the compression pressure ratio $(\mathrm{CPR})$ - defined as the instantaneous ratio of peak-firing pressure to compression pressure. The averages in Figure 18 are rolling averages (FIFO).

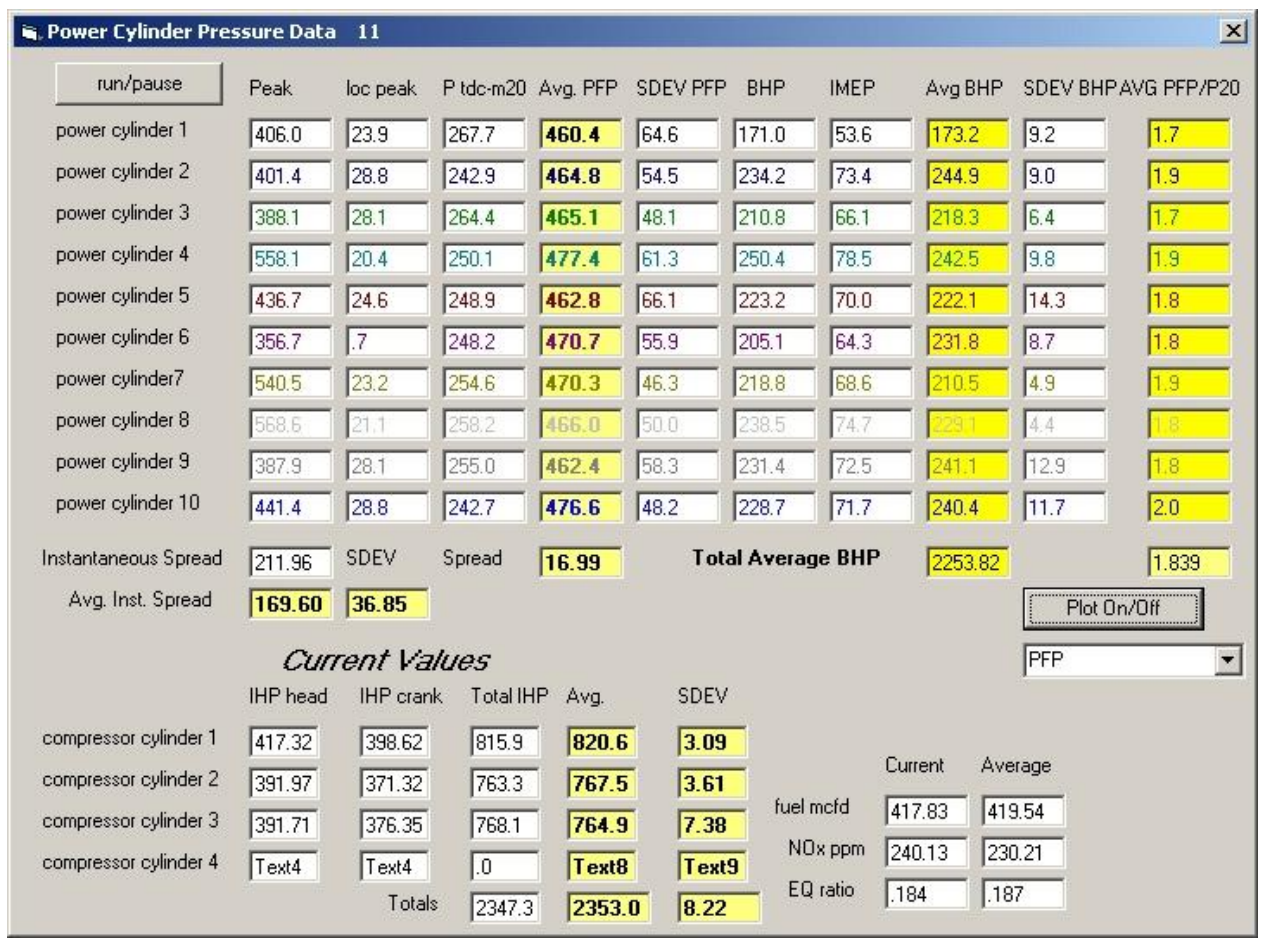

Figure 18. Snap Shot of On-Site Real-Time Calculations

It is noted that the standard deviation in peak-firing pressure varies from 46.3 to 66.1 PSI - a 20 PSI difference in standard deviation between cylinders. Standard deviations are about 13 percent of the average peak-firing pressure. 
Below the cylinder data columns are various averages, totals, and spreads from this typical snapshot:

- The Instantaneous Spread (211.06)

- The Average Instantaneous Spread (169.6)

- The Standard Deviation in Peak-Firing Pressure Instantaneous Spread (36.85)

- $\quad$ The Spread in Average Peak-Firing Pressure (16.99)

- The Total Average Horsepower (2253.82)

- $\quad$ The Average CPR (1.839)

Under the data for the ten power cylinders are the indicated horsepowers for the two ends of each of the three compressor cylinders, together with the total of the two ends for each cylinder. These instantaneous value columns are followed by the average and the standard deviation of the cylinder's horsepower $(2353,8.22)$.

The exceptionally low (17 PSI) spread in average PFP in this snapshot is attributable to the automated balancing system installed as part of $\mathrm{HPFI}^{\mathrm{TM}}$. This system is designed to constantly adjust the bias in pulse width on individual fuel injectors in order to minimize the spread in cycle averaged peak-firing pressure. Although disabled during the tests, the biases from prior automated balancing clearly remained close enough during the test program to keep this spread very low.

The total instantaneous indicated horsepower for the compressor cylinders (2347) and the average total indicated horsepower are also shown (2353), with the total standard deviation in horsepower across all the cylinders (8.22). Also on this screen are the current and rolling average values for fuel flow (417.83/419.54), NOx PPM (240.13/230.21), and global equivalence ratio (0.184/0.187). This is a low global equivalence ratio. The influence of the air and injection system appears to be to allow operation acceptably close to the lean limit at a low equivalence ratio. 
It may be observed that the power for the power cylinders is measured as about $100 \mathrm{HP}$ below the compressor cylinders. This, of course, is not realistic. The sensors are well calibrated, but the required power cylinder sensor installation shown in Figures 9 and 10 is undoubtedly a factor in reducing the apparent horsepower. Because the required piggy-backing separates the SwRI transducers from the cylinder chamber by an additional length, the channel distortion is exaggerated. The filtering induced by the flow passage geometry attenuates the higher frequency dynamic variation, and thereby lowers the observed horsepower. The channel attenuation phenomenon has been well documented for power cylinders [2, 3]. The similarity of installation for the ten transducers and the similarity in form of the power cylinder traces makes it strongly arguable that the distortion induced in each cylinder is the same for each cylinder and, therefore, that trends observed in horsepower and peak pressure are valid. The very low spread observed by both the SwRI instruments and the $\mathrm{HPFI}^{\mathrm{TM}}$ system makes it very likely that the cylinder pressure measurements are consistent with those of the $\mathrm{HPFI}^{\mathrm{TM}}$ system (upon which they are piggy-backed).

Further analysis of this channel distortion phenomenon is planned.

Figure 19 shows typical averaged pressure traces for the ten power cylinders. These include a numerical value for the current average spread in average peak-firing pressure of about 60 PSI for this condition. This higher spread (and higher peak pressures) probably correspond to a test condition (e.g., increase in timing advance), which caused both PFP and spread to increase. The similarity of the traces is notable, and even 60 PSI is a relatively low spread in average peak pressure - not above about 12 or 13 percent of PFP.

Figure 20 shows the corresponding cylinder pressure traces. The header pressures are superimposed. The pulsations in the cylinder pressure, which reflect dynamic response to cylinder/valve dynamics in the attached piping, are apparent in the cylinder traces. The piping normally includes pulsation control features, which filter out pulsations above a relatively low cut-off frequency with minimum flow resistance. However, the reflections 
of lower order pulsations in the cylinder pressure traces and the small, but non-zero flow resistance associated with pulsation control filters and choke tubes can influence the unproductive horsepower in the compressor cylinders, and thereby can influence cylinder thermal efficiency.

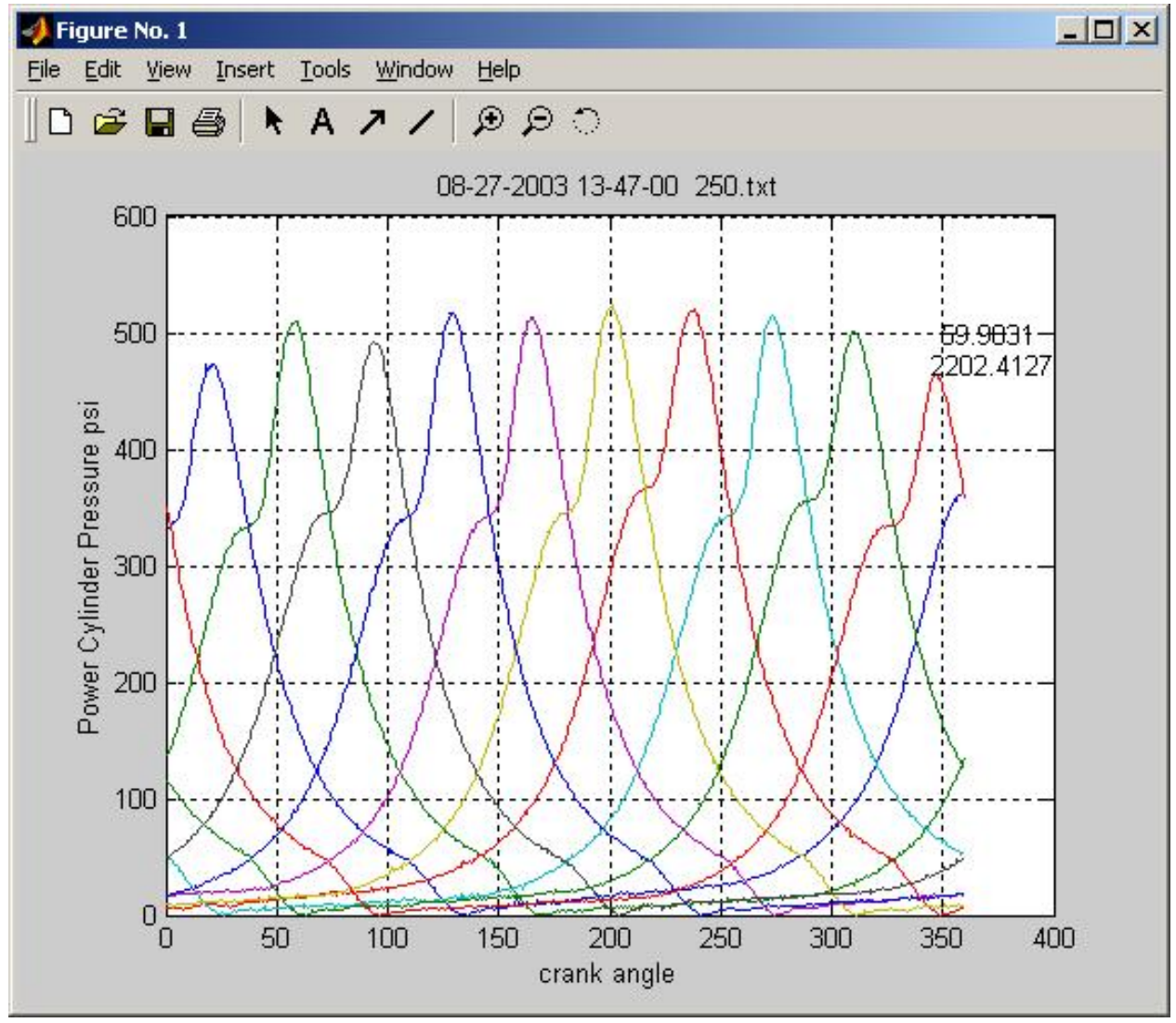

Figure 19. Typical Power Cylinder Pressure Data

Figure 21 shows the dynamic variation in inlet air manifold pressure at the location of measurement. The top trace presents the pressure as a function of crank angle over one engine cycle (360 degrees). The lower trace shows the result of transforming the upper trace to the frequency domain, presenting zero-to-peak pressure variation as a function of orders of rotational speed. The upper trace indicates a range from about 4.6 to 5.7 PSIA; i.e., close to 20 percent of the average, with a series of reversals in the trace within one revolution. The lower frame of Figure 21 shows that there are peaks at about $3^{\text {rd }}, 10^{\text {th }}$, $16^{\text {th, }}$ and $25^{\text {th }}$ orders, and action to the $40^{\text {th }}$ order. 


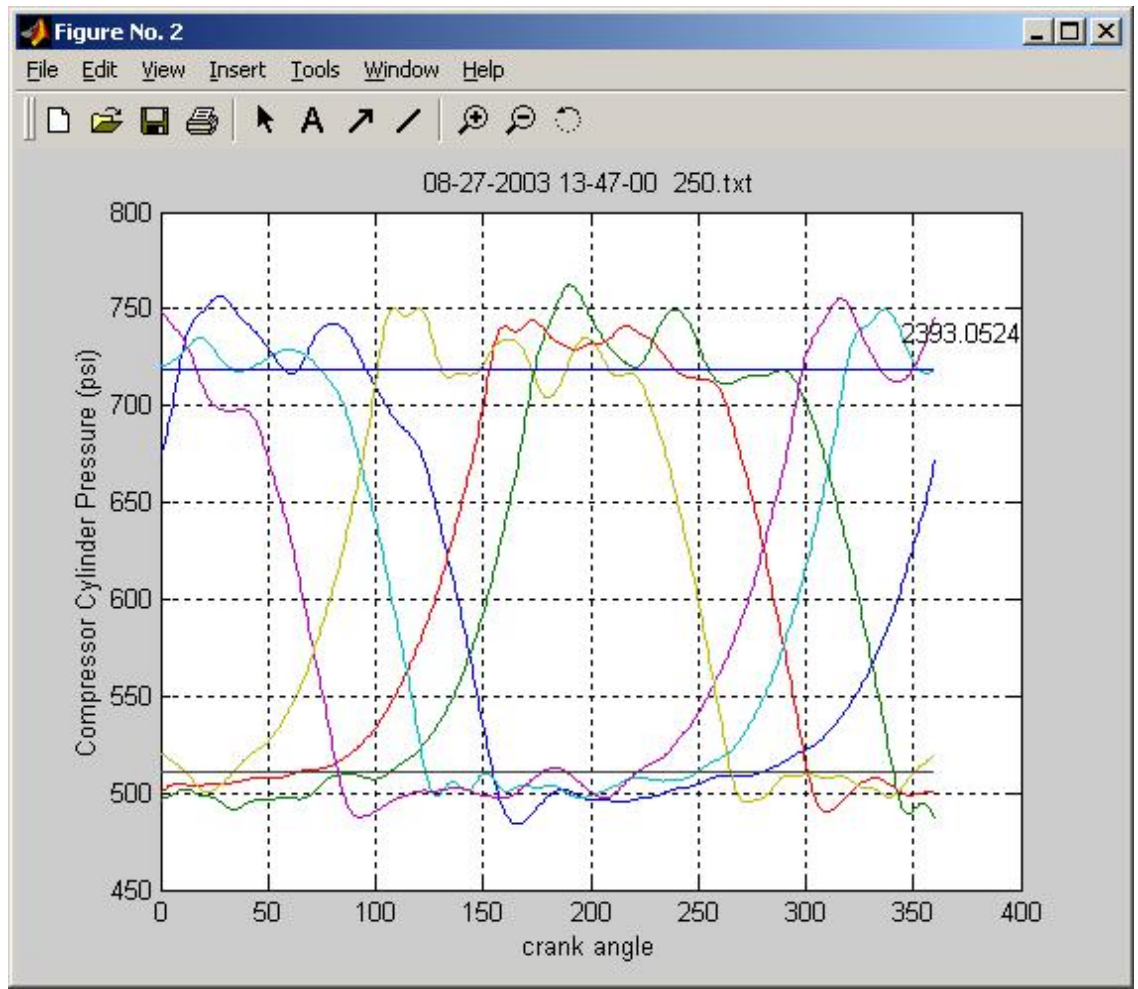

Figure 20. Typical Compressor Cylinder Pressure Data

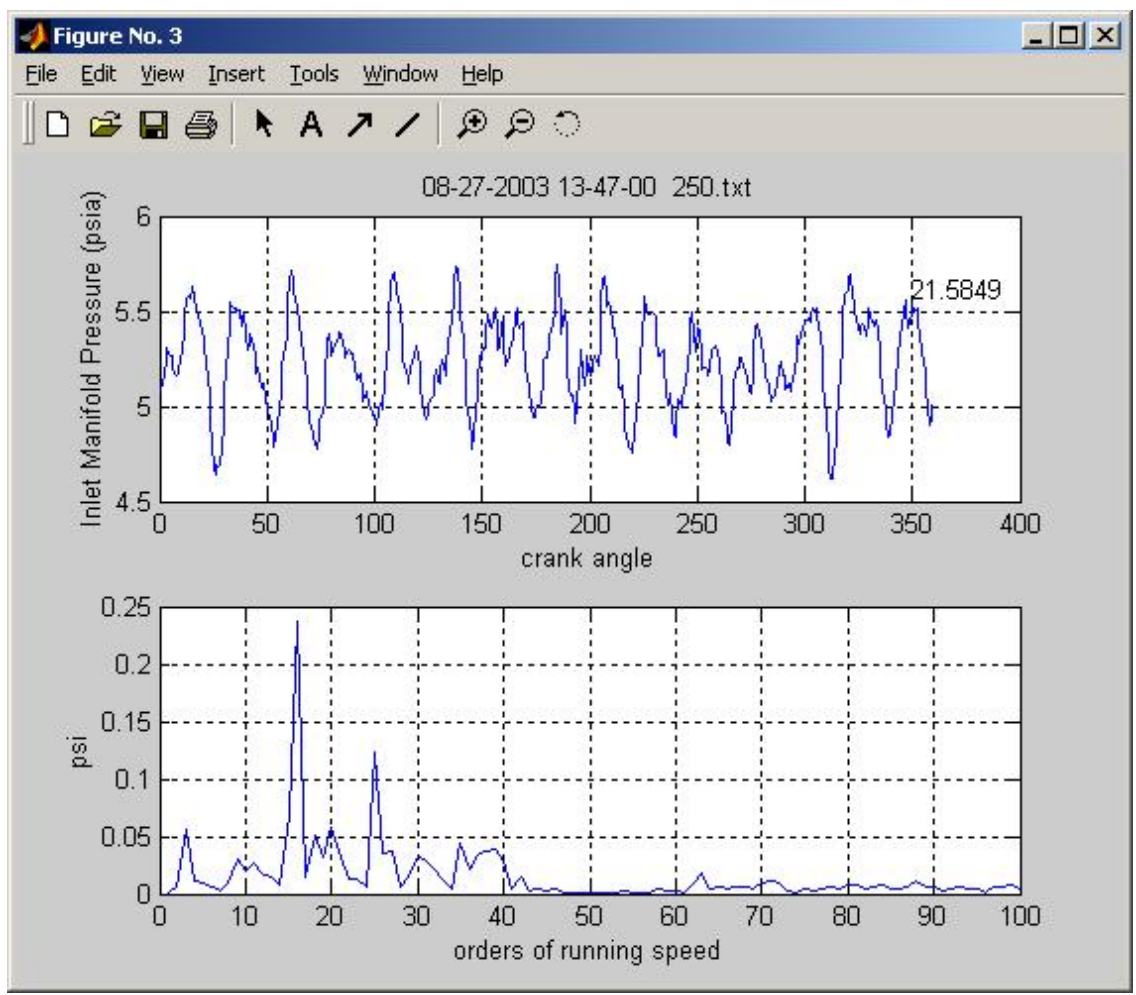

Figure 21. Typical Inlet Manifold Pressure Trace and Order Spectrum 
Figure 22 makes a similar presentation to Figure 21 for exhaust manifold pressure. The range shown in the upper trace is from 3 PSI to 4.9 PSI; i.e., close to 50 percent of the average. The lower trace shows peaks at the $4^{\text {th }}, 9^{\text {th }}, 12^{\text {th }}$, and $22^{\text {nd }}$ orders of running speed.

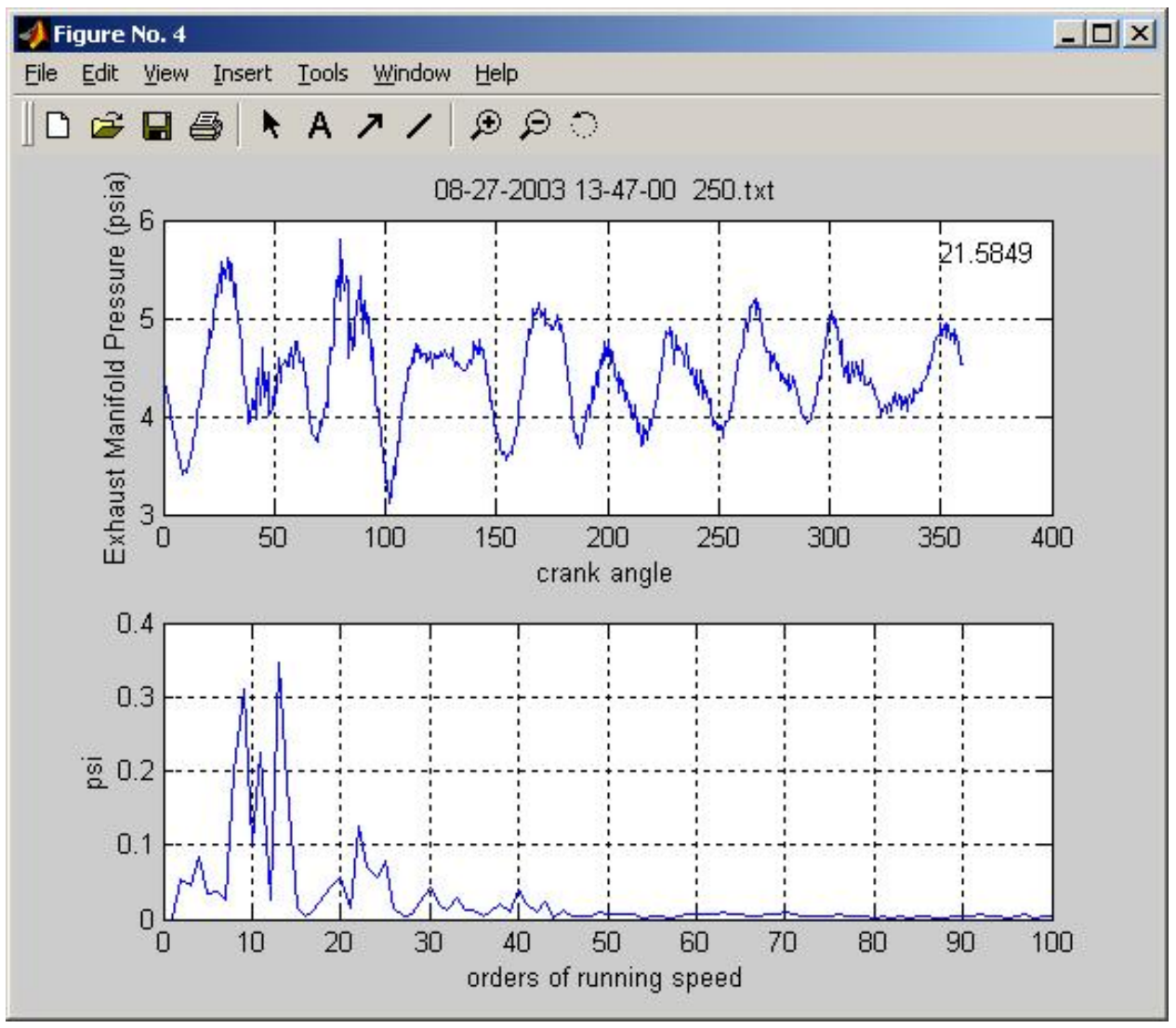

Figure 22. Exhaust Manifold Pressure Trace and Order Spectrum

Figure 23 summarizes the range of variation - typical in manifold pressures - throughout a day of testing. In general, the inlet air manifold dynamic range lies just below 20 percent of its average, although a few points exceed 20 percent. The exhaust manifold dynamic range lies generally just over 50 percent, ranging from 45 to 70 percent. These are cycle-averaged pressures indicating both time variation and variation during the manifolds. Since flow into and out of the cylinder is directly influenced by these pressures, the trapped air would be expected to vary from cylinder to cylinder as a result of the time/space variation. 


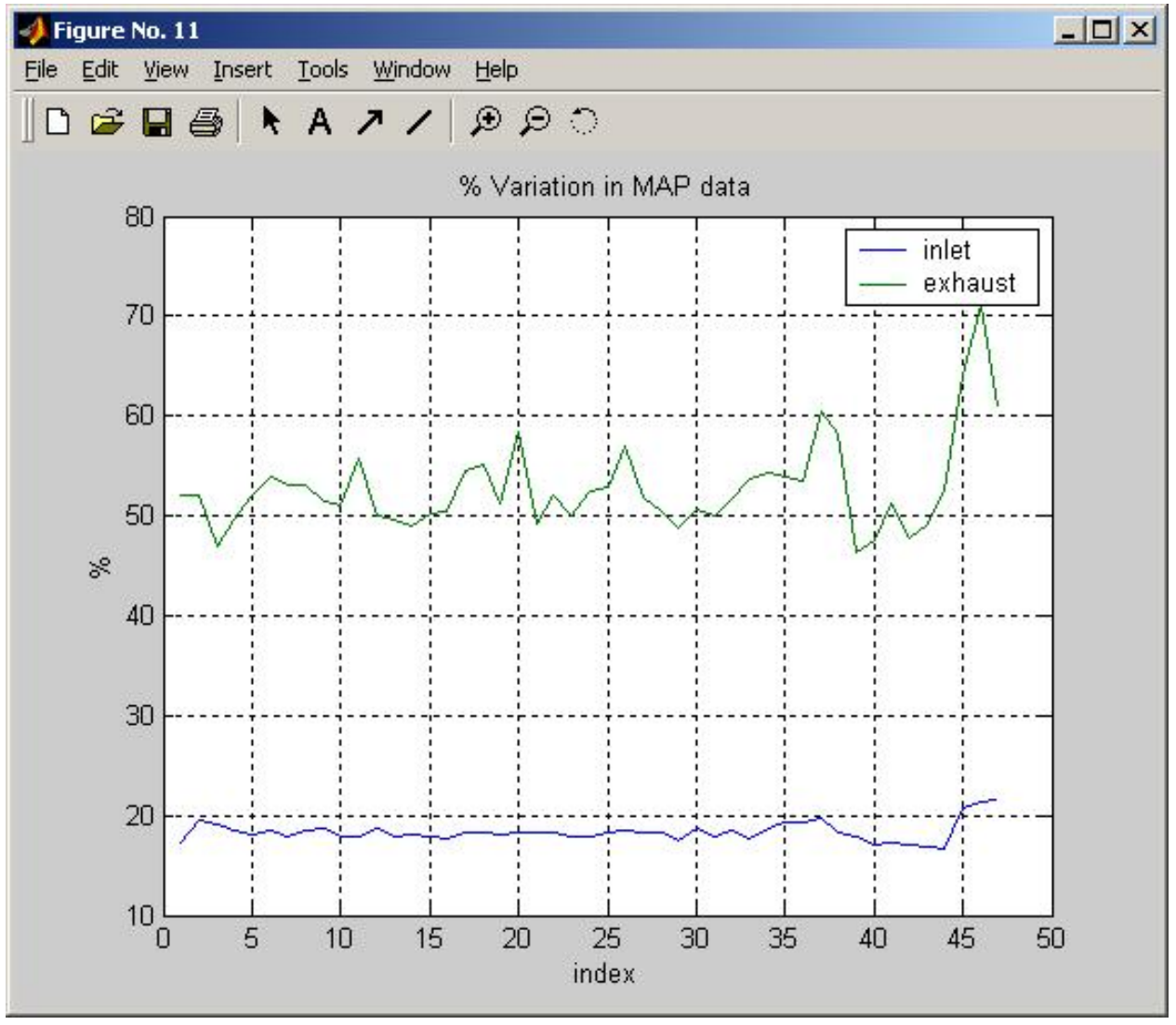

Figure 23. Variation in Inlet and Exhaust Pressures at Point of Measurement

Figure 24 shows the cycle-averaged output of the rod load sensor in the format of rod load versus crank angle over a single revolution (360 degrees). The inferred rod load ranges from $-47,000 \mathrm{lb}$. to $+55,000 \mathrm{lb}$. - a total range of 102,000 lb. The variation reflects the difference between head-end pressure force and crank-end pressure force, together with the inertia force resulting from acceleration and deceleration of the piston. Further analysis in conjunction with piston kinematic analysis will yield horsepower data from the rod load measurement. 


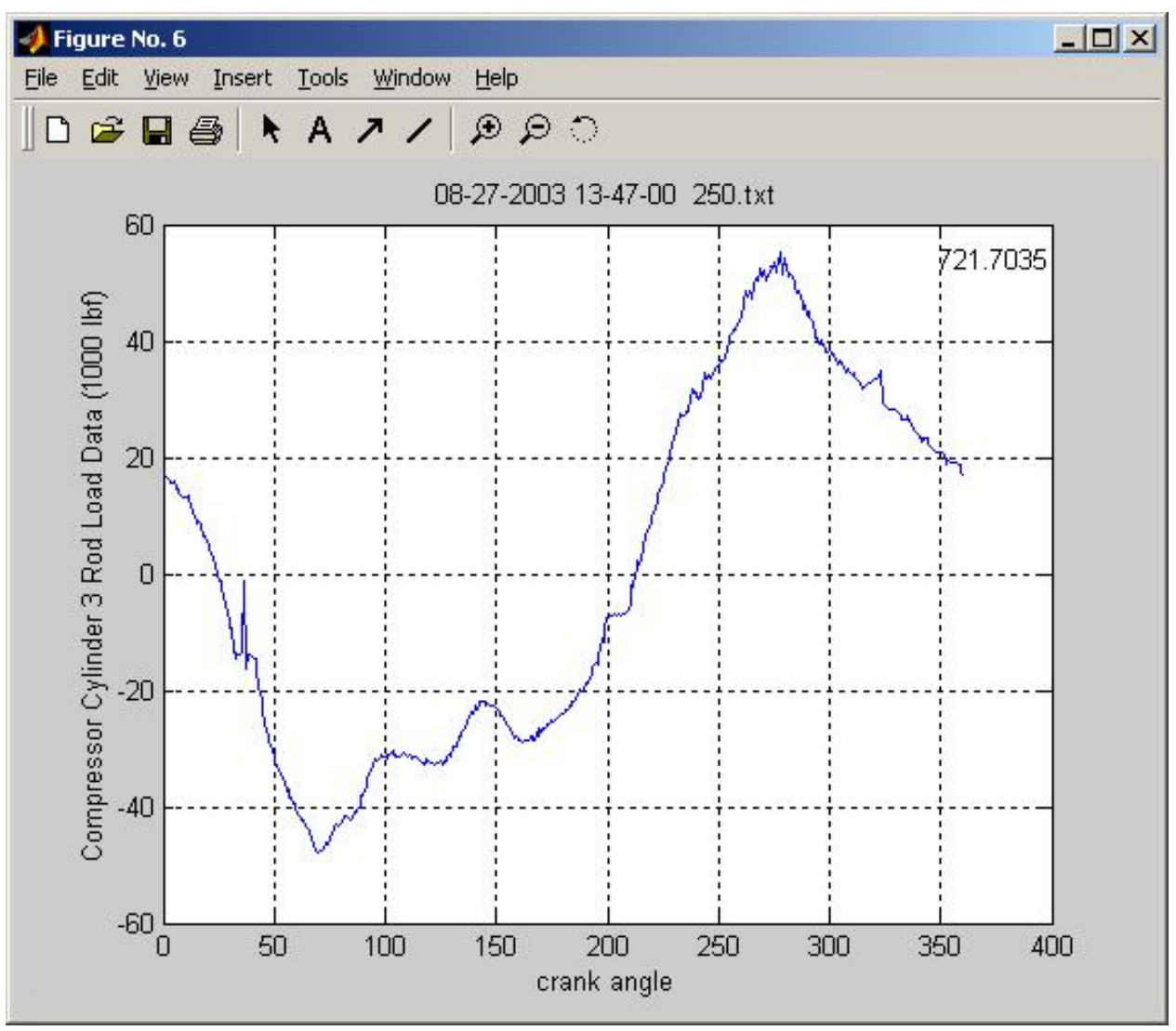

Figure 24. Typical Rod Load Variation Over One Revolution

Figure 25 shows the variation of compressor and engine horsepower indicated by the cylinder pressure transducers as a function of test record number (index). It will be seen that the indicated compressor power remains rather constant over the day's testing at an average of about $2375 \mathrm{HP}$, with a scatter range of about $50 \mathrm{HP}$ about this average value. The indicated engine power appears to drop gradually during the day from an initial average around $2275 \mathrm{HP}$ to about $2225 \mathrm{HP}$. There is, again, a range of about $50 \mathrm{HP}$ about the average, but the reducing trend in engine power, by 2 to 2.5 percent over the day, is clear. 


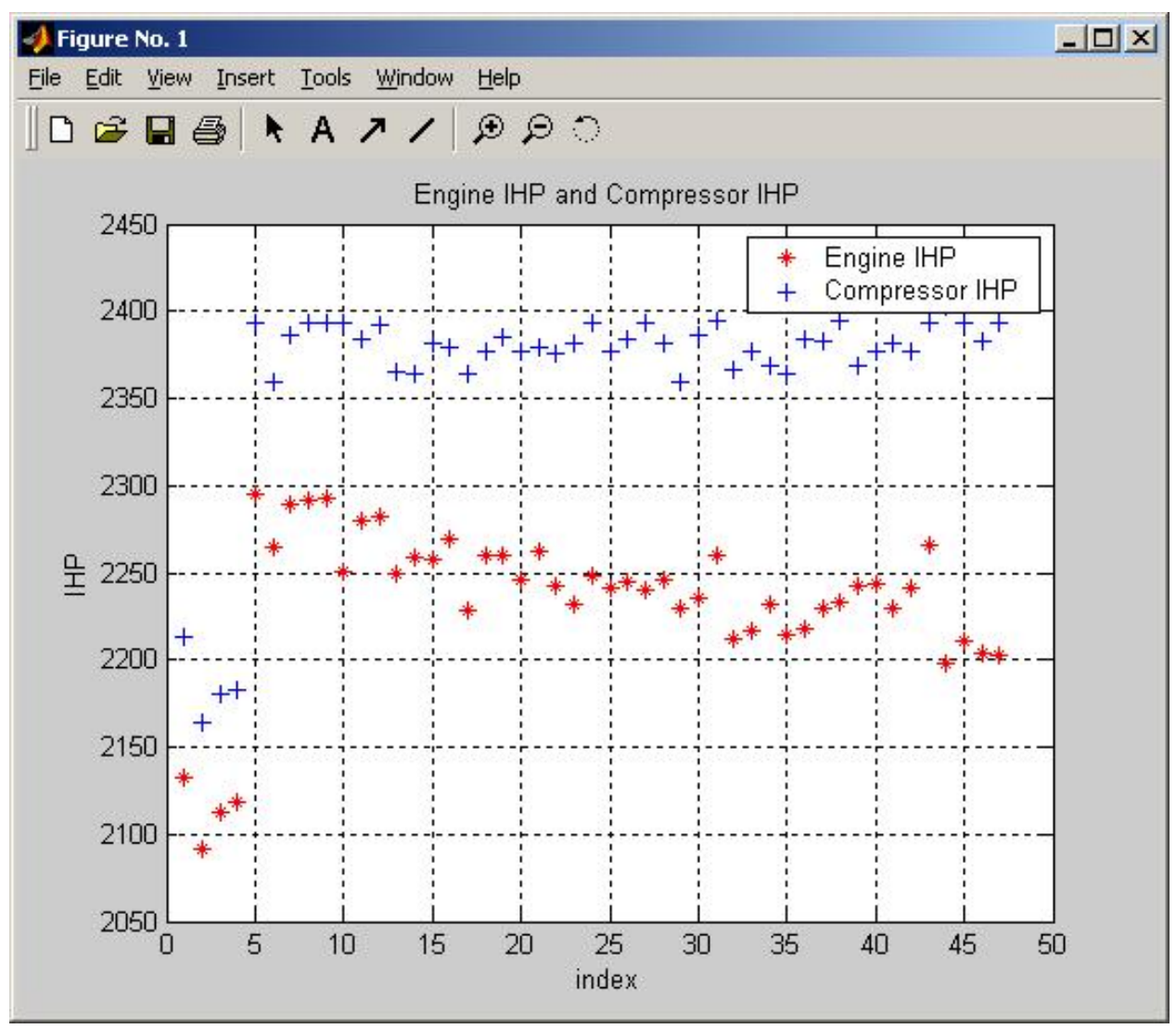

Figure 25. Indicated HP Over Test Day

A similar trend was seen in the data at the first test site (which will be discussed further below) - an apparent reduction in the losses between engine and compressor pistons over a 5- to 6-hour period following the start of the day's tests.

The first four data sets, shown in Figure 25, show much lower power for both compressor and engine - reflecting the transients immediately following start-up.

Figure 26 shows how the ratio of indicated compressor power to indicated engine power varies over 47 test data sets. Discounting the first four part load conditions, the ratio runs from 104.1 to about 106.5 through test series 5 through 43 . Test series 44 through 47 reflect some substantial changes in engine conditions (timing and air manifold pressure), and indicate a higher ratio of compressor to engine power (108 to 109 percent). Thus, the main body of data indicates an increase in the ratio of compressor to engine power consistent with the reduction in engine power discussed with reference to Figure 25 . The 
artifact of higher compressor power than engine power has been discussed and explained previously.

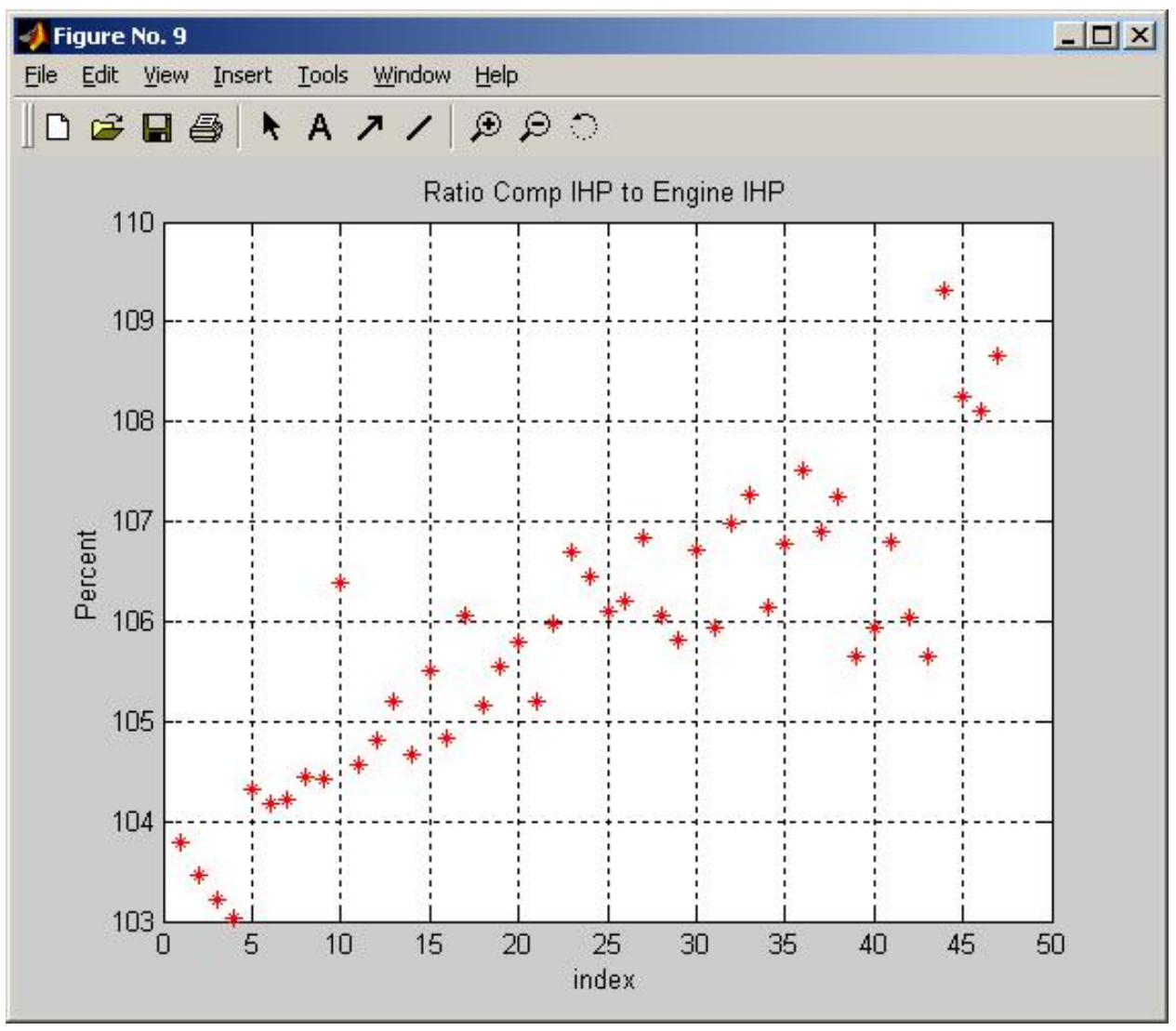

Figure 26. Ratio of Indicated HP During Test Day

Figure 27 shows how compression pressure (defined for these data sets as the pressure 20 degrees before top dead center) varies over the test data series. The spread in compression pressure reflects a potential difference in trapped air mass in the different cylinders, and over the test series, the profile of compression pressure across the ten cylinders has a clear and repeatable pattern. With minor qualification, when one cylinder's compression pressure goes up or down, the compression pressure for all cylinders goes up or down by a similar amount. A reasonable interpretation is that trapped air in each cylinder remains linked to the other cylinders through the air and exhaust manifold flow dynamics, even when global behavior of the engine cylinders changes. This suggests the importance of these manifold flow dynamics in determining engine behavior as influenced by air balance across the cylinders. 


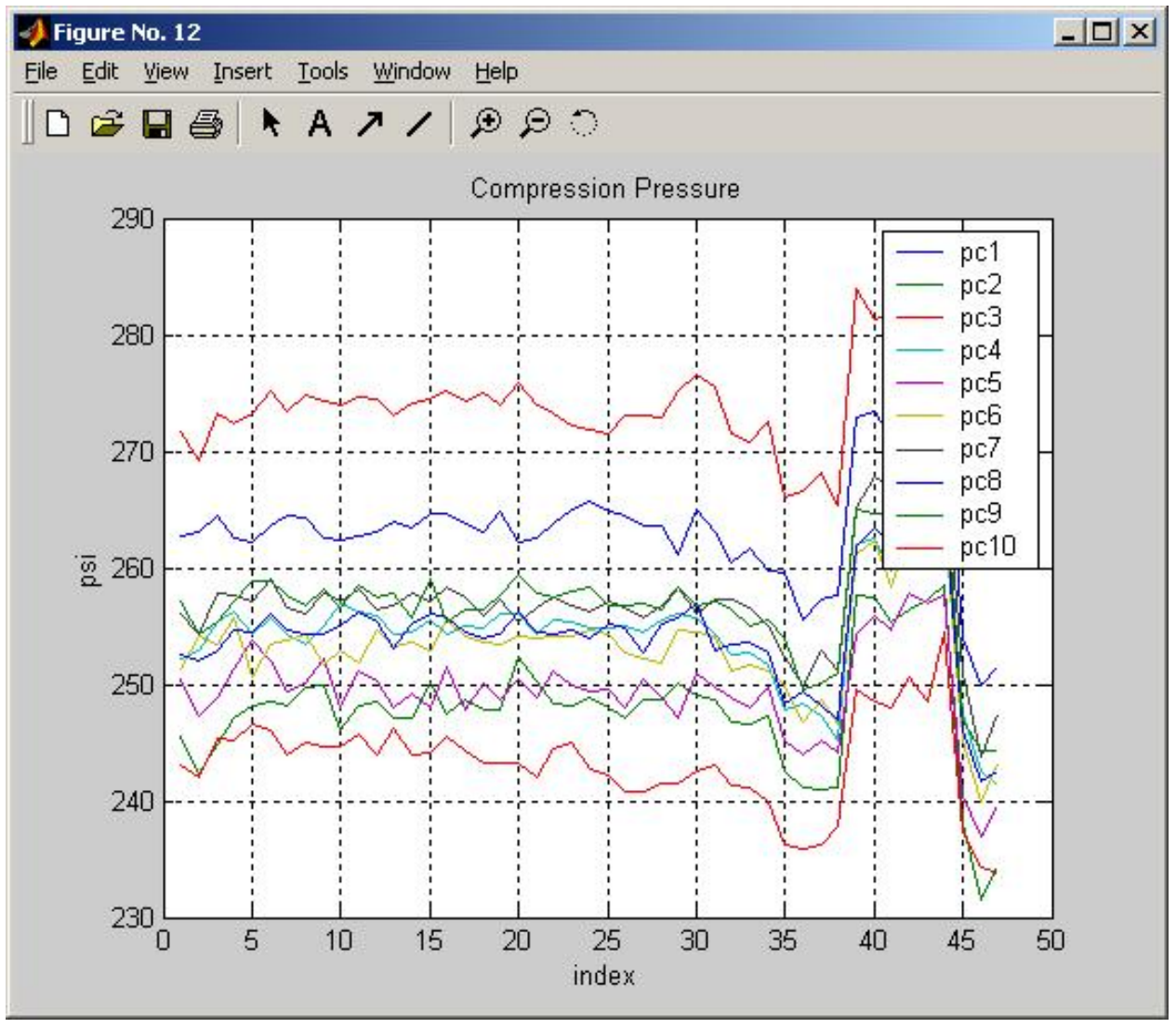

Figure 27. Power Cylinder Compression Pressure

Figure 28 shows how compressor thermal efficiency varies during the test series. Even including the first four part load data sets, the efficiency covers a rather small range from 85 to 86.8 percent. With these first four points removed, the thermal efficiency for the complete compressor has a range of one point from 85 to 86 percent. This is a very consistent data set, reflecting in part the consistency of conditions under which the compressor was operating. Consistency can also be seen between efficiencies calculated using differential indicated power based on the toes of the PV card, and the thermal efficiencies based on header conditions. In general, the header-based thermal efficiency is slightly lower than the cylinder pressure based efficiency, but only by typically 0.2 percentage points. 


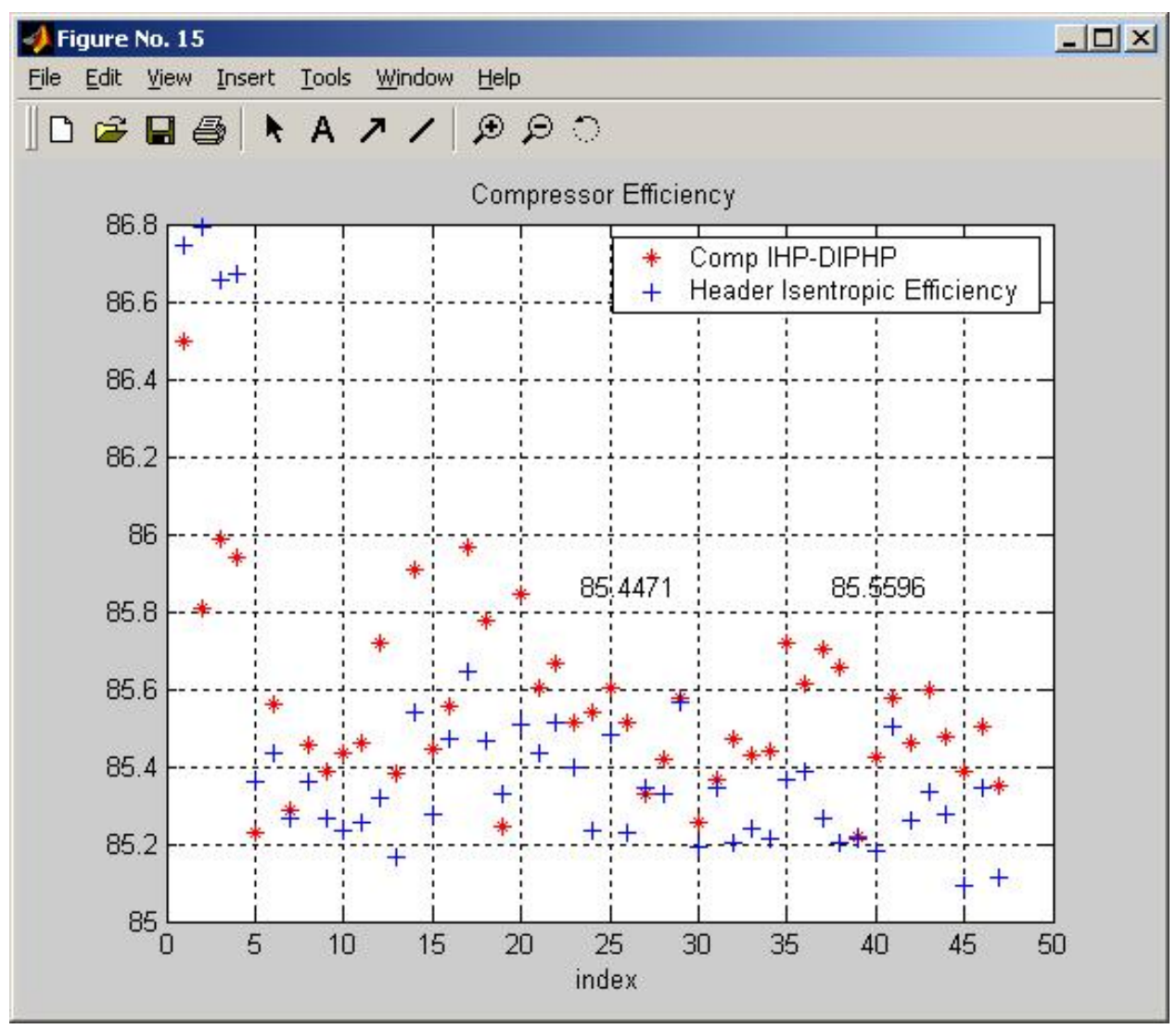

Figure 28. Compressor Efficiency

Figure 29 shows the waveform from the strain data capture module (SDCM) over eight engine revolutions. There is some variation from one revolution to the next, which could well correspond to the variation from cycle-to-cycle in combustion, as reflected in peakfiring pressure variations from cycle-to-cycle. 


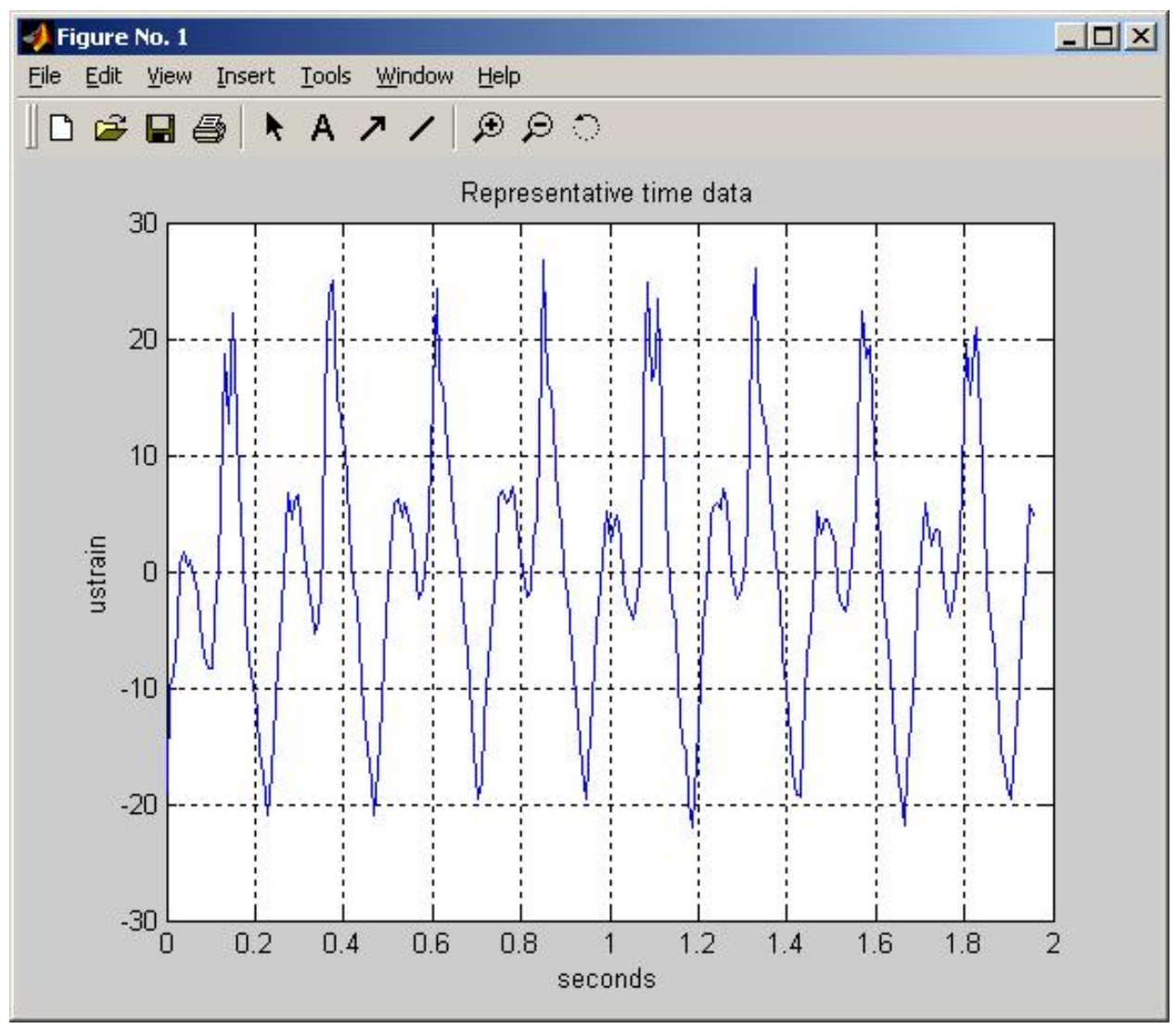

Figure 29. Typical Waveform (PC34)

Figure 30 shows the variation of strain data capture module output (expressed as peak-topeak microstrain) throughout the approximately 7-hour test series. The start of the unit can be identified by sharp continuous increase from below 10 microstrain to above 50 microstrain at about 50 minutes, and the stop is identifiable by a drop with similar range at about 415 minutes. The SDCM is installed and starts recording data every five minutes. Then, the covers are installed and preparations are made to start the unit, which occurred in this case after about 50 minutes. The short-term variation after start-up shows a gradual increase from about 50 to 57 microstrain - probably reflecting the final speed increase and loading of the unit after start-up, which covered about 30 minutes. The level of microstrain generally decreased from 57 microstrain to about 50 over the next 250 minutes (4 hours) - matching the trend in steadily reducing engine load over this similar period, as reflected in Figure 25. In the last two hours of testing, some timing and air manifold pressure changes were included in the testing, which may have resulted 
in the short-term increase in peak-to-peak microstrain seen at about 345 minutes in Figure 30.

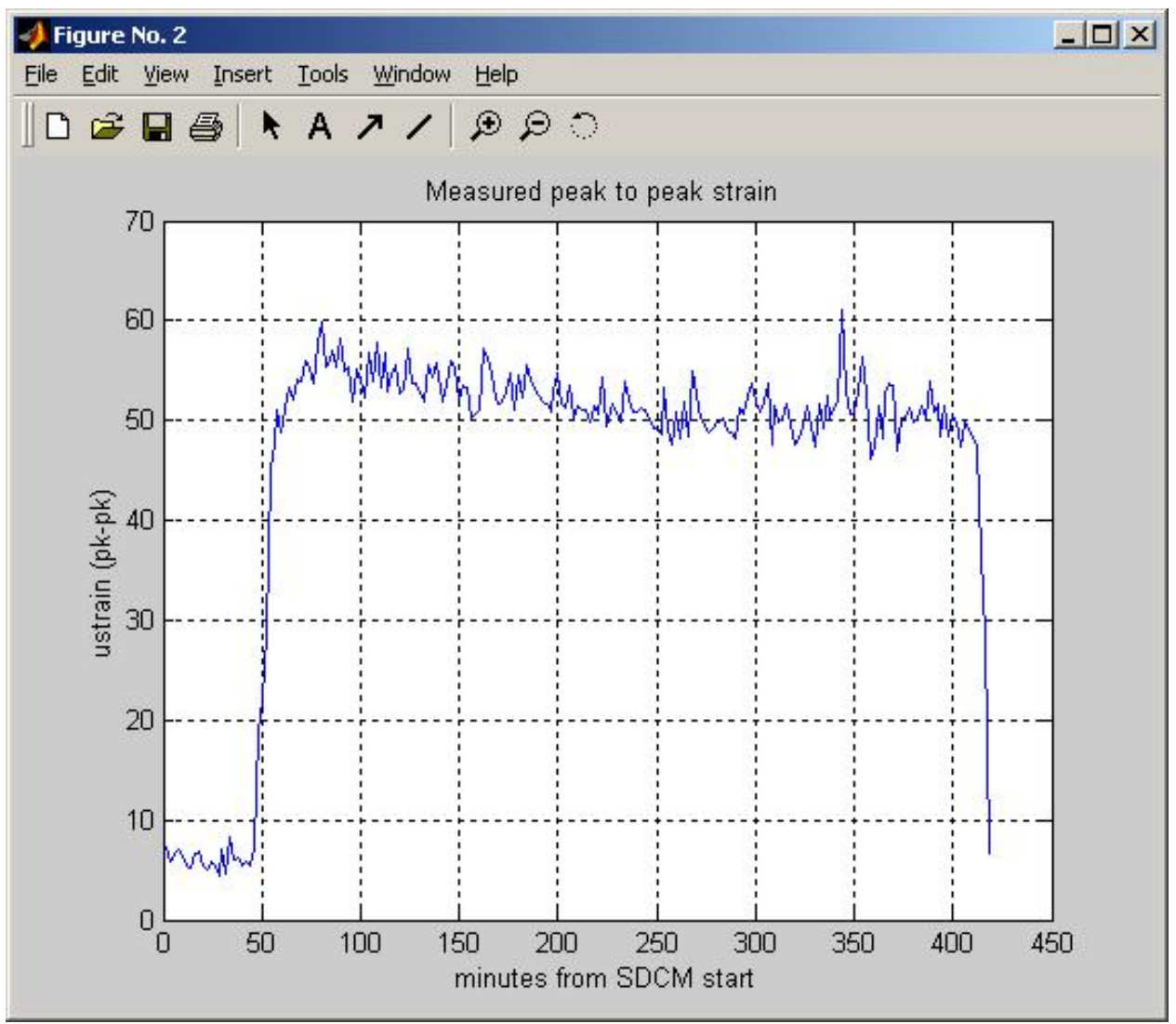

Figure 30. Peak-to-Peak Variation in Crankshaft Web Bending Stream (PC34)

The cycle-to-cycle variation is illustrated in 20 cycles of continuous pressure recording from power cylinder \#1, presented in Figure 31. Clearly, this sort of variation in power cylinder load could be the cause of the variation in SDCM data, shown in Figure 29. 


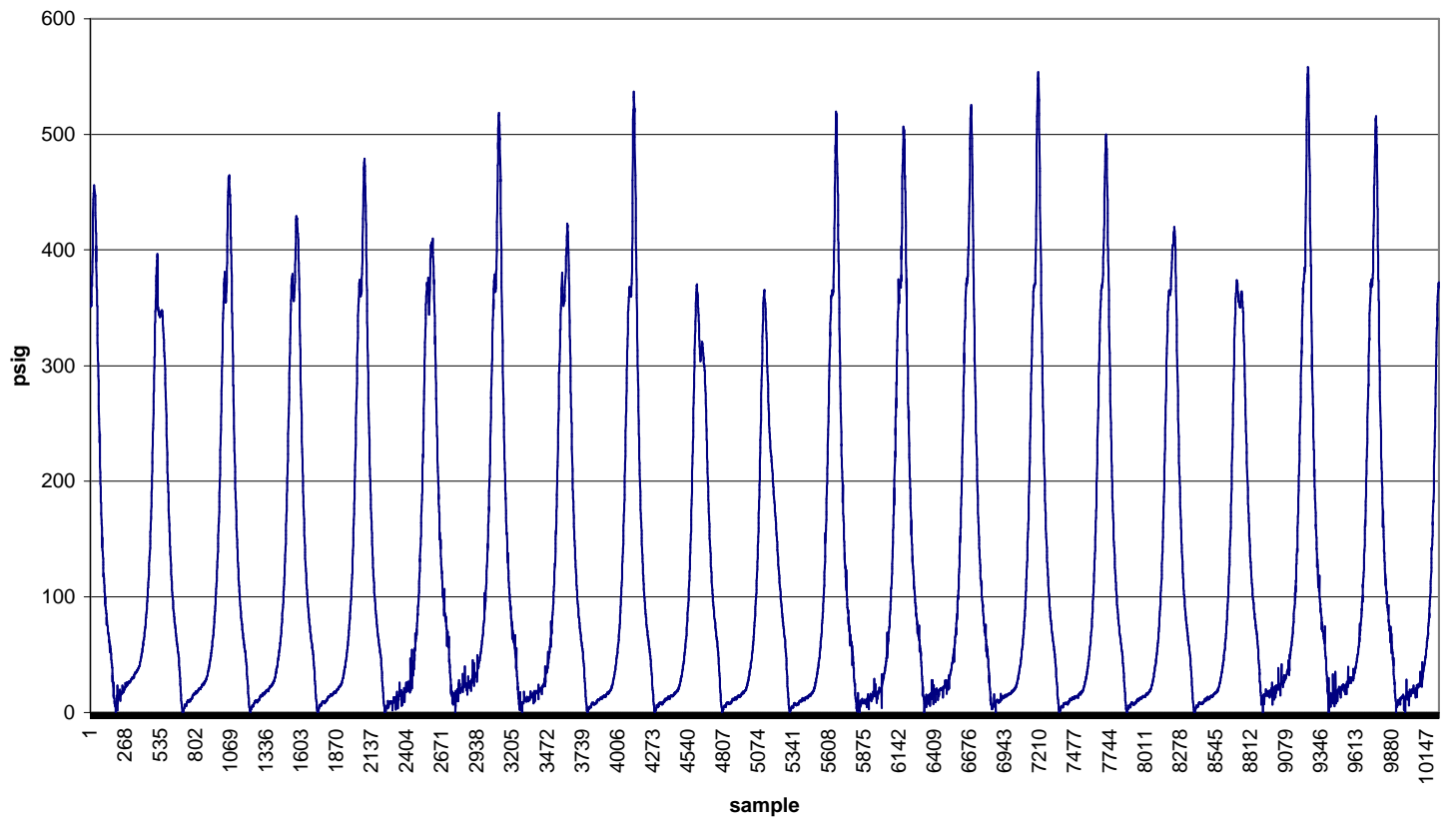

Figure 31. Typical 20 Successive Cycles - Power Cylinder 1

Figure 32 shows the variation of fuel flow over about seven hours of testing. The fuel flow reduces in a manner qualitatively consistent with the reduction in engine horsepower over time during the tests. The magnitude of the reduction is from about 427 MMSCFD to 420 MMSCFD. This is slightly less than 2 percent. A potential reason for this reduction in fuel flow being lower than the 2 to 2.5 percent reduction in engine power is that engine brake thermal efficiency typically decreases with decreasing load on the engine. The sharp dip in fuel flow from 420 to 404 MMSCFD at about 1:00 PM corresponds to an advance in timing from 8.5 to 11 degrees at that time, and the spike up to 441 MMSCFD corresponds to a timing value of 6 degrees. 


\section{Fuel Flow}

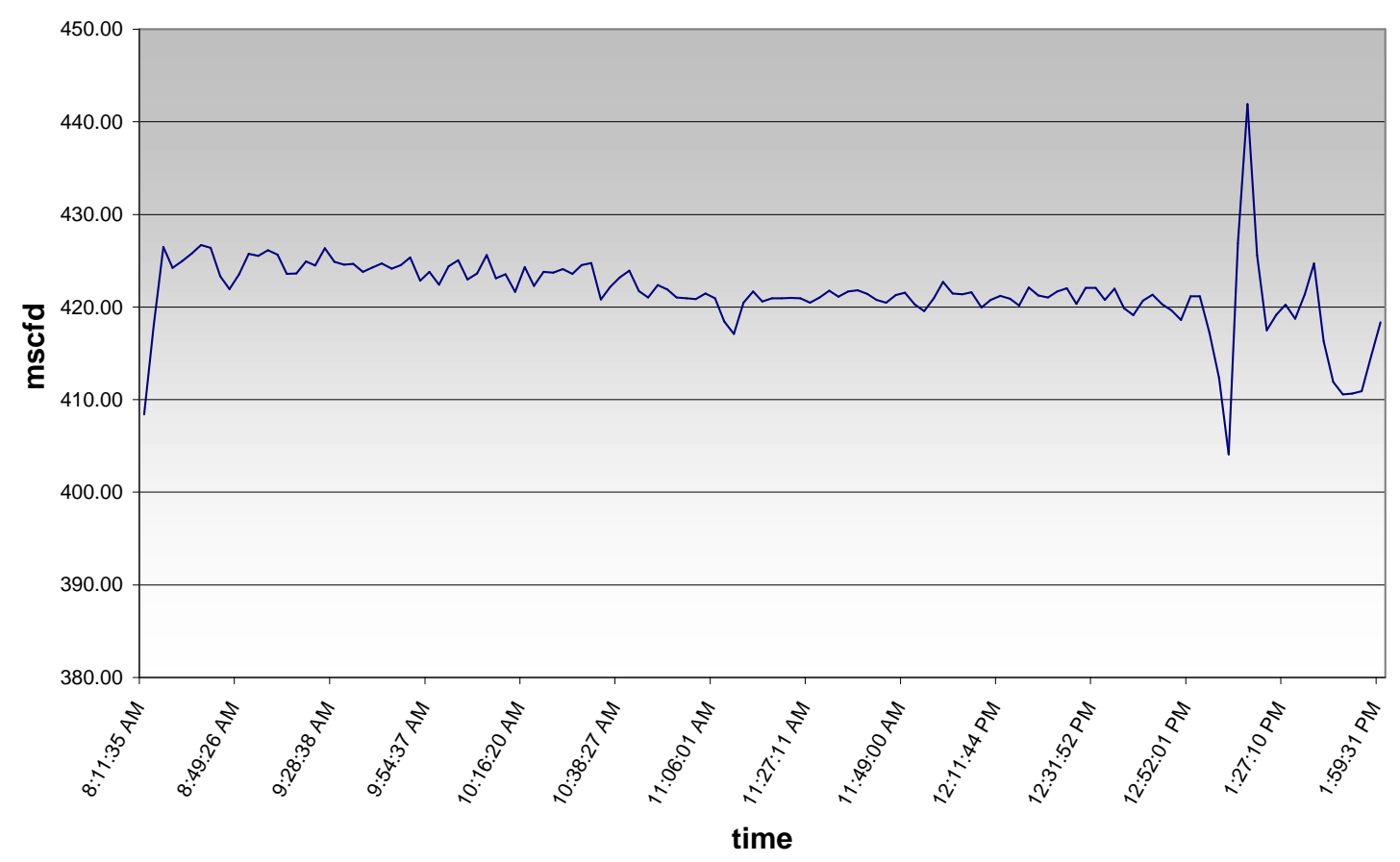

Figure 32. Engine Fuel Flow

Figure 33 shows how NOx and equivalence ratio vary with time throughout the testing. There is no significant change for several hours once the unit has started up. The spike before start-up, of course, has no relevance. After that, for most of the test, the NOx remained close to constant until about 1:00 PM when some timing change and air manifold pressure changes were made. These changes had a noticeable influence on NOx, and the NOx changes tracked the equivalence ratio changes. 


\section{NOx and EQ ratio}

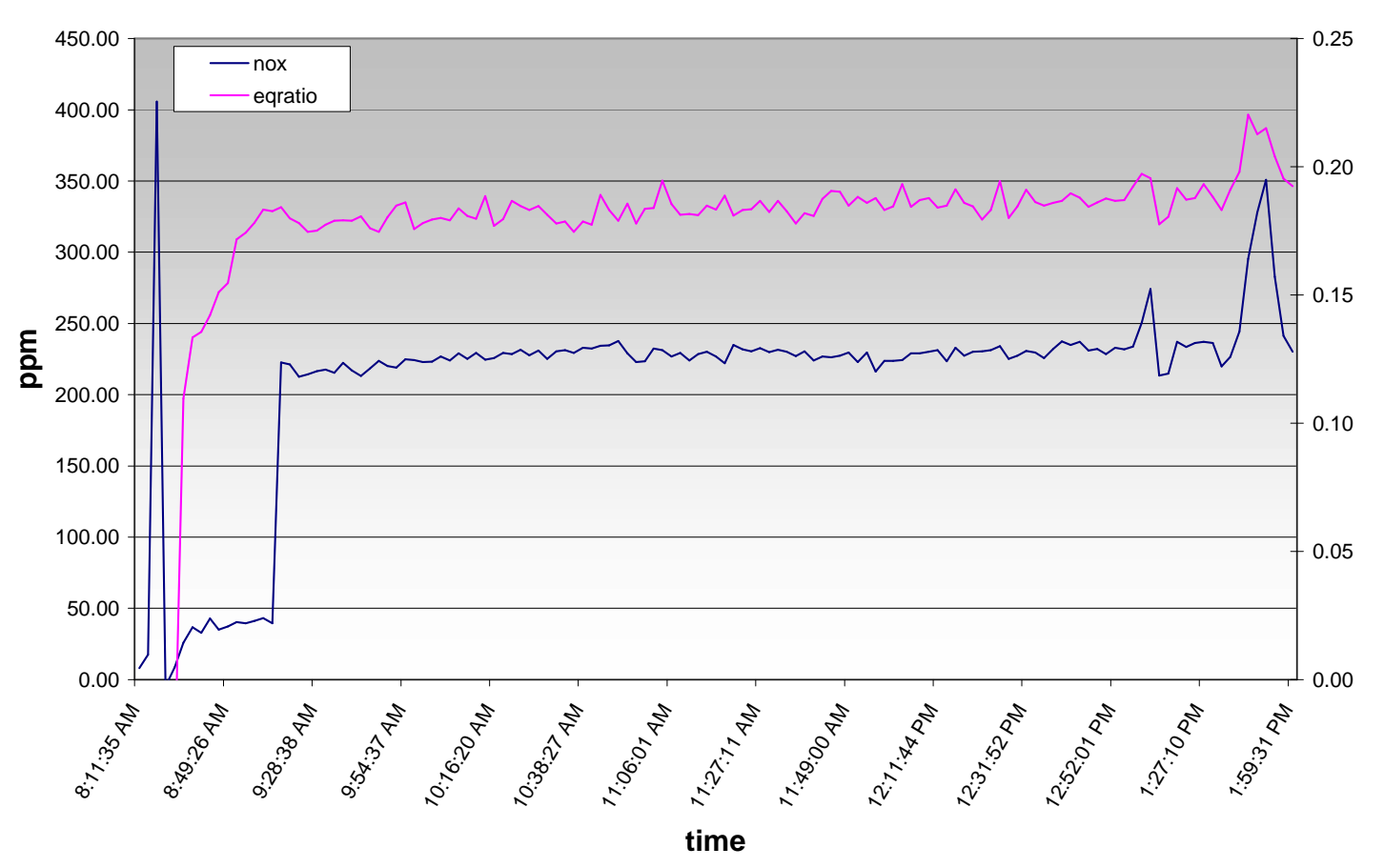

Figure 33. NOx and EQ Ratio

Figure 34 shows the variation in instantaneous spread in PFP across the ten cylinders and the spread in average PFP across the cylinders over a days testing. The instantaneous spread does not change much, except late in the day when timing and air manifold pressure changes were investigated. The spread in average PFP is typically around 30 PSI. It changes upwards as a result of two changes. First, the engine was intentionally unbalanced around 10:00 AM, and returned to its previous balanced condition around 11:00 AM. Then, around 11:30 AM, the unit was balanced using CPR balancing (which seeks to equalize the ratio of PFP to compression pressure - termed the combustion pressure ratio, or CPR). The result of CPR balancing is to raise the spread in peak-firing pressure, because there is imbalance in compression pressure. However, the anticipated benefit of CPR balancing is to approach more closely a condition of equal air fuel ratio across the cylinders. 


\section{Engine Spread}

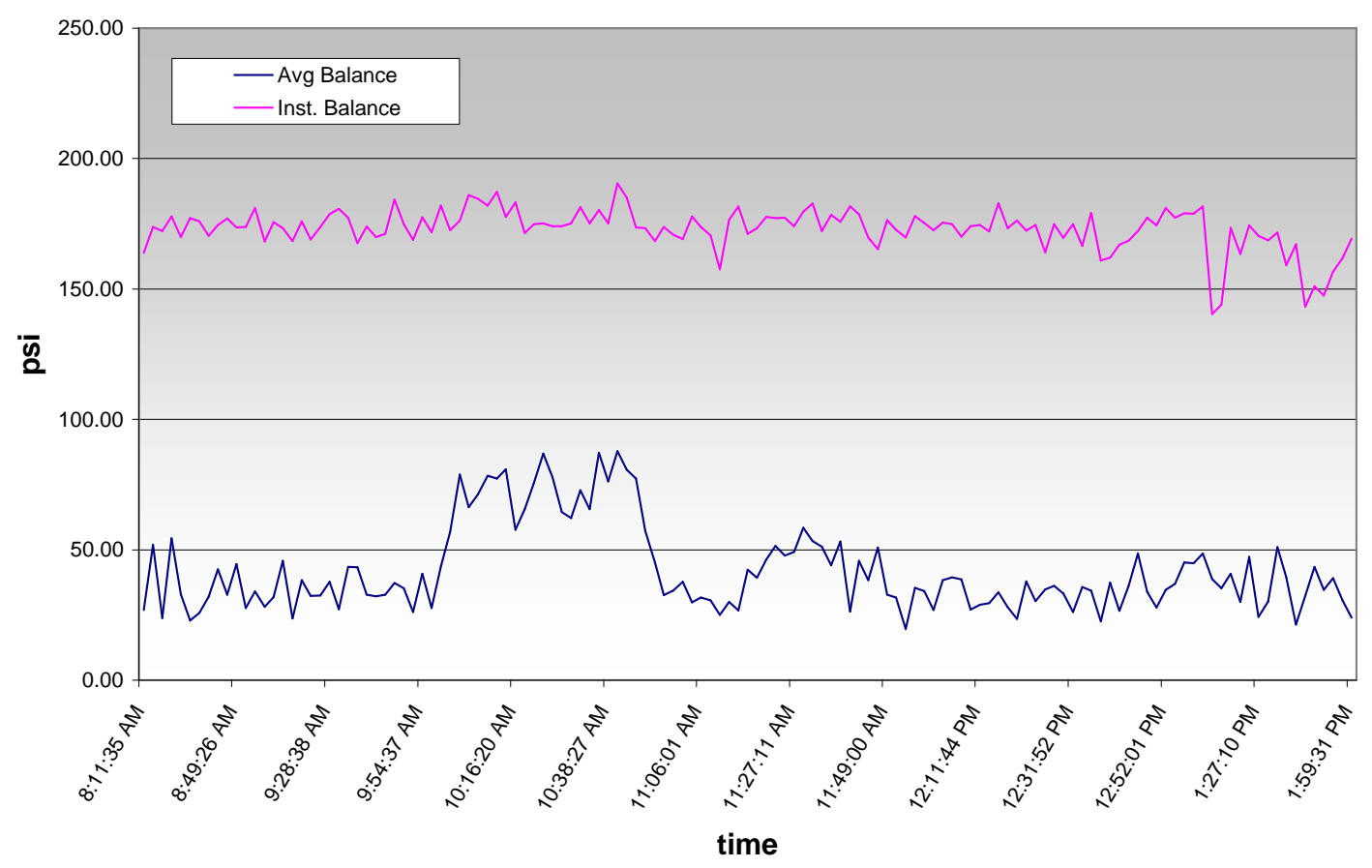

Figure 34. Engine PFP Spread

Figure 35 presents the evidence of accomplishment of CPR balancing. It shows how for all ten cylinders, the ratio of peak-firing pressure to compression pressure is effectively equal. The actual maximum tolerance on these CPR values is $+/-2.5$ percent, when they display as equal, as a result of the precision to which they are graphed.

Figure 36 shows how average combustion pressure ratio (CPR) varies over the test series, and also how the standard deviation in CPR divided by average CPR falls under the condition when the engine is CPR balanced. There appears to be a small but consistent increase in CPR over the test from about 1.81 at 8:30 AM to about 1.84 at 12:50 PM. The Sdev (CPR)/avg. CPR exhibits noticeable modulation sample-to-sample about 4 percent average for most of the test. This is the COV of CPR across the cylinders. During CPR balancing, this quantity drops to about 2 percent, as would be expected, since bringing all CPR values close to the average CPR is the accomplished objective of CPR balancing! 


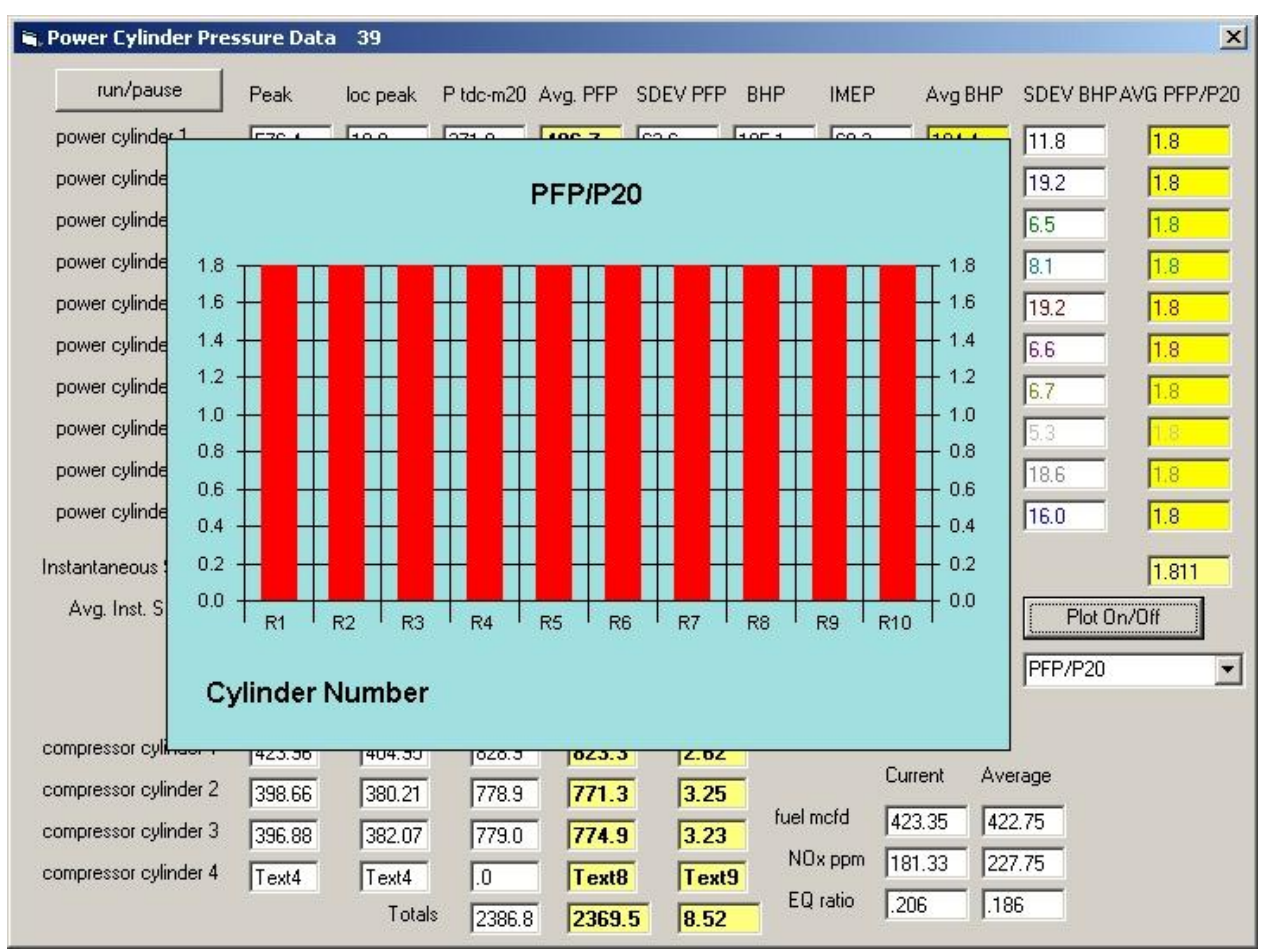

Figure 35. CPR Balancing Feasibility Demonstration

\section{CPR verus Time}

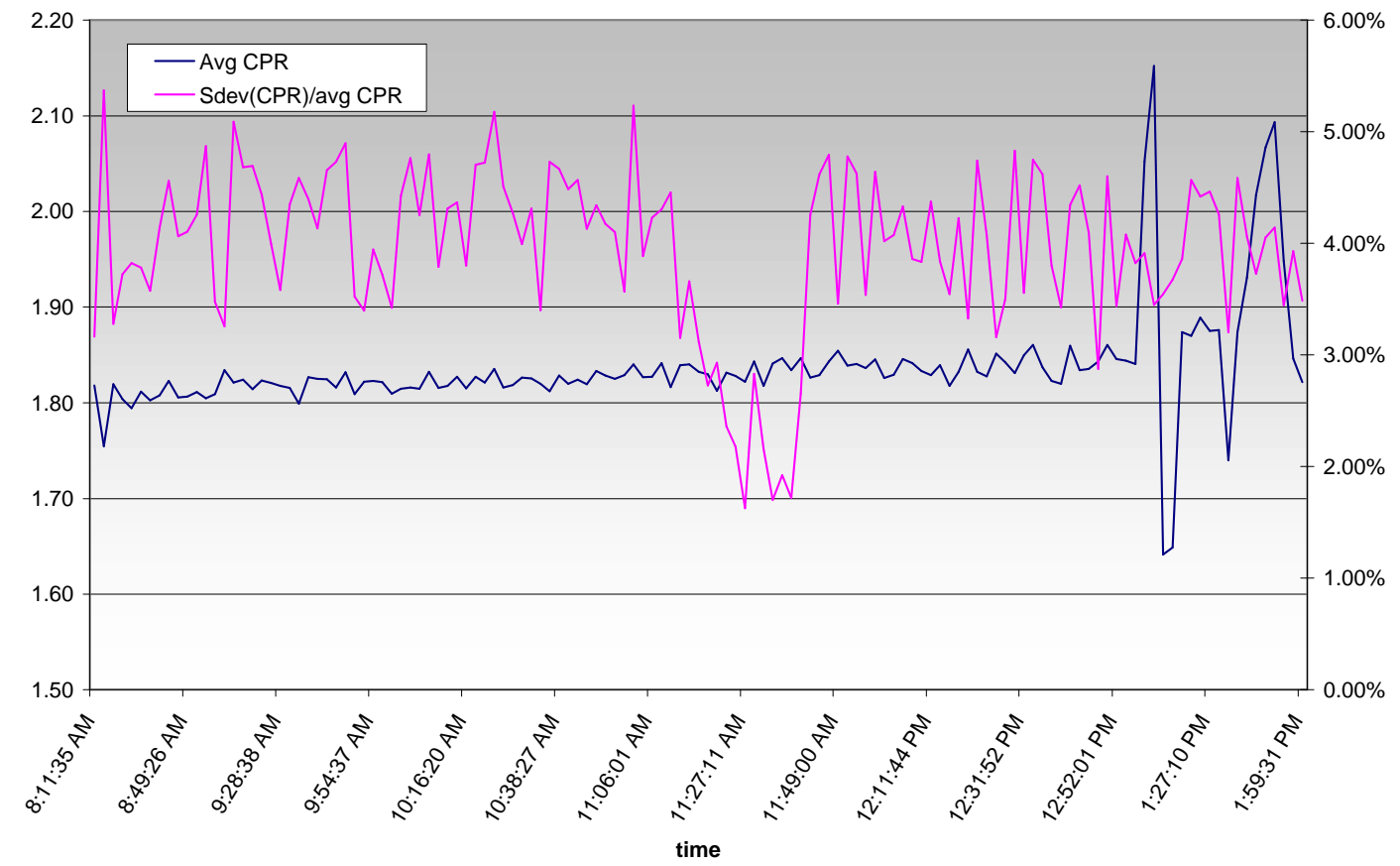

Figure 36. Ratio of PFP to Compression Pressure - Average and COV 
Figure 37 shows how the heat rate of the engine (BTU/BHP-hr.) varies, where BHP-hr. represents the indicated cylinder energy. It also shows how the overall system efficiency (conversion of LHV fuel energy to useful compression energy) varies over the test. The heat rate is low for this recently converted engine, lying in the range 7200 to 7300 BTU/BHP-hr. for most of the test. The overall system efficiency is about 29.7 percent, once the mechanical efficiency has reached its asymptotic condition. With the timing advance towards the end of the test, the heat rate drops to $6950 \mathrm{BTU} / \mathrm{HP}-\mathrm{hr}$., and the overall system efficiency increases to almost 31 percent, a high number for an integral engine compressor. This and other data will be reviewed to define appropriate industry benchmarks for overall system efficiency.

Overall Performance

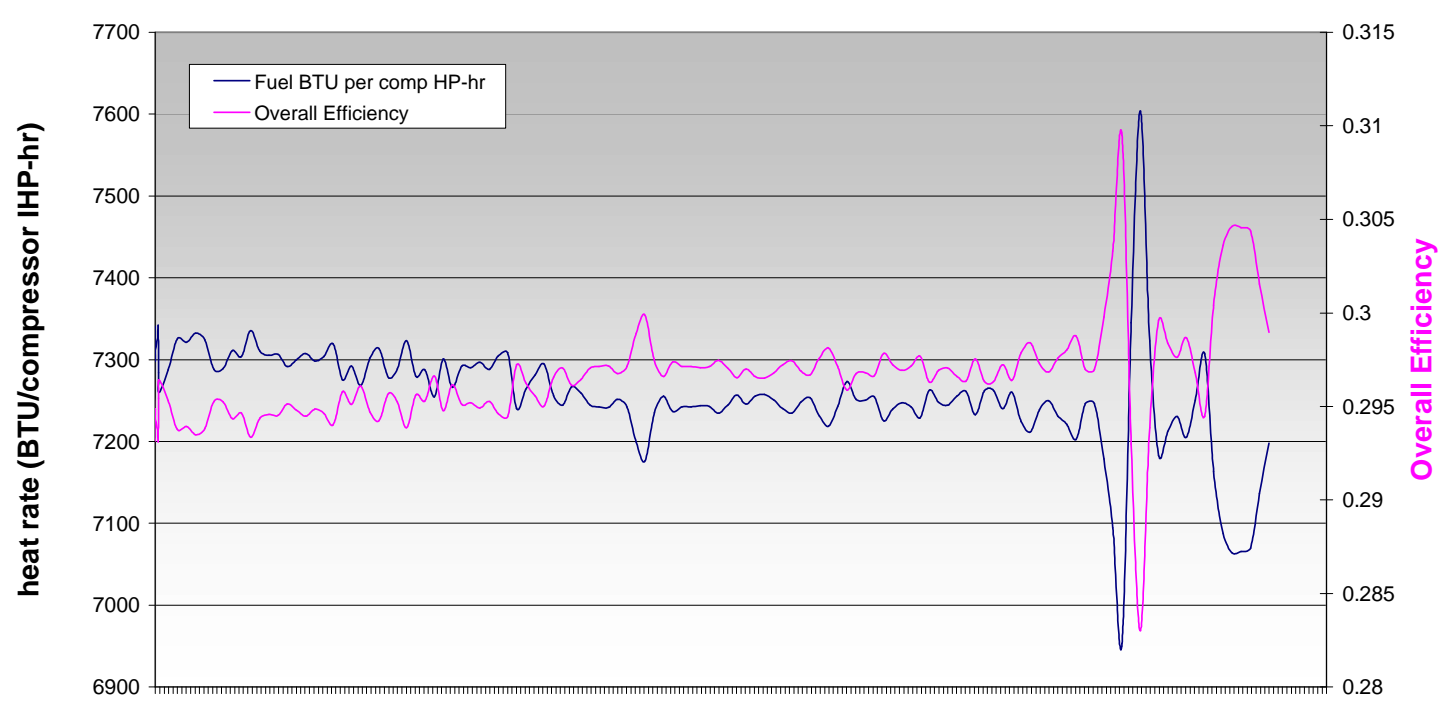

time

Figure 37. System Performance 


\section{DATA ANALYSIS}

The following addresses analysis of the data obtained from the first visit to the first test site (El Paso Kinder Station 823).

\section{Engine SimuLATion Model}

To assist understanding of engine characteristics observed during the HBA-6T tests, a single cylinder combustion model (virtual engine) was applied and adjusted to fit observed burn rate characteristics of the average cylinder. The cycle simulation model utilized is based on prior models developed specifically for two-stroke spark-ignited integral engines [4].

This model was then applied to assess the sensitivity of fuel consumption and emissions to changes in trapped air in the cylinder. These changes in trapped air were achieved by changing air manifold pressure in the model. A constant pressure ratio (intake/exhaust) was assumed. While no exhaust pressure measurements were taken, previous data on another straight six indicated a closely constant average pressure ratio at a constant engine speed. Empirical relationships for burn rate and combustion efficiency were based on the HBA-6T data.

The NOx model is based on a rate formation model and tuned to the HBA-6T data. The heat transfer model is based on the correlation by Woschni, and also tuned to the HBA6T data. With these tuned models, the first law of thermodynamics is used to determine cylinder temperature, then pressure.

The single cylinder data was used to predict performance of a six-cylinder engine in which the air manifold pressure driving air into the cylinders was assumed to have an evenly distributed range from high to low across the six cylinders. The fuel flow (or air fuel ratio) was adjusted to achieve constant peak-firing pressure in this engine. The performance and effects of balancing with this engine condition will be compared to the 
engine condition in which the air manifold pressure is constant across all cylinders, the air fuel ratio is also constant, and as result of this desirable condition peak-firing pressure is constant across the cylinders.

As a starting point, Figure 38 shows the pressure distribution in which a random imbalance in air fuel ratio of about 15 percent is superimposed on air imbalance caused by a manifold pressure spread of 10 percent across the engine. This air manifold spread is assumed uniformly distributed from low to high. The compressor pressure spread is 35 PSI and the peak pressure spread is 180 PSI.

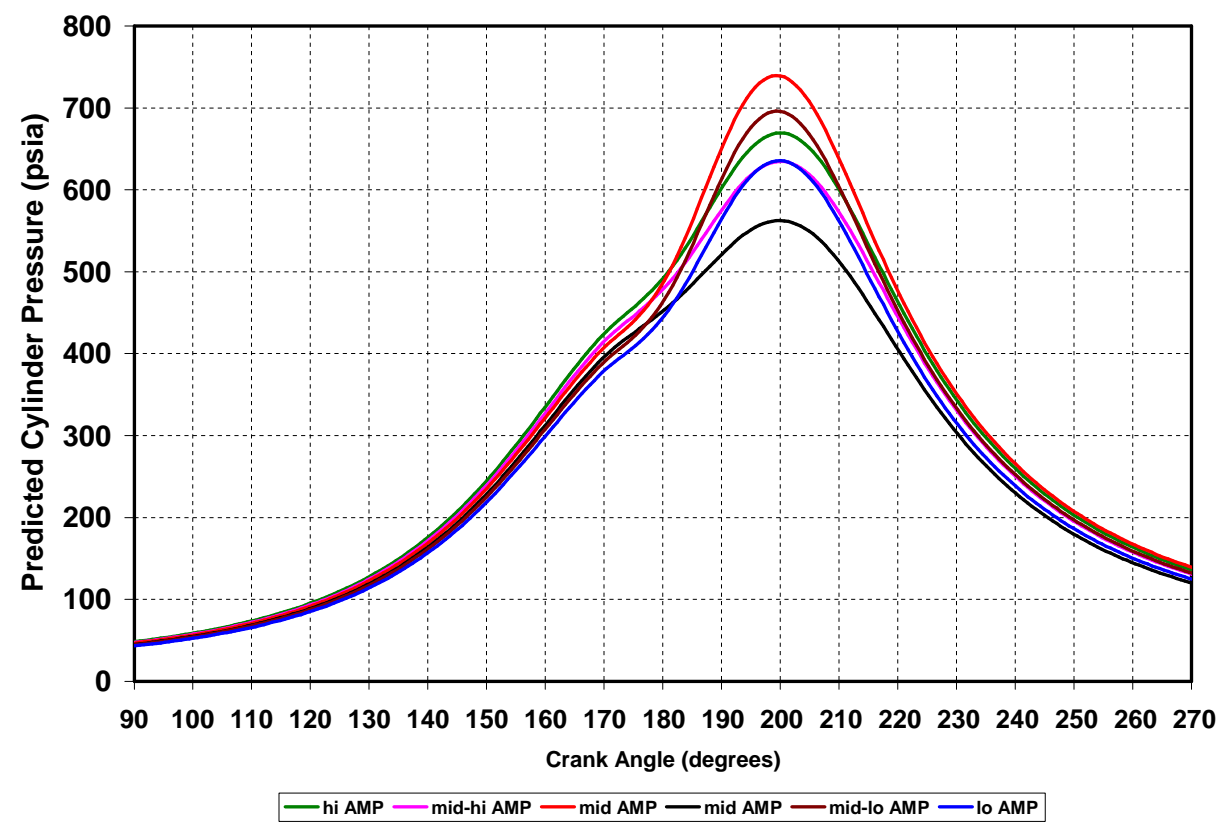

Figure 38. Unbalanced Engine Simulation - Spread in Compression Pressure Induced by Even Increment Spread in AMP - 15\% Random Spread in A/F Ratio

\section{Relating Combustion Balancing to Engine Performance with Air IMBALANCE}

Figure 39 then shows the predicted cylinder pressure variation for the engine balanced to achieve equal peak-firing pressure across all six cylinders. 


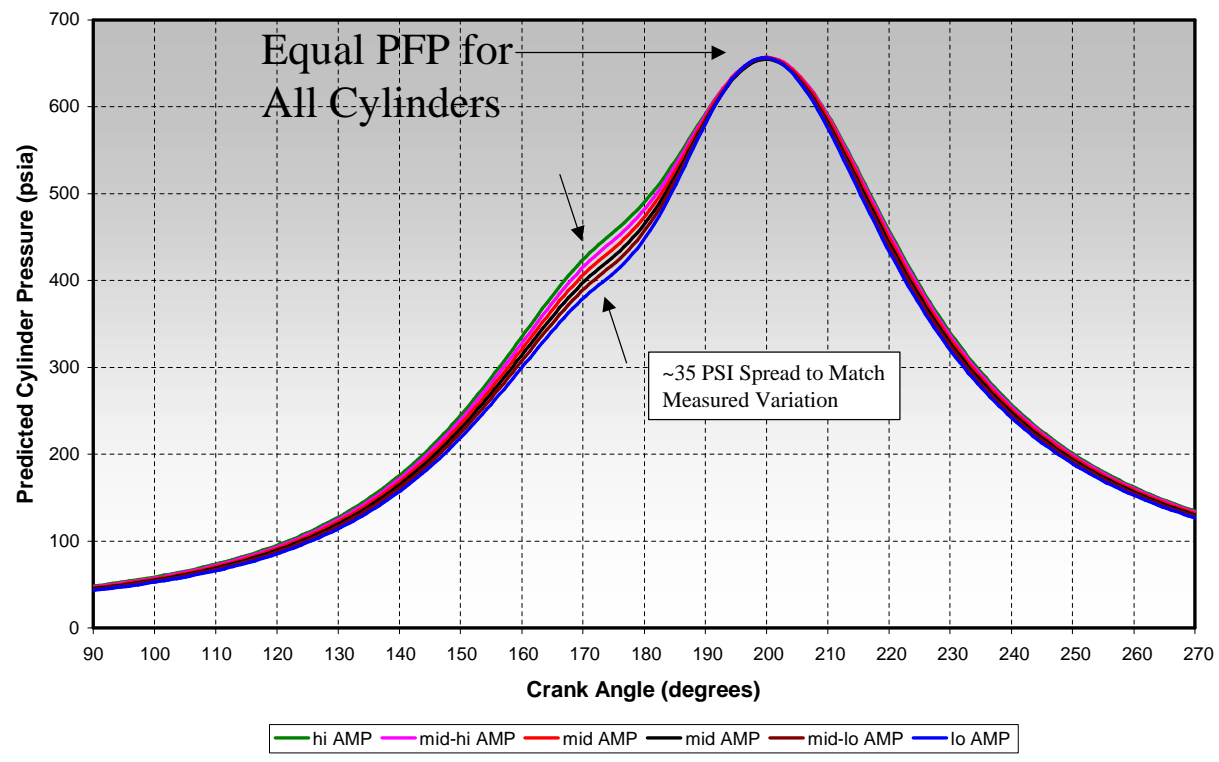

Figure 39. Predicted Cylinder Pressures - Simulation with Evenly Distributed Variation of Air Manifold Pressure

Figure 40 shows the distribution of trapped air fuel ratios required to achieve a constant peak-firing pressure. These range from 23.8 to 25.9. Anecdotal evidence exists that enforcing a wide range of air fuel ratio could lead to detonation on some engines with wide air imbalance. Fuel adjustment range available may also limit the ability to achieve this range of air fuel ratio. 


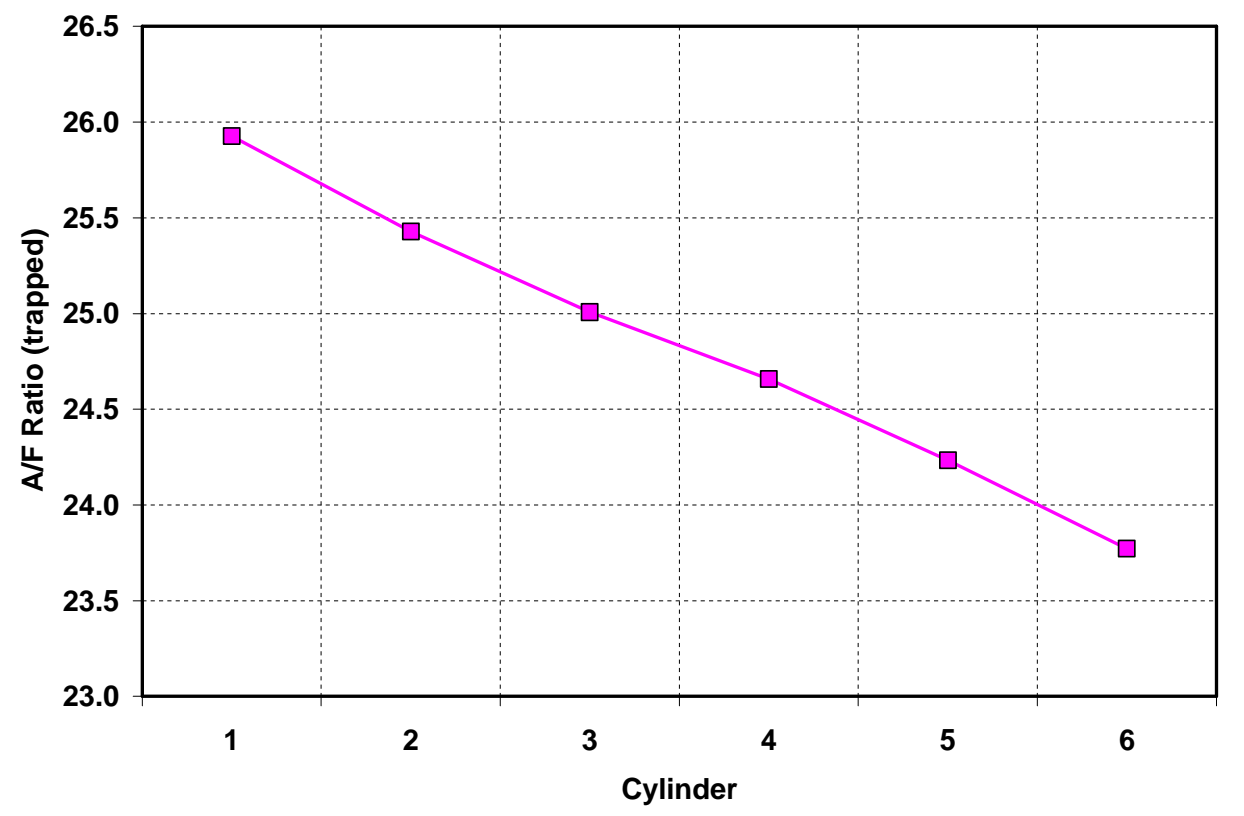

Figure 40. Variation of A/F Ratio Across Cylinders to Achieve Balanced Peak-Firing Pressure with Spread in Compression Pressure

Figure 41 compares predicted NOx and BTU/HP-hr. for three conditions:

1. With air manifold imbalance leading to 35 PSI compression spread and a random additional 15 percent spread in $\mathrm{A} / \mathrm{F}$ ratio.

2. With air manifold imbalance leading to 35 PSI compression spread and air fuel ratio adjusted to achieve equal values for peak-firing pressure in all cylinders.

3. With no air manifold imbalance and zero compression pressure spread balanced to achieve constant PFP across the cylinders. 


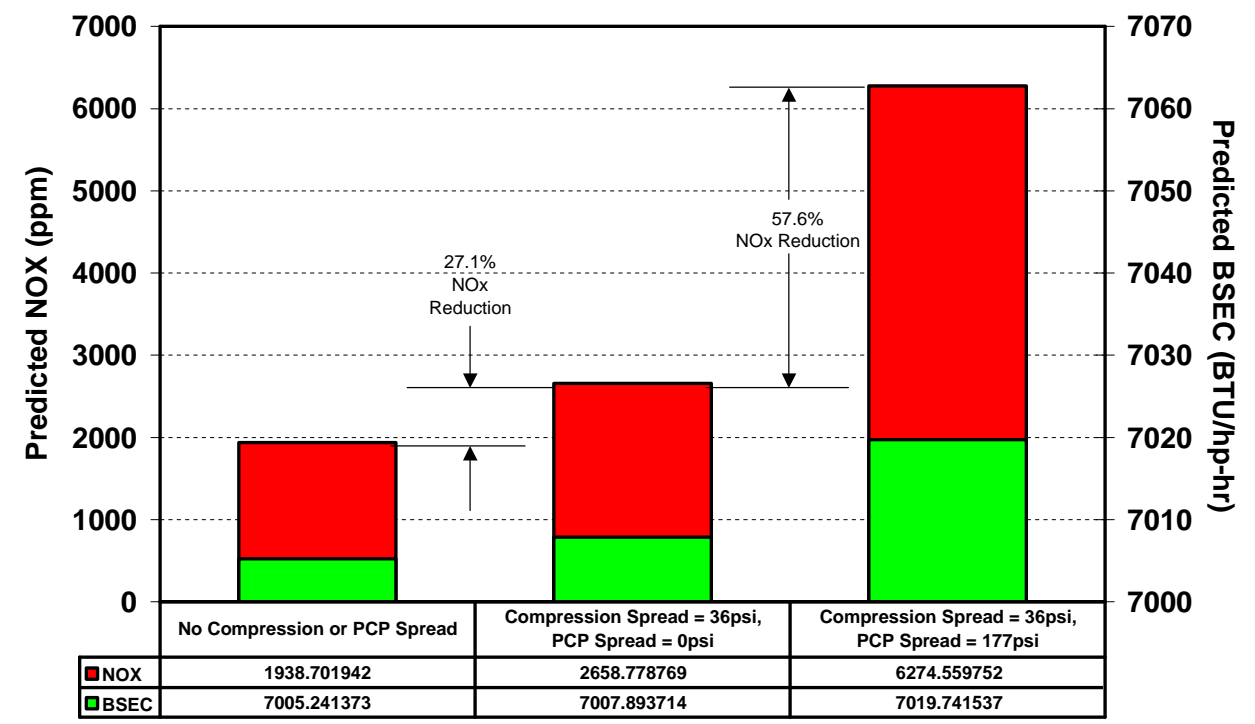

Figure 41. 6-Cylinder Engine Simulation Comparison - Balanced and Unbalanced Peak Cylinder Pressure

Figure 41 shows that balancing to achieve equal peak-firing pressure is very valuable and leads to 57.6 percent reduction in NOx, and a 12 BTU/HP-hr. reduction. Further balancing of the air and achieving equal air fuel ratio is predicted to achieve a further 27.1 percent NOx reduction, and a further $3 \mathrm{BTU} / \mathrm{HP}-\mathrm{hr}$. reduction. It is suspected that benefits in reduced fuel consumption are understated, because the model does not include cycle-to-cycle variation. Cylinders leaner than the average may have larger cycle-tocycle variation and more frequent misfires. Bringing lean cylinders up by balancing the air should reduce misfires.

Therefore, traditional balancing of PFP will likely help achieve emissions compliance, and this simulation shows that further gains are possible by equalizing the cylinder-tocylinder air flow or trapped mass. The contributions of improved mixing and other incylinder technology enhancements are also critical factors in reducing emissions and fuel consumption. Their benefit will, however, be maximized for cylinders with optimized air balance. 


\section{Equivalence Ratio BaLANCing}

Figure 42 shows the pressure distributions which result from imposing constant trapped air fuel ratio in each cylinder for the engine with 10 percent air manifold spread, and a resultant 35 PSI compression pressure spread. The predicted NOx and fuel consumption, which this condition achieves, is the same as that for PFP balancing with the air manifold spread eliminated. The qualification with this is that there may be insufficient fuel adjustment range on cylinders with excessively high trapped air mass to achieve equal equivalence ratio. Also, the load distribution along the crankshaft under equal equivalence ratio may not be optimum for crankshaft integrity.

Figure 43 shows the distribution of peak pressure normalized with respect to pressure 20 degrees before top dead center (combustion pressure ratio (CPR)) for three conditions of an engine with 10 percent air manifold spread:

- Air Fuel Ratio (Equivalence Ratio) Balanced

- Unbalanced

- Peak-Firing Pressure Balance

The unbalanced condition causes an arbitrary spread in the CPR. Peak-firing pressure (PFP) balancing causes the CPR to vary in proportion to the air imbalance. Air fuel ratio balancing causes the CPR to be exactly equal for every cylinder. Thus, CPR balancing according to this model is a direct surrogate for air fuel ratio balancing. CPR balancing is the subject of an invention disclosure by SwRI, for which a patent is pending. 


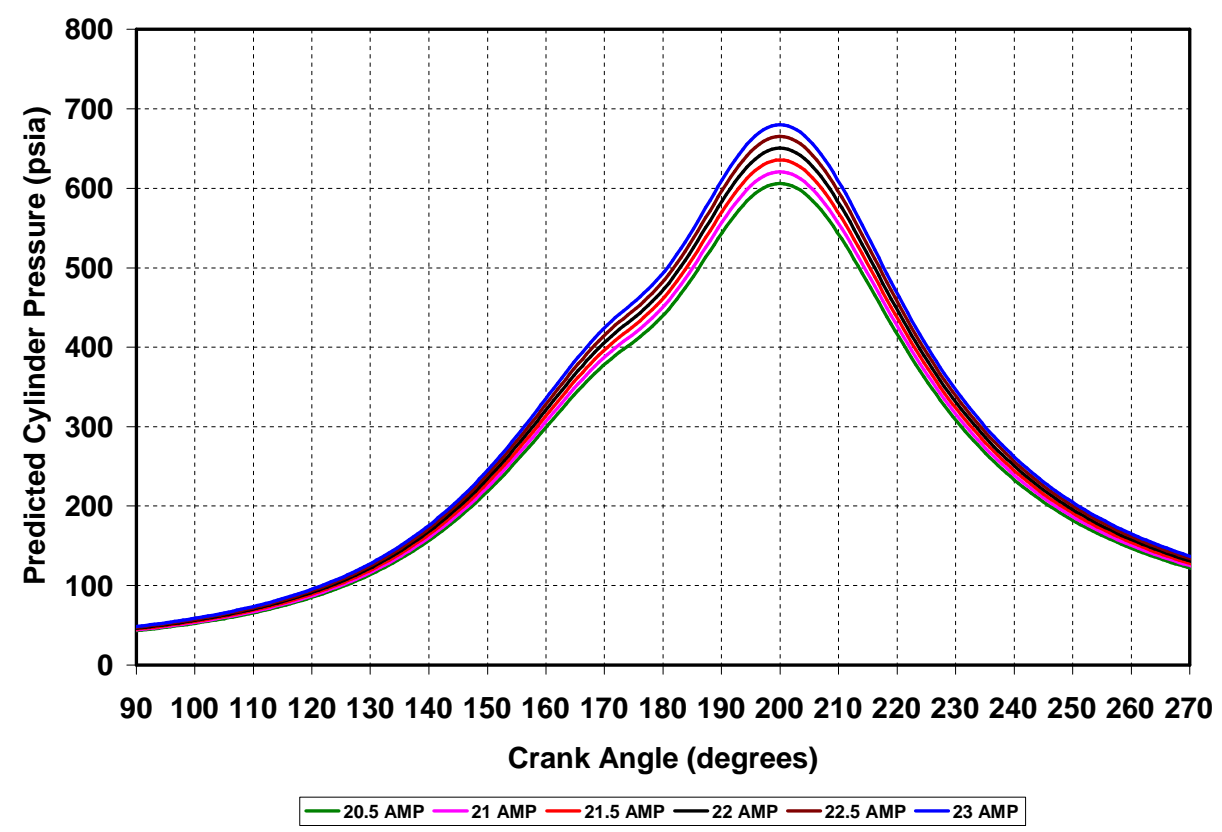

Figure 42. Engine Simulation - Pressures for Constant Equivalence Ratio with Spread in Compression Pressure

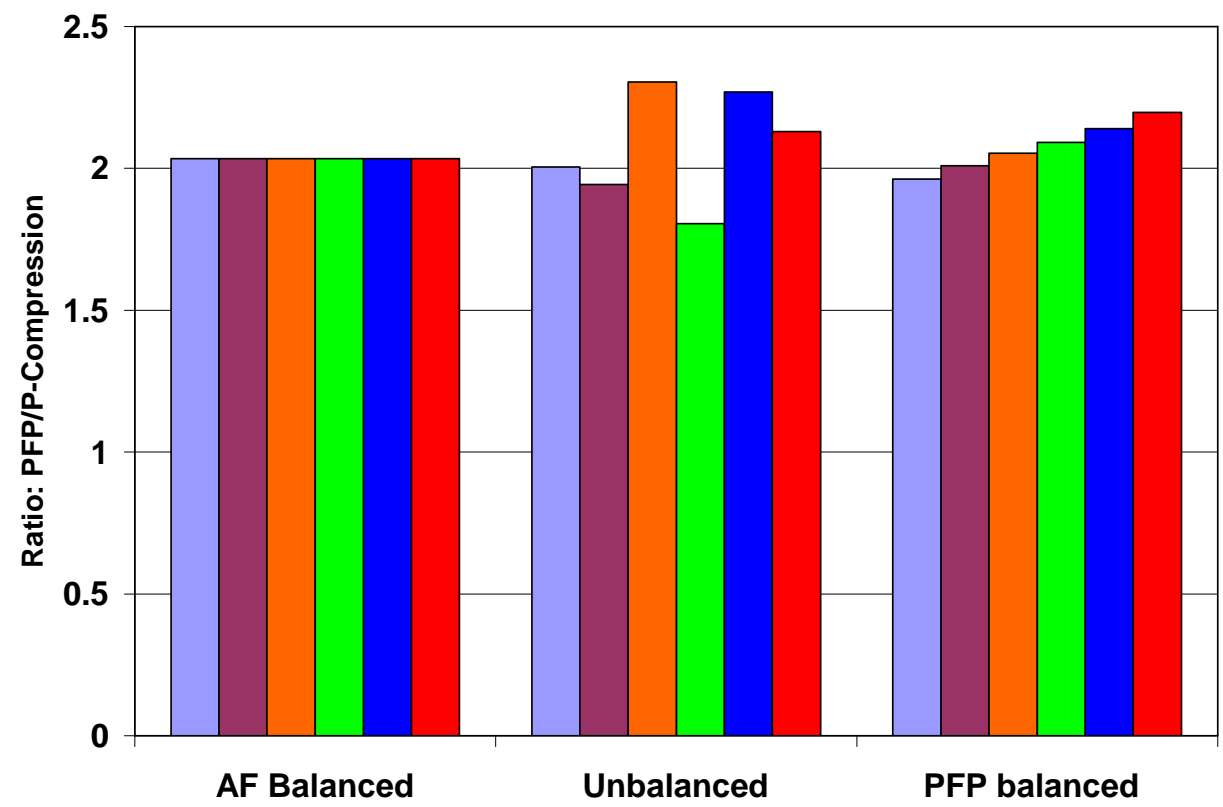

Figure 43. Ratio of PFP to Compression Pressure from HBA-6T Simulations (Basis for Invention Disclosure) 


\section{Relating System Mechanical Efficiency to Oil Temperature and Time}

The term "system mechanical efficiency" is used in recognition that the mechanical efficiency, used as common practice by the industry to relate BHP delivered to the crosshead to power at the compressor piston face, may in concept include fewer losses than in the mechanical efficiency between power piston face and compressor piston face. Figure 44 shows for the HBA-6T engine tested how compressor piston power, engine piston power, and their ratio (inferred system mechanical efficiency) varies over six hours of testing. The ratio of compressor piston power to engine piston power increases (with a few momentary reversals of this trend) from the start of the test series.

Engine \& Compressor HP \& Inferred Mechanical Efficiency

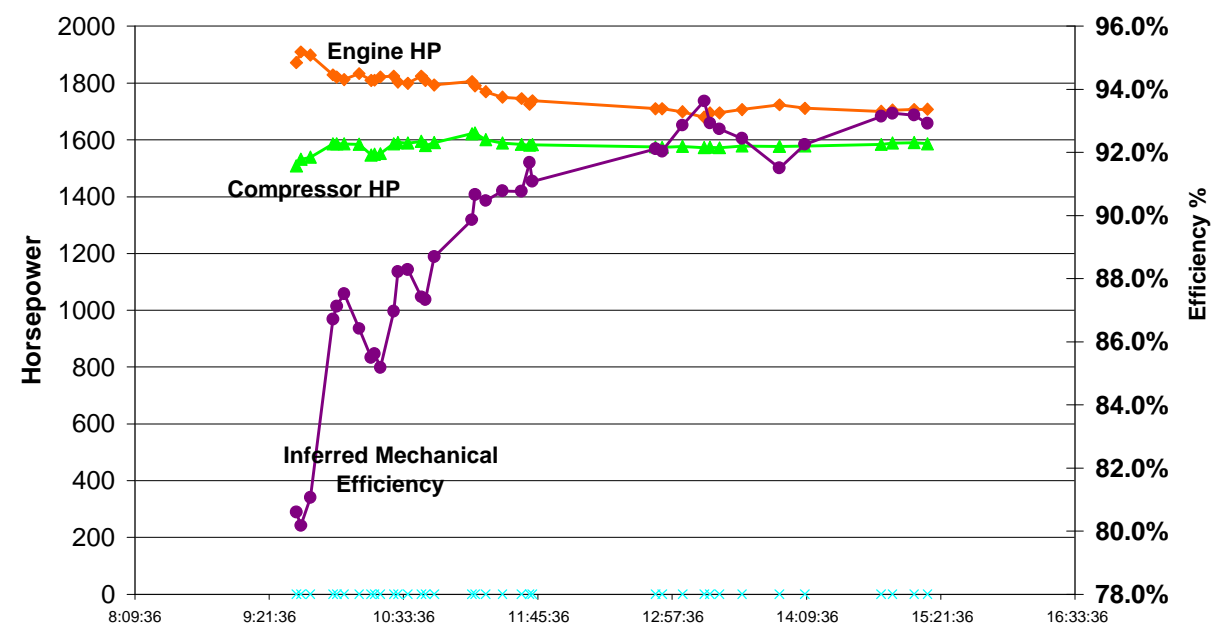

Figure 44. Engine HP, Compressor HP, and Inferred Mechanical Efficiency

Figure 45 provides some supportive evidence that the engine heat rate (BTU/HP-hr.) dropped over the same period. The change is 4 to 5 percent. This is not as large as the apparent increase in system mechanical efficiency, but an effect that would partially explain this is the influence of engine load or brake thermal efficiency. This efficiency tends to reduce as engine load reduces, so reducing the impact on fuel flow in comparison to a proportional relationship. 


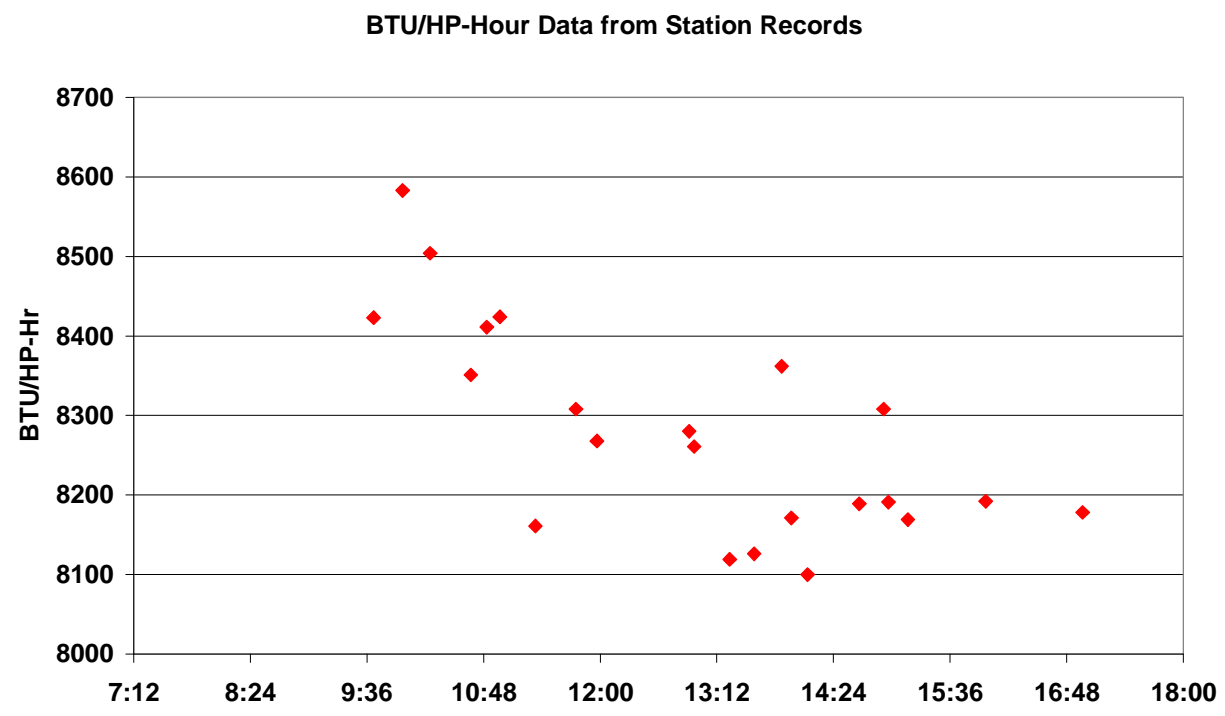

Figure 45. BTU/HP-Hr. Data from Station Records

The most obvious parameter which might be changing after start-up, and which would influence system mechanical efficiency is oil temperature - the period might seem long for oil temperature to stabilize, but records show that, at least for the HBA engine, oil sump temperature is surprisingly slow to reach a stable operating temperature. Data recorded in 1984 on a PRCI project related to crankshaft alignment (reproduced in Figure 46) indicate that sump oil temperature continues to rise for as many as five hours after a start-up, starting at 80 to 90 degrees and reaching 145 to 150 degrees. There is a daily temperature cycle for sump oil temperature, in addition to the increase in temperature following start-up. Sump oil temperature is an indicator of the oil temperature, which reaches the crosshead bearings, main bearings and pin bearings through the crankshaft, and the temperature of oil reaching the rider bands. This temperature has a direct influence on the viscosity of the oil being sheared in the bearings, and at other close clearances between moving parts. For the recent tests, data is not available for the sump temperature, but in Figure 47, lube oil outlet temperature is plotted as a function of time, and clearly has a shape remarkably similar to the mechanical efficiency curve. Oil temperature, at inlet to the bearing, will be lower than this, and so there is a credible hypothesis that mechanical efficiency is a strong function of oil inlet temperature, since viscosity is also a strong function of oil temperature. 


\section{Sump Temperature Data During Startup}

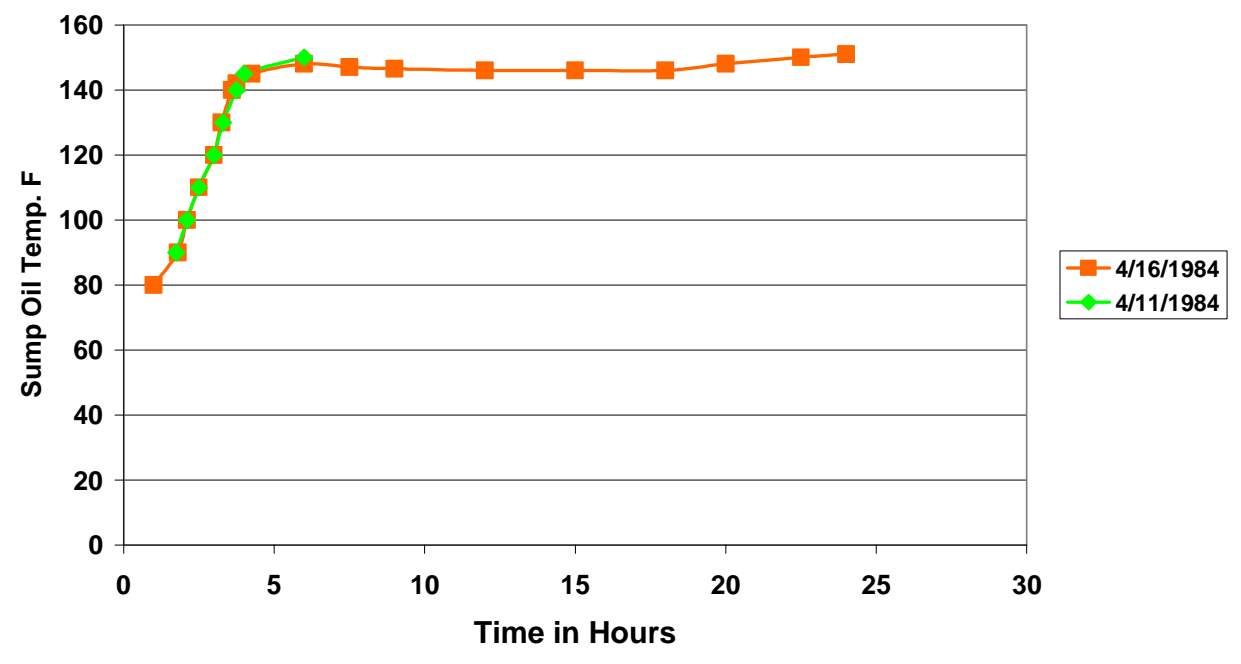

Figure 46. HBA8 Sump Temperature Data (1984)

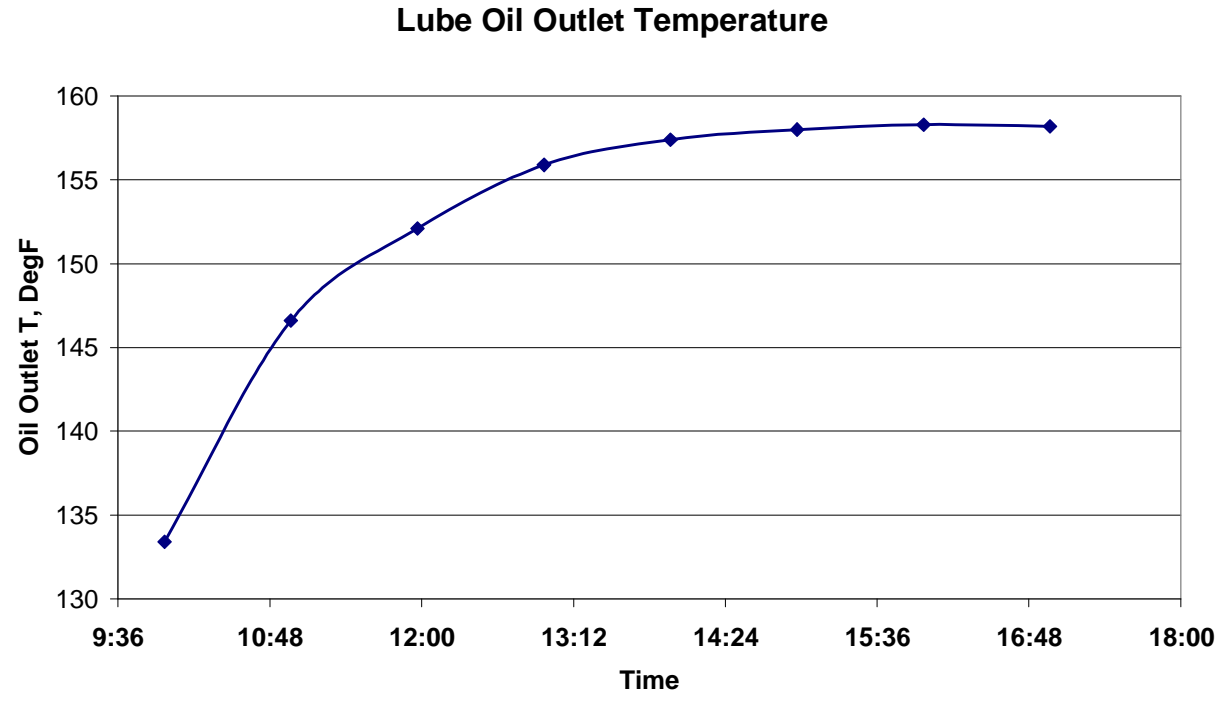

Figure 47. Oil Outlet Temperature versus Time from Station Records (Note Increase Over 5 Hours Matches Mechanical Efficiency Trend) 


\section{Engine-Compressor System Thermal EfFiciency}

The purpose of discussing and evaluating system thermal efficiency is to focus on the overall efficiency of fuel use in providing useful compression energy to the transported gas. This addresses the complete function of the compressor and combines several measures of component efficiency commonly discussed in relation to integral engine compressors:

- The Engine Brake Thermal Efficiency - the ratio between power available to the crossheads of the compressor and power consumed as fuel gas energy by the engine.

- The Compressor Mechanical Efficiency - the ratio between power available at the compressor piston faces and power available to the crossheads.

- The Compressor Thermal Efficiency - the ratio between the ideal (lossless) power to raise the pressure of the gas from suction to discharge pressure, and the actual power consumed in the compressor cylinder. Figure 48 provides confirmation of the high values (around 91 percent) obtained from the PV card. In this figure, two spot checks using suction and discharge pressure and temperature to calculate isentropic efficiency are included. Both points yielded 91 percent for this efficiency confirming the PV card values almost exactly.

Engine/compressor system thermal efficiency is the product of these three component efficiencies. Because of the incomplete measurement set at the first test site, the following discussion uses data with several inferences and assumptions in it, but is intended to provide some approximate trends, and to illustrate expectations of what may be better inferred with a more complete instrumentation set. 


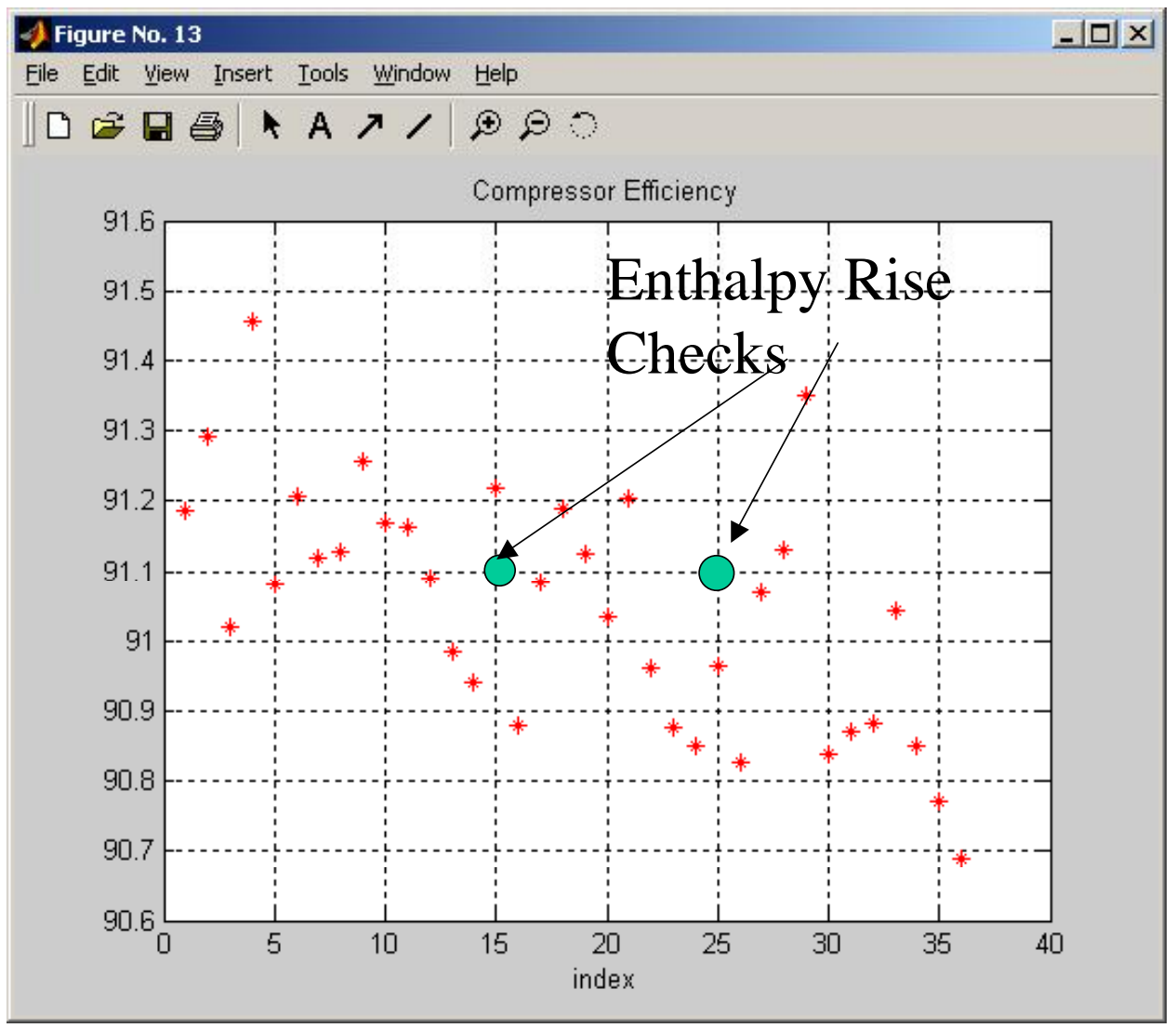

Figure 48. Compressor Performance Data from DIPs (HBA-6T)

For this test, the only available fuel flow measurement available was from the station instrumentation. Figure 45 has shown that the inferred heat rate in BTU/BHP-hr. from the station data dropped over six hours of testing from 8500 to 8200 . It should be noted that this efficiency relates power at the crosshead to fuel power. Expressed as a brake thermal efficiency, this data implies an increase over six hours from 29.9 percent to 31.0 percent. Combined with an assumed constant compressor mechanical efficiency of 95 percent and compressor thermal efficiency of 91 percent (see Figure 48) the engine compressor system thermal efficiency appears to vary from 25.8 percent to 26.8 percent.

The inferences and assumptions mainly apply to the BHP in the BTU/HP-hr. calculation. This is obtained from a model of the compressor gas horsepower as used by the host company. In this model, a standard compression exponent is used to calculate from suction pressure, suction temperature, and discharge pressure an ideal compressor gas horsepower. This ideal is then corrected (increased) for flow resistance losses and 
pulsation effects. The resultant gas horsepower is then translated to an inferred brake horsepower by dividing by a value for compressor mechanical efficiency ( 95 percent is used in this calculation). Comparison of station BHP to the data obtained during the test indicates the station BHP numbers were 3 to 5 percent below those based on measured cylinder pressure. Thus, the 25.8 percent to 26.8 percent discussed above might be corrected to record 26.8 percent to 27.8 percent based on the cylinder pressure measurements.

Reference [5] provides a typical heat balance for a compressor station, suggesting that 26 to 29 percent of the fuel energy is delivered to gas discharged from the compressor. Thus, the HBA-6T data is comparable to this assessment. The GMW10 data from the second site shows 29.7 percent under asymptotic system mechanical efficiency, which is slightly higher than the best energy conversion efficiency of Reference [5].

The limited GMRC compressor efficiency survey indicates a median of 79 percent rather than the 91 percent obtained in these tests - thus, with median thermal efficiency, the industry might exhibit lower system thermal efficiencies (as low as 23 to 24 percent), with engine efficiencies similar to the HBA-6T.

As has been discussed, the system mechanical efficiency starts low and increases as the oil heats up over several hours for the HBA-6T. Thus, immediately after start-up and for the next few hours, lower system efficiencies may be expected than the ranges inferred above.

Limited data is available on brake thermal efficiency norms for the industry. Smalley, et al [6] shows that on average, the industry burns 8.25 SCF per BHP-hr. At an assumed average of $950 \mathrm{BTU} / \mathrm{SCF}$, the implied industry brake thermal efficiency is 32.5 percent slightly above the 31 percent value after 6 hours of testing the HBA-6T. Of course, this is a very coarse number and includes turbines as well as four-stroke engines - both separable and integral. 
In summary, the first site tests provide data indicating 26.8 percent to 27.8 percent system thermal efficiency for an integral engine compressor, once thermally stable operation is established. Industry averages for engine thermal efficiency and compressor thermal efficiency suggest that the median system thermal efficiency for the industry may be lower than this. Engine start-up transients can further lower system thermal efficiency for recently started engines.

\section{INSTALLATION EFFICIENCY}

In addition to engine and compressor losses, the adjacent pulsation control systems, coolers, and other peripheral station components incur losses, such that the net compressor installation efficiency is yet lower than the system thermal efficiency discussed above. It is planned that future project work will address appropriate methods of defining and measuring station installation efficiency, and enhancing it.

\section{SUMMARY OF BALANCING TERMS}

This and previous reports have referred to balance, imbalance, and balancing with various qualifiers and related terms. The following is a start on a glossary of such terms:

- "Balance" and "imbalance," in general, refer to the variation across the power cylinders values of a particular parameter. The term "imbalance" measures the difference between maximum and minimum values for the set of cylinders at a particular time and condition. "Spread" is also used with the same meaning. On occasion, the term "balance" has been used with the same meaning as "spread" and "imbalance".

- "Average" is often used in conjunction with balance, imbalance or spread, as follows:

- To determine "average instantaneous spread," the difference between maximum and minimum of the parameter of interest (most commonly peak firing pressure) 
for all cylinders is determined for each of a series of engine cycles (say 50), and then these individual cycle spreads are averaged (where an engine cycle is one revolution of the crankshaft).

- To determine "spread in the average," the parameter of interest for each cylinder is averaged over a series of cycles, and then the difference between maximum and minimum values of these averages amongst all cylinders is calculated.

- "Air Imbalance" - A condition where the mass of trapped air differs significantly from one cylinder to the next.

- "Peak-Firing Pressure" - This is the maximum pressure which occurs in a cylinder following ignition.

- "Compression Pressure" - This is the pressure in the cylinder at some consistently defined angle shortly before top dead center (TDC), and before ignition. For the purpose of this report, the angle for compression pressure has been set at 20 degrees before TDC, but other angles closer to TDC would satisfy the definition with equal effectiveness.

- "Compression Pressure Imbalance" - The difference between maximum and minimum compression pressure across the cylinders.

- "Balancing" normally refers to the process of adjusting fuel flow in order to reduce the spread in peak-firing pressure but, in general, can refer to any approach to making combustion the same in all cylinders. With mechanical fuel inlet valves, a pinch valve upstream of each inlet valve is adjusted during the process. With electronically controlled fuel injection, the elapsed time between start and end of injection is adjusted. 
- "Peak-firing pressure balancing" specifically describes the process of seeking to reduce the spread in peak-firing pressure.

- "COV balancing" seeks to reduce the difference in standard deviation of peak-firing pressure across the cylinders. As practiced by Raymer [7], the quantity to be reduced is the standard deviation over all cylinders in standard deviation (over many cycles), divided by the average standard deviation. As with other balancing methods, the fuel flow to individual cylinders is changed by pinch valve setting or injection duration to achieve this objective.

- "Combustion Balancing" - This term implies seeking to make the combustion processes in each cylinder equal without being specific.

- "Air/fuel ratio balancing" or "equivalence ratio balancing" implies seeking to make the trapped air fuel ratio or equivalence ratio the same for each cylinder. However, $\mathrm{A} / \mathrm{F}$ or equivalence ratio cannot be readily measured cylinder by cylinder, so surrogates such as COV or CPR balancing are required.

- "CPR balancing" is a term coined to uniquely describe a process developed under this DOE project, for which a patent has been applied. It seeks to reduce the spread in the combustion pressure ratio $(\mathrm{CPR})$. $\mathrm{CPR}$ is the ratio of peak-firing pressure to compression pressure in each cylinder. Modeling has shown that when this pressure is the same across cylinders with air imbalance, then the air fuel ratio is also the same across those cylinders. As with other balancing methods, the fuel flow to individual cylinders is changed by pinch valve setting or injection duration to achieve this objective. 
- "Air Balance" - A term used to describe the goal of reducing differences in trapped air across the cylinders. The ability to achieve this is anticipated to require hardware changes to the air and /or exhaust manifolds, as opposed to changes in valve settings or controls. 


\section{OPERATIONAL OPTIMIZATION}

Based on the preceding analysis of data from the first test site, the following potential methods for optimizing operation have been identified:

- Combustion Balancing to Equalize Combustion Pressure Ratio (CPR Balancing)

- Advancing Timing Subject to Knock Detection and Avoidance

- Closed-Loop Control of Global Equivalence Ratio

- Starting the Engine with Pre-Heated Oil

- Running with Hotter Oil

- Manifold Redesign and Retrofit to Reduce Air Imbalance

Other opportunities for operational optimization may be identified as further data analysis is undertaken. It is planned to evaluate most of the first five of these on a return visit to El Paso Station 823 at Kinder, Louisiana - scheduling of this visit and preparation of equipment for the further testing will be undertaken in the next quarter. 


\section{CONCLUSIONS}

7.1 The planned use of a broad suite of instrumentation to look at loads, integrity, and efficiencies of the engine/compressor system and components, and the project's view of the engine/compressor as a system are producing revealing results, and pointing to opportunities for operational enhancement.

7.2 The strain data capture module has indicated its sensitivity to small changes in engine load. The cycle-to-cycle variability on the SDCM appears to relate to the engine combustion cycle-to-cycle variability, as illustrated for the second test site.

7.3 Imbalance across the power cylinders in the compression pressure prior to ignition was clearly shown by the data for both engines tested so far. Differences in flow of air to the cylinders, induced by spatial and temporal differences in air manifold pressure, are a major contributor to this phenomenon.

7.4 To achieve peak-firing pressure balancing, with such air imbalance, has been shown to require significant imbalance in equivalence ratio between the cylinders. In some cases, this imbalance might lead to detonation.

7.5 Peak-firing pressure balancing is shown by data analysis to benefit NOx emissions and fuel consumption, but eliminating air imbalance will further increase the benefit to be gained from balancing on peak-firing pressure.

7.6 A method to seek cylinder-to-cylinder balance in trapped equivalence ratio, by adjusting individual cylinder fuel flow for engines with moderate air imbalance, has been defined based on results from the first test site. A new balancing method (CPR balancing) has been invented and the feasibility of executing this method of combustion balancing has been demonstrated by the tests from the second site. 
7.7 With high air imbalance limits in fuel adjustment range of individual cylinder flow valves may limit the ability to achieve cylinder-to-cylinder balance in equivalence ratio.

7.8 Data indicates a dependence of system mechanical efficiency on oil temperature and, as a result, on time from cold start-up. The system mechanical efficiency from the HBA-6T data rose over to 93 percent over a six-hour test period. This relationship may offer operational approaches to increase system mechanical efficiency, and thereby increase available capacity for a given engine power.

7.9 Qualitatively, similar trends in the ratio of compression power to engine power have been shown by the data from the second test site.

7.10 The increases in ratio of compressor to engine power have been validated by reductions in fuel flow based heat rate.

7.11 For the HBA-6T, the compressor thermal efficiency, based on measured differential indicated power losses, is about 91 percent; this is high by industry standards.

7.12 This compressor efficiency shows that 91 percent is an achievable industry benchmark; high compressor efficiency helps maximizes the beneficial use of fuel gas energy; it also maximizes capacity for a given engine horsepower.

7.13 Lower compressor efficiencies than 91 percent and low system mechanical efficiencies can reduce available compression capacity.

7.14 System thermal efficiencies (useful compression energy for the gas transported divided by fuel gas energy consumed) of about 27 percent have been measured for thermally stable operation for the HBA-6T tested. The potential for lower system thermal efficiencies arises if the compressor efficiency is lower than 91 percent, if the heat rate is higher than 8200 BTU/HP-hr., or if the system mechanical efficiency is reduced due to cold oil. 
7.15 System thermal efficiency of 29.7 percent was observed for the second test site. 


\section{REFERENCES}

[1] Harris, R.E., Edlund, C.E., Smalley, A.J., and Weilbacher, G., (2000) "Dynamic Crank Web Strain Measurements for Reciprocating Compressors," presented at the GMRC Gas Machinery Conference (GMC), Colorado Springs, Colorado.

[2] Harris, R.E. and Beeson, C.M., (1990) "Channel Resonance Correction for Improved Cylinder Performance and Diagnostic Analyses," Proceedings, PCRC Fifth Annual Reciprocating Machinery Conference, Nashville, Tennessee.

[3] Harris, R.E. and Edlund, C.E., (1998) "Performance Measurement of High Speed/High Ratio Reciprocating Compressors," presented at the GMRC Gas Machinery Conference (GMC), Denver, Colorado.

[4] Wood, C.D. and Kubesh, J.K., (1995) "Evaluation of Emissions Control Technology for Reciprocating Integral Engine-Compressor Units," SwRI Report for Tenneco Gas Environmental and Technology Department.

[5] Transmission, Book T-2: Compressor Station Operations, GEOP - Gas Engineering and Operating Practices, The American Gas Association Operating Section, Vol. II, A.G.A. Catalog No. XY0185.

[6] Smalley, A.J., Mauney, D.A., and Ash, D.I., (1997) Final Report PR-15-9529, "Compressor Station Maintenance Cost Analysis," prepared for the Compressor Research Supervisory Committee of PRC International, SwRI Project No. 047424.

[7] Raymer, R. R., "Engine Tuning, Not Balance, is the Key to Performance: The "COV" Method," presented at the GMRC Gas Machinery Conference (GMC), Salt Lake City, Utah. 


\section{LIST OF ACRONYMS AND ABBREVIATIONS}

$\begin{array}{ll}\text { A/F } & \text { Air/Fuel Ratio } \\ \text { AGA } & \text { American Gas Association } \\ \text { AMP } & \text { Air Manifold Pressure } \\ \text { BEI } & \text { Manufacturer's Trade Name } \\ \text { BHP } & \text { Brake Horsepower } \\ \text { BTU } & \text { British Thermal Unit } \\ \text { CO } & \text { Carbon Monoxide } \\ \text { COV } & \text { Coefficient of Variance } \\ \text { CPR } & \text { Compression Pressure Ratio } \\ \text { DAS } & \text { Data Acquisition System } \\ \text { DOE } & \text { U.S. Department of Energy } \\ \text { ECOM A+ } & \text { An Emissions Analyzer Model } \\ \text { EQ } & \text { Equivalence Ratio } \\ \text { FIFO } & \text { First In, First Out } \\ \text { GMC } & \text { Gas Machinery Conference } \\ \text { GMRC } & \text { Gas Machinery Research Council } \\ \text { GMW10 } & \text { Pipeline Engine Model } \\ \text { HBA-6 } & \text { Clark Engine Model } \\ \text { HBA-6T } & \text { Clark Engine Model } \\ \text { HBA8 } & \text { Clark Engine Model } \\ \text { HP } & \text { Horsepower } \\ \text { HPFI } & \text { Enginuity's High Pressure Fuel Injection System } \\ \text { IAC } & \text { Industry Advisory Committee } \\ \text { IMEP } & \text { Indicated Mean Effective Pressure } \\ \text { IRV } & \text { Instantaneous Rotational Velocity } \\ \text { LHV } & \text { Lower Heating Value } \\ \text { MMSCFD } & \text { Million of Standard Cubic Feet Per Day } \\ \text { MW } & \text { Megawatts } \\ \text { NGK } & \text { Manufacturer's Trade Name } \\ \text { NO } & \text { Nitric Oxide } \\ \text { NO } 2 & \text { Nitrous Oxide } \\ \text { NOx } & \text { Oxides of Nitrogen } \\ \text { O } & \text { Oxygen Molecule } \\ \text { PCB } & \text { Manufacturer's Trade Name } \\ \text { PFP } & \text { Peak-Firing Pressure } \\ \text { PPM } & \text { Parts Per Million } \\ \text { PSI } & \text { Pounds Per Square Inch } \\ \text { PSIA } & \text { Lb./Sq. Inch Absolute } \\ \text { PV } & \text { Pressure-Volume } \\ \text { RLM } & \text { Rod Load Monitor } \\ \text { RPM } & \text { Revolutions Per Minute } \\ & \end{array}$




$\begin{array}{ll}\text { SCF } & \text { Standard Cubic Feet } \\ \text { SDCM } & \text { Strain Data Capture Module } \\ \text { Sdev } & \text { Standard Deviation } \\ \text { SwRI }^{\circledR} & \text { Southwest Research Institute } \\ \text { TDC } & \text { Top Dead Center } \\ \text { TGP } & \text { Tennessee Gas Pipeline }\end{array}$

